NBER WORKING PAPER SERIES

\title{
SOVEREIGN CREDIT RISK AND EXCHANGE RATES: EVIDENCE FROM CDS QUANTO SPREADS
}

\author{
Patrick Augustin \\ Mikhail Chernov \\ Dongho Song \\ Working Paper 24506 \\ http://www.nber.org/papers/w24506 \\ NATIONAL BUREAU OF ECONOMIC RESEARCH \\ 1050 Massachusetts Avenue \\ Cambridge, MA 02138 \\ April 2018, Revised June 2018
}

We thank Nelson Camanho, Peter Hoerdahl, Alexandre Jeanneret, Francis Longstaff, Guillaume Roussellet, Lukas Schmid, Jesse Schreger, Gustavo Schwenkler, and Andrea Vedolin for comments on earlier drafts and participants in the seminars and conferences sponsored by the 2018 Financial Intermediation Research Conference, the 2018 SFS Cavalcade, the 15th IDC Herzliya Annual Conference in Financial Economics, the Bank of France, Duke-UNC 2018, HEC Paris, Hong Kong Monetary Authority, McGill, Penn State, the Swedish House of Finance, UCLA. Augustin acknowledges financial support from the Fonds de Recherche du Québec Société et Culture grant 2016-NP-191430. The views expressed herein are those of the authors and do not necessarily reflect the views of the National Bureau of Economic Research.

NBER working papers are circulated for discussion and comment purposes. They have not been peer-reviewed or been subject to the review by the NBER Board of Directors that accompanies official NBER publications.

(C) 2018 by Patrick Augustin, Mikhail Chernov, and Dongho Song. All rights reserved. Short sections of text, not to exceed two paragraphs, may be quoted without explicit permission provided that full credit, including $(\odot$ notice, is given to the source. 
Sovereign Credit Risk and Exchange Rates: Evidence from CDS Quanto Spreads

Patrick Augustin, Mikhail Chernov, and Dongho Song

NBER Working Paper No. 24506

April 2018, Revised June 2018

JEL No. C1,E43,E44,G12,G15

\begin{abstract}
$\underline{\text { ABSTRACT }}$
Sovereign CDS quanto spreads-the difference between CDS premiums denominated in U.S. dollars and a foreign currency-tell us how financial markets view the interaction between a country's likelihood of default and associated currency devaluations (the Twin Ds). A noarbitrage model applied to the term structure of quanto spreads can isolate the interaction between the Twin Ds and gauge the associated risk premiums. We study countries in the Eurozone because their quanto spreads pertain to the same exchange rate and monetary policy, allowing us to link crosssectional variation in their term structures to cross-country differences in fiscal policies. The ratio of the risk-adjusted to the true default intensities is 2, on average. Conditional on the occurrence of default, the true and risk-adjusted 1-week probabilities of devaluation are 5\% and $77 \%$, respectively. The risk premium for the euro devaluation in case of default exceeds the regular currency premium by up to $0.3 \%$ per week.
\end{abstract}

Patrick Augustin

Desautels Faculty of Management

McGill University

1001 Sherbrooke Street West, Room 552

Montreal, Qc H3A 1G5 Canada

patrick.augustin@mcgill.ca

Mikhail Chernov

Anderson School of Management

University of California, Los Angeles

110 Westwood Plaza, Suite C-417

Los Angeles, CA 90095

and NBER

mikhail.chernov@anderson.ucla.edu
Dongho Song

Carey Business School

100 International Drive

Baltimore, MD 21202

dongho.song@jhu.edu 


\section{Introduction}

The risk of sovereign default and exchange rate fluctuations are inextricably linked. The depreciation of a country's currency is often a reflection of poor economic conditions. Default events tend to be associated with currency devaluations. Such devaluations may either strategically support the competitiveness of the domestic economy, or penalize a country's growth due to increased borrowing costs or reduced access to international capital markets.

Despite the importance of studying the Twin Ds (default and devaluation), the subject has received relatively limited attention in the literature. In our view, one reason for this is that it is exceedingly difficult to measure the interaction between the two. Indeed, both types of events are rare, so few data are available for researchers to use. Disagreement over measurements are a clear manifestation of the problem. For example, Reinhart (2002) estimates the probability of devaluation conditional on default at $84 \%$, while Na, SchmittGrohé, Uribe, and Yue (2017) find it to be 48\%. Another hard-to-measure dimension of the Twin Ds is whether default has an immediate or long-term impact on the exchange rate. Krugman (1979) argues that default leads to a change in the expected depreciation rate (change in exchange rate), while Na, Schmitt-Grohé, Uribe, and Yue (2017) suggest a one-off drop in the exchange rate at default.

In this study, we are the first to take advantage of a recent development in financial markets to offer an asset-pricing perspective on the measurement of the risk premia associated with the Twin Ds. Specifically, sovereign credit default swap (CDS) contracts are available in different currency denominations starting from August 2010. For example, contracts that protect against a credit event in Germany could be denominated in euros (EUR) or U.S. dollars (USD) (we use the terms default and credit event interchangeably). The difference between the two respective CDS premiums of the same maturity, also known as quanto $C D S$ spread, reflects the market's view about the interaction between the Twin Ds. Quanto spreads of different maturities are informative about the interaction over different horizons.

We focus on quanto spreads in the 17 European countries that share the euro as the common exchange rate. We find the associated CDS markets particularly interesting for two reasons. First, despite the common currency and monetary policy, the term structures of quanto spreads are different, suggesting intriguing implications regarding the different fiscal policies. Second, the contractual arrangements of the European contracts make observed quanto spreads transparent in terms of the implications for the Twin Ds. Specifically, in contrast to contracts for emerging markets (EM), payouts on Western European sovereign CDS of all denominations are triggered irrespective of whether a default is associated with domestic or foreign debt.

We start by explaining the institutional arrangements behind sovereign CDS in different currencies. We then explain how quanto spreads are related to the interaction between the Twin Ds. Next, we develop a model that allows us to characterize the relation between default and devaluation probabilities. 
Describing the joint behavior of 17 different term structures and an exchange rate is a daunting task. Therefore, we limit ourselves to a no-arbitrage affine term structure model that allows us to evaluate whether it is possible to reconcile all of this evidence within a tractable specification. Along the way, we encounter a typical problem in the analysis of credit-sensitive financial instruments: as the realization of credit events is rare, we can identify only the risk-adjusted distribution of these events based on asset prices. We exploit (i) the interaction between credit risk and currency risk, and (ii) the currency commonality to identify the true distribution of credit events. As a bonus, our approach allows us to identify the loss given default (LGD), which we assume to be constant and the same for all countries. While this assumption is an oversimplification, it nevertheless offers progress on a thorny empirical problem.

The model we propose features the following critical components: a model of the U.S. reference interest rate curve, a model of credit risk, and a model of the spot/forward FX curve. We use overnight indexed swap (OIS) rates as a reference curve and construct a two-factor model to capture its dynamics.

The starting point for our credit risk model is a credit event whose arrival is controlled by a doubly-stochastic Cox process, a popular modeling device in the literature. The default intensity in each country is controlled by two factors - global and regional - which are weighted differently for each country. We identify the global factor by setting the weights on Germany's regional factors to zero. Given that our data are from countries in the Eurozone during the sovereign debt crisis, we derive an extension of our model to allow for the possibility of credit contagion: the occurrence of a credit event in one country affecting the probability of a credit event in another country.

Last but not least, we model the behavior of the spot USD/EUR FX rate and the associated forward rates. We follow the literature on realistic modeling of the time series on FX rates. We allow for time-varying expected changes in the depreciation rate, heteroscedastic regular shocks to the rates, and extreme events.

We connect jumps in the FX rate to sovereign credit risk by requiring them to take place simultaneously with credit events. This modeling feature is our identifying assumption that helps us to establish the true distribution of credit events. To enhance the statistical reliability of our estimates, we follow Bai, Collin-Dufresne, Goldstein, and Helwege (2015) and complement our identification strategy by associating realized credit events with extreme movements in quanto spreads.

We use joint data on the term structure of the quanto spreads of six countries, which represent the most liquid CDS contracts across the European core and periphery, some data on Greece prior to its credit event, the spot and forward FX rates, and a cross-section of credit events for the six countries. We estimate the model via the Bayesian Markov Chain Monte Carlo (MCMC) method. The model offers an accurate fit to the data. It also fits the quanto spreads of the remaining 10 Eurozone countries that were not used in the estimation. 
We find that a more parsimonious model without contagion fits the data just as well and does not differ significantly from the larger model in terms of its likelihood. Therefore, we perform the rest of the analysis using the simpler model, which features only four factors: three credit factors (one global and two regional) and one FX variance factor.

We find a substantial cross-sectional variation in how the credit risks of countries load on the credit factors. For instance, exposure to the global factor varies from a high of 4 times the German level (for Spain) to a low of 1/14 times (for Finland). Finland is unambiguously the least risky country. There are multiple candidates, primarily from Southern Europe, for the most risky. Some countries, both core and peripheral, have significant exposure to the global factor only.

As we conjectured earlier, a large part of this cross-sectional variation ( $44 \%$ to be precise) is driven by differences in the fiscal policies as measured by a country's debt. A fixed effects regression of hazard rates on the debt-to-GDP ratio implies that a one percentage point increase in the ratio of a given country is, on average, associated with an increase in its CDS premium of approximately 8 basis points (bps).

Our setting allows for the estimation of the true distribution of credit events. As a result, we can characterize the time-varying credit risk premium, which is typically measured by the ratio of the risk-adjusted to the true default intensity. We find that the credit risk premium is about 2, on average. This estimate is consistent with earlier studies of corporate credit risk that were estimating a constant risk premium. We also find evidence for a significant amount of variation over time, as the credit risk premium ranges between 1 and 6 during our sample period.

Our estimated model can also inform the measurement issues highlighted earlier. For instance, we find the true 1-week probability of devaluation conditional on default to be $4 \%$, which is consistent with the view by Na, Schmitt-Grohé, Uribe, and Yue (2017) of a large drop in the exchange rate upon default. In addition, we find that that the expected depreciation rate is unrelated to credit factors, contradicting the view of Krugman (1979).

The risk-adjusted probability of devaluation conditional on default is $75 \%$, suggesting a hefty risk premium for this event. Indeed, the model-implied risk premiums for exposure to the Twin Ds exceed the regular currency risk premiums by as much as $0.3 \%$ per week. Thus, the default-contingent currency risk premium is significantly larger than the default risk premium, which is suggestive of the large economic importance of that risk. All of this evidence suggests that default-contingent devaluation, although not highly probable, occurs during the worst states of the economy when the marginal utility of investors is particularly high.

\section{Related literature}

This study is related to two strands of the literature. First, it is most closely related to the literature on the relation between sovereign credit and currency risks. Della-Corte, Sarno, 
Schmeling, and Wagner (2016) empirically show that the common component in sovereign credit risk correlates with currency depreciations and predicts currency risk premia. Carr and $\mathrm{Wu}(2007)$ propose a joint valuation framework for sovereign CDS and currency options with an empirical application to Mexico and Brazil. Du and Schreger (2016) study the determinants of local currency risk as a distinct component of foreign default risk in EM. Buraschi, Sener, and Menguetuerk (2014) suggest that geographical funding frictions may be responsible for persistent mispricing of EM bonds denominated in EUR and USD. While related, our work is conceptually different because of the aforementioned differences in the treatment of credit events associated with domestic and foreign debt. We exploit the entire term structure of CDS quanto spreads to pin down the time variation in the risk premia associated with expectations of exchange rate depreciation conditional on default.

The most recent development in the joint FX-sovereign risk literature is research on CDS quanto spreads. Mano (2013) proposes a descriptive segmented market model that is consistent with nominal and real exchange rate depreciation upon an exogenous default trigger. DeSantis (2015) uses quanto spreads to construct measures of redenomination risk. No-arbitrage term structure models for quanto spreads are proposed by Ehlers and Schoenbucher (2004) for Japanese corporate CDS, and by Brigo, Pede, and Petrelli (2016) for Italian CDS.

In contemporaneous and independent work, Lando and Nielsen (2017); Monfort, Pegoraro, Renne, and Roussellet (2017) develop models of sovereign quanto CDS spreads in the Eurozone. The former study is focused on the contribution of each of the normal and jump risks to the shape of the quanto term structure. The latter study uses quanto spreads in a modeling application of the Gamma-zero distribution, often denoted as $A R G_{0}$. Both studies estimate their models of quanto spreads on a country-by-country basis, whereas we jointly model the exchange rate risk and quanto spreads for the entire term structure of six countries. This distinction is important, because the dynamics of exchange rates in CDS spreads ought to respect the common behavior of the EUR-USD exchange rate movements in conjunction with the country-specific default risk. In addition, using an identifying assumption that exploits the common currency, we estimate both the true and risk-adjusted default intensities. As a result, we can discuss the implications for time-varying risk premia associated with the default risk and the expected depreciation risk conditional on default. Joint estimation is also necessary for identifying the propagation of shocks across countries, that is, contagion, a subject of public and academic debate.

Second, our study builds on the vast literature on no-arbitrage affine term structure modeling and credit-sensitive instruments, prominently summarized in Duffie and Singleton (2003). Duffie, Pedersen, and Singleton (2003), Hoerdahl and Tristani (2012), and Monfort and Renne (2013) study sovereign credit spreads. With respect to the valuation of sovereign CDS, the early affine term structure models focus on country-by-country estimations such as Turkey, Brazil, Mexico (Pan and Singleton, 2008), and Argentina (Zhang, 2008), or on a panel of emerging (Longstaff, Pan, Pedersen, and Singleton, 2011), or developed and emerging countries (Doshi, Jacobs, and Zurita, 2017). Ang and Longstaff (2013) extract 
a common systemic factor across Europe and the U.S. using sovereign CDS written on European countries and U.S. states, while Ait-Sahalia, Laeven, and Pelizzon (2014) study pairwise contagion among pairs of seven European countries during the sovereign debt crisis.

Most studies in this area do not estimate the LGD separately from the default intensity because of a joint identification problem. Some papers are able to identify the LGD using CDS data because of the recovery of face value assumption (Pan and Singleton, 2008; Elkamhi, Jacobs, and Pan, 2014). Doshi, Elkamhi, and Ornthanalai (2017) exploit senior and subordinate CDS to identify the LGD. Lastly, the most recent studies exploit the insensitivity of equity valuation to the LGD (Kuehn, Schreindorfer, and Schulz, 2017; Li, 2017). Our approach is more closely related to the first and the last studies because we assume recovery of face value and that a jump in exchange rate is unrelated to the LGD.

Finally, we use a model of contagion, which is an active topic in the recent credit risk literature. Bai, Collin-Dufresne, Goldstein, and Helwege (2015) emphasize that contagion should be an important component of credit risk pricing models in the context of a large number of corporate names. Benzoni, Collin-Dufresne, Goldstein, and Helwege (2015) offer evidence of contagion risk premiums in sovereign CDS spreads in the context of ambiguityaverse economic agents. Ait-Sahalia, Laeven, and Pelizzon (2014) find evidence of contagion under risk-adjusted probability in sovereign CDS spreads. Azizpour, Giesecke, and Schwenkler (2018) find evidence of contagion in a descriptive model of realized corporate defaults. Monfort, Pegoraro, Renne, and Roussellet (2017) reach a similar conclusion in the context of bank CDS. We study contagion under both the risk-adjusted and true probabilities.

A table in Appendix F summarizes the specific modeling elements across the key studies with affine intensity-based frameworks for sovereign credit spreads. The table visually highlights the primary differences between the current study and others. Methodologically, our work encompasses most of the existing approaches.

\section{Sovereign CDS contracts and currencies}

\subsection{Cash flows and settlement}

Sovereign CDS are contracts that pay off in case of a sovereign credit event. This section reviews what such an event represents. Given the focus on USD/EUR quantos of Eurozone countries, we limit the discussion to the legal details associated with European contracts. See Appendix A.

We use $S_{t}$ to denote the nominal USD/EUR FX rate (amount of USD per EUR) at time $t$. The first row of Figure 1 depicts the cash flows associated with a EUR-denominated CDS contract (long protection) with a premium of $€ C_{0}^{€}$ established at time 0 (the time of the contract's maturity $T$ is omitted for brevity). In this example, the notional is $\$ 1=€\left(1 / S_{0}\right)$, 
implying an annualized payment of $€ C_{0}^{€} / S_{0}$. For the purpose of this discussion, we ignore the quarterly or semi-annual frequency of the premium payment settlement, and focus on the annual amounts. The second row shows a USD-denominated contract (short protection) with a premium of $\$ C_{0}^{\$}$. Given the same notional, the annual payment is $\$ C_{0}^{\$}$, which is equivalent to $€ C_{0}^{\$} / S_{t}$ at the spot exchange rates on the settlement dates.

We highlight three implications of the rules that are particularly relevant for this paper. First, a credit event that affects all CDS contracts regardless of the currency of denomination could be triggered by a default pertaining to a subset of bonds, such as a sovereign defaulting on domestic debt but not on bonds issued in other jurisdictions. Therefore, a CDS quanto spread would not reflect the risk of selective default. This is in contrast to EM bonds, studied by $\mathrm{Du}$ and Schreger (2016), where differences between the credit spreads denominated in USD and local currency could reflect such a risk, and to EM CDS contracts, studied by Mano (2013), for which a credit event is not triggered by default on domestic currency or domestic law bonds.

Second, an obligation is deemed deliverable into the contract settlement regardless of its currency of denomination or that of the CDS contract. This means that one and the same bond could be delivered into the settlements of CDS contracts of different denominations. Thus, recovery is free of any exchange rate consideration, a point also made by Ehlers and Schoenbucher (2004). Compare this with Mano (2013), who, in the context of EM bonds explicitly considers different currency denominations of the recovery amount.

As an extreme example, imagine a European sovereign that has $1 \%$ of all its debt issued in EUR, and the rest issued in USD. Both EUR- and USD-denominated contracts would be triggered in the case of selective default on the small amount of outstanding EURdenominated debt. Because one can deliver a bond of any denomination into a contract of any denomination, the cash value of payments in case of a credit event could be viewed as an identical fraction, denoted by $L$ (LGD) in Figure 1, of a contract's notional amount. We fix $L$ to be a constant, in line with the literature on CDS pricing (Pan and Singleton, 2008). This removes any uncertainty about payments in the respective currencies.

The only uncertainty that arises with a credit event is due to expressing these payments in the same currency. For example, the EUR-denominated contract pays a certain amount of $L / S_{0}$, while the EUR value of the payment of the USD-denominated contract is $L / S_{\tau}$, with $\tau$ denoting the time of a credit event. This comparison illustrates the impact of devaluation. If the EUR devalues during the credit event, $S_{\tau}$ is lower than $S_{0}$, and, as a result, the value of the payment on the EUR-denominated contract is lower than that on the USD-denominated one.

Third, outright default is only one of the scenarios that may trigger a credit event. A common concern among observers of the Eurozone credit market is that a CDS payout would be triggered by a restructuring of a Eurozone member country's liabilities through a redenomination of the principal or interest payments into the country's pre-EUR currency. There are two CDS definitions, those of 2003 and 2014, which treat this event differently. 
For contracts based on the 2003 definitions, redenomination does not trigger a credit event as long as it involves the currencies of the G7 countries and AAA-rated OECD economies. The newer definitions limit these currencies to the lawful currencies of Canada, Japan, Switzerland, the United Kingdom, the United States of America, and the Eurozone.

After the 2014 definitions were introduced, CDS could be concurrently traded satisfying either definition. We use data on the contracts guided by the 2003 definitions throughout our full sample to ensure internal consistency. Kremens (2018) explores the differences in premiums for the two types of contracts. Regardless of the definition used, some countries might trigger a credit event by redenomination. Our framework automatically accounts for that because our credit factors are designed to capture the probability of a credit event without discerning its type.

\subsection{Relation to sovereign bonds}

Historically, Eurozone sovereign CDS were denominated in USD only. One point worth emphasizing is that EUR-denominated CDS contracts that were introduced in 2010 are not redundant securities. One might think of cash flows as similar to those of a portfolio that consists of a USD-denominated bond and a currency swap (e.g., Du and Schreger, 2016). However, such a strategy does not hedge the behavior of the FX rate conditional on default - the risk that is the focus of this paper.

To see this, consider the third and fourth rows of Figure 1, which show cash flows to a sovereign par bond and a currency swap of matching maturity. The bond is USD denominated, but the issuer prefers a EUR exposure, hence the additional swap position. The cash flows are presented per $\$ 1$ of face/notional values.

At time 0 , the issuer sells the bond for $\$ 1$ and swaps this amount for the equivalent value in EUR, $€ 1 / S_{0}$. Prior to maturity, the issuer has to pay interest of $\$ C_{0}$ on a bond, which it receives from the swap as interest on the USD value of the notional. In exchange, the issuer has to pay interest of $€ F_{0} / S_{0}$ on the EUR value of the swap, with $F_{0}$ denoting the currency swap rate that is determined at time 0 .

If there is no credit event, the last transaction takes place at maturity, where the issuer has to repay $\$\left(1+C_{0}\right)$ on the bond and the EUR/USD notionals combined with the last interest payments that are exchanged in the swap transaction. As a result, the combined position has a pure EUR exposure with pre-determined cash flows: $€ 1 / S_{0}$ at inception, $-€ F_{0} / S_{0}$ thereafter (including the day of maturity), and $-€ 1 / S_{0}$ at maturity. This is conceptually similar to cash flows on the EUR-denominated sovereign CDS if there is no credit event (the difference is in the latter being an unfunded instrument).

If there is a credit event, then the bond-swap combination faces uncertain cash flows between the time of the event $\tau$ and maturity $T$. The bond pays $\$(1-L)$ at $\tau$ and ceases to exist. In 
the meantime, the swap does not terminate (assuming no counterparty risk) and continues the exchange of cash flows. As a result, the values of the combined cash flows in EUR are $\left(L+C_{0}-1\right) / S_{\tau}-F_{0} / S_{0}$ at $\tau$, and $C_{0} / S_{t}-F_{0} / S_{0}$ for $\tau<t \leq T$. In contrast, the EUR-denominated sovereign CDS has a single cash flow of $€ L / S_{0}$.

\subsection{Interpretation of the quanto CDS spread}

Figure 1 allows us to take a first step toward thinking about quanto CDS spreads. Adding up the two positions described in the first two rows (long EUR-denominated and short USDdenominated protection) gives an exposure to devaluation conditional on default, because the only uncertain cash flow is the EUR value of $L$ in the USD contract. Specifically, by buying the EUR-denominated protection and selling the USD-denominated one, we construct a position that benefits if there is no EUR devaluation conditional on default. The payout $€ L\left(S_{0}^{-1}-S_{\tau}^{-1}\right)$ is negative if $S_{\tau}<S_{0}$.

Because CDS contracts have a fixed time to maturity, we observe premiums for new contracts in every period. In other words, we only get to see the difference between the premiums $€\left(C_{0}^{\$}-C_{0}^{€}\right) / S_{0}$. Because the choice of notional is arbitrary, the quanto spread $C_{0}^{\$}-C_{0}^{€}$ becomes the relevant premium for exposure to the Twin Ds.

To streamline the analytical interpretation of the quanto CDS spread, consider a hypothetical contract that trades all points upfront, meaning that a protection buyer pays the entire premium at time $t$. Further, assume that the risk-free rate is constant. Then, the EUR-denominated CDS premium simplifies to

$$
C_{0}^{€}=L \cdot E_{0}\left[M_{0, \tau} I(\tau \leq T) S_{\tau \wedge T} / S_{0}\right] \equiv L \cdot E_{0}^{*}\left[e^{-r(\tau \wedge T)} I(\tau \leq T) S_{\tau \wedge T} / S_{0}\right],
$$

where $M$ denotes the USD-denominated pricing kernel, * refers to the risk-adjusted probability, and $I(\cdot)$ is an indicator variable. The USD-denominated premium is similar. As a result, the relative quanto spread is

$$
\begin{aligned}
\frac{C_{0}^{\$}-C_{0}^{€}}{C_{0}^{\$}} & =\frac{E_{0}^{*}\left[e^{-r(\tau \wedge T)} I(\tau \leq T)\left(1-S_{\tau \wedge T} / S_{0}\right)\right]}{E_{0}^{*}\left[e^{-r(\tau \wedge T)} I(\tau \leq T)\right]} \\
& =E_{0}^{*}\left[1-\frac{S_{\tau \wedge T}}{S_{0}}\right]-\operatorname{cov}_{0}^{*}\left[\frac{e^{-r(\tau \wedge T)} I(\tau \leq T)}{E_{0}^{*} e^{-r(\tau \wedge T)} I(\tau \leq T)}, \frac{S_{\tau \wedge T}}{S_{0}}\right],
\end{aligned}
$$

where $\wedge$ denotes the smallest of the two variables. The first term reflects the risk-adjusted expected currency depreciation, conditional on a credit event (a positive number corresponds to EUR devaluation). The covariance term reflects the interaction of default and FX risks. 


\subsection{Data}

\section{CDS}

Sovereign CDS contracts became widely available in multiple currencies in 2010. This determines the beginning of our sample, which runs from August 20, 2010 to December 30, 2016. We source daily CDS premiums denominated in USD and EUR from Markit for all 19 Eurozone countries. We require a minimum of 365 days of non-missing information on USD/EUR quanto spreads. This requirement excludes Malta and Luxembourg. Thus, our sample features 17 countries: Austria, Belgium, Cyprus, Estonia, Finland, France, Germany, Greece, Ireland, Italy, Latvia, Lithuania, Netherlands, Portugal, Slovakia, Slovenia, and Spain.

We work with weekly data to minimize noise due to the potential staleness of some of the prices and to maximize the continuity in subsequently observed prices. We have continuous information on 5-year quanto spreads throughout the sample period for all countries except Greece, as the trading of its sovereign CDS contract halted following its official default in 2012. In addition, we retain the maturities of $1,3,7,10$, and 15 years (we omit the available 30-year contracts because they are similar to the 15-year ones; in particular the term structures between 15 and 30 are flat). Although the 5-year contract is the most liquid, liquidity across the term structure is less of a concern for sovereign CDS spreads than for corporate CDS spreads, as trading is more evenly spread across the maturity spectrum (Pan and Singleton, 2008).

Although these sovereign CDS contracts trade in multiple currencies, there might be differences in liquidity given that an insurance payment in EUR would probably be less valuable if Germany defaulted. Consistent with this view, USD-denominated contracts tend to be more liquid, as documented in Table 1, which reports the average number of dealers quoting such contracts in either EUR or USD over time; that is, CDS depth (Qiu and Yu, 2012). The average difference between the number of USD and EUR dealers ranges between 0.60 and 2.66. EUR CDS contracts are quoted by 2.73 to 6.30 dealers, on average, which is economically meaningful given that the CDS market is largely concentrated among a handful of dealers (Giglio, 2014; Siriwardane, 2014). In relative terms, the average number of quoting dealers for the USD contracts exceeds that for the EUR by 1 . That suggests that the difference in liquidity of the two types of contracts is not large.

Notional amounts outstanding, also reported in Table 1, offer a sense of the cross-sectional variation in the size of the market. Regardless of the currency of denomination, the notionals are converted into USD and reported on the gross and net basis. To facilitate comparison, we express these numbers as a percentage of the respective quantities for Italy, which has the largest gross and net notionals (Augustin, Sokolovski, Subrahmanyam, and Tomio, 2016). The amounts for France, Germany, and Spain stand out as a fraction of Italy's amounts, followed by Austria, Belgium, and Portugal. 
To provide a first feel for the data, Figure 2A displays the time-series of one of the most liquid and arguably the least credit-risky CDS contracts, namely the 5-year USD-denominated contract for Germany. We highlight important events to help frame the magnitudes of CDS premiums. The premium for such a safe country is about 20 bps during the calmest periods, varies over time, and exceeds 100 bps during the sovereign crisis.

To further gauge the size of the market for single-name sovereign CDS, we compare the gross notional amounts outstanding to the aggregate market size. Augustin (2014) reports that in 2012, single-name sovereign CDS accounted for approximately $11 \%$ of the overall market, which was then valued at $\$ 27$ trillion in gross notional amounts outstanding. The corporate CDS market accounted for about $89 \%$ of the market, with single- and multi-name contracts amounting to $\$ 16$ trillion and $\$ 11$ trillion, respectively. While the CDS market has somewhat shrunk in recent years, statistics from the Bank for International Settlements suggest that sovereign CDS represented $\$ 1.715$ trillion, about $18 \%$ of the entire market, in 2016.

\section{Quanto spreads}

Table 2 provides basic summary statistics for the quanto spreads. There is a significant amount of both cross-sectional and time-series variation in the spreads. In the cross-section, the average quanto spread ranges from $6 \mathrm{bps}$ for Estonia to $90 \mathrm{bps}$ for Greece, at the 5-year maturity. The average quanto slope, defined as the difference between the 10-year and 1-year quanto spreads, ranges from -29 bps for Greece to 29 bps for France. Overall, both the level and slope of CDS quanto spreads vary significantly over time in each country.

We limit the estimation of our model to data on six sovereigns because of parameter proliferation. We choose the countries that exhibit the greatest market liquidity and the fewest missing observations. In addition, we incorporate both peripheral and core countries that feature the greatest variation in the average term structure of CDS quanto spreads. This leads us to focus on Germany, Belgium, France, Ireland, Italy, and Spain. Figure 3A plots the average quanto term spreads of different maturities for these countries. We also use a limited amount of data on Greece, as described later in this section. We use data on the remaining countries to conduct an "out-of-sample" evaluation of our model.

\section{Exchange rate}

We collect the time series of the USD/EUR FX rate from the Federal Reserve Bank of St. Louis Economic Database (FRED) and match it with the quanto data, using weekly exchange rates, sampled every Wednesday. Figures $2 \mathrm{~B}$ and $3 \mathrm{~B}$ display the exchange rate and (log) depreciation rate, respectively. A broad devaluation of the EUR is evident in Figure 2B. 
Figure 3B suggests that the exchange rate movements were close to being independent and identically distributed (iid) during our sample period. Motivated by that, Appendix B shows that the term structure of credit premia is flat if both the default intensity and depreciation rates are iid but correlated with each other. This result establishes a useful benchmark for interpreting the evidence summarized in Figure 3A.

CDS premiums and exchange rates are interrelated and move together over time. This is summarized by the cross-correlogram between the first principal component of changes in 5 -year CDS premiums and depreciation rates in Figure 2C. The Figure highlights that this interaction is primarily contemporaneous, and not readily visible in leads and lags.

Figure 2D stays with Germany to show an example of time-series variation in (5-year) quanto CDS spreads. As explained in Section 2.3, the spreads reflect the interaction between the Twin Ds and are informative about the covariance risk and the currency jump at default risk. A model is needed to understand the interactions over different horizons and to extract the quanto risk premium.

\section{Interest rates}

To develop the model, we also need information on the term structure of U.S. interest rates. Prior to the global financial crisis (GFC) of 2008/09, it was common practice to use Libor and swap rates as the closest approximation to risk-free lending rates in the interdealer market (Feldhutter and Lando, 2008). Since the GFC, practitioners have shifted toward full collateralization and started using OIS rates as better proxies of risk-free rates (Hull and White, 2013). This shift has implications for Libor-linked interest rate swaps (IRS) because discounting is performed using the OIS-implied curves. We source daily information on OIS and IRS rates for all available maturities from Bloomberg, focusing on OIS rates with maturities of $3,6,9,12,36$, and 60 months and IRS rates with maturities of $7,10,15$, and 30 years.

We bootstrap zero coupon rates from all swap rates. We transform all swap rates into par-bond yields, assuming a piece-wise constant forward curve, and then extract the zerocoupon rates of the same maturities as the swap rates. Thus, we obtain a zero-coupon yield estimated from OIS rates up to 5 years, and from IRS rates for maturities above 5 years. To extend the OIS zero-curve for maturities beyond 5 years, we use the zero-coupon yield bootstrapped from IRS rates, but adjusted daily by the differential between the IRS- and OIS-implied zero-coupon curves. A figure in Appendix G displays the resulting rates.

Once we have a model of the joint behavior of interest rates and exchange rates, it has implications for forward exchange rates. To discipline our model, we use weekly Thomson Reuters data on forward exchange rates obtained from Datastream. We use the Wednesday quotes for our analysis to match the Wednesday OIS rates and quanto spreads focusing on the maturities of 1 week and 1 month. Our analysis does not require the European interest 
rate values, hence we can avoid addressing the important analysis of CIP violations in Du, Tepper, and Verdelhan (2017). Covered interest parity holds in our model. Therefore, the inferred foreign interest rate could be viewed as an implicit foreign bank funding rate. Such an interpretation is valid in the light of research focusing on various market frictions leading to violations of CIP in terms of true Libor rates (e.g., Borio, McCauley, McGuire, and Sushko, 2016).

\section{Credit events}

Our last piece of evidence pertains to the true occurrence of credit events. True default information is insufficient for estimating conditional credit event probabilities because realized credit events are rare. This issue is common to the literature on credit-sensitive instruments. When modeling corporate defaults, it is possible to infer something about true conditional default probabilities by grouping companies by their credit rating, as done by Driessen (2005), for instance.

We are considering high quality sovereign names, so we have only the credit event in Greece in our sample. Formal defaults are often avoided because of bailouts, as was witnessed multiple times during the sovereign debt crisis (Greece, Ireland, Portugal, Spain, Cyprus). These bailouts result in large movements in credit spreads, although no formal credit event occurred. Therefore, we associate credit events with extreme movements in quanto spreads (see also Bai, Collin-Dufresne, Goldstein, and Helwege, 2015). Specifically, we deem a credit event to have occurred if a weekly (Wednesday to Wednesday) change in the 5-year quanto spread is above the 99th percentile of the country-specific distribution of quanto spread changes. ${ }^{1}$ A figure in Appendix G displays the observed credit events identified in this way for the 16 countries in our sample.

Although Greece experienced a formal credit event, it is difficult to use the full available series for pragmatic reasons (see also Ait-Sahalia, Laeven, and Pelizzon, 2014). As a figure in Appendix G shows, the Greek CDS premium jumped to 5,062 bps on September 13, 2011, long before the true declaration of the credit event on March 9, 2012. It exceeded the 10,000 bps threshold, which is equivalent to $100 \%$ of the insured face value, on February 15, 2012. Furthermore, trading of Greece CDS spreads was halted between March 8, 2012 and June 10, 2013, so the time series exhibits a long gap in quoted premiums. Assuming the Markit-reported aggregation of quoted spreads was tradable, Greek CDS trading restarted on June 10, 2013, at a level of 978 bps. The corresponding quanto spreads displayed in the same figure exhibit similar swings in magnitudes and gaps in the data. These data problems create severe credit risk identification issues and make it difficult to study the joint behavior of credit factors across countries.

\footnotetext{
${ }^{1}$ One concern is that such a definition may bias downwards the coincidence of large drops in the EUR value and credit events. Changing from quanto spreads to USD CDS premiums or introducing an identicial cut-off (two standard deviations of all CDS premiums changes across time and countries) does not materially affect estimated probabilities of the coincidence of these two types of events.
} 
As a result, we designate September 7, 2011, as a credit event instead of the official one. After that day, the available data are unusable. This period is too short to identify the Greek default hazard rate throughout the full sample. Therefore, we also use some data from the period when the trading resumed in June 2013. Out of concern that very large premiums may not be reflective of true traded prices, we use only those premiums that are within $150 \%$ of the maximum of premiums with a corresponding maturity among the remaining GIIPS countries. The omitted premiums are so large, that the estimation results are not sensitive to the choice of the maximum cutoff point.

\section{The model}

In this section, we present a no-arbitrage model of the joint dynamics of U.S. interest rates, USD/EUR FX rate, forward FX rates, and CDS quanto spreads for Eurozone countries. In broad strokes, the key part of the model is the connection between a devaluation of the FX rate and a sovereign credit event. Mathematically, we model the arrival of a credit event via a Poisson process. Credit hazard rates feature one common component that is linked to Germany, and regional components. Furthermore, we allow for default contagion effects. To connect devaluation to credit risk, we make the identifying assumption that jumps in the FX rate can take place only if one of the Eurozone sovereigns experiences a credit event. This assumption is motivated by Figure $2 \mathrm{C}$ and links sovereign default hazard rates to the FX Poisson arrival rate.

\subsection{Pricing kernel}

Suppose, $M_{t, t+1}$ is the USD-denominated nominal pricing kernel. We can value a cash flow, $\mathcal{X}_{t+1}$, using the pricing kernel via $E_{t}\left(M_{t, t+1} \mathcal{X}_{t+1}\right)$, where the expectation is computed under the true conditional probability $p_{t, t+1}$. Alternatively, we can value the same cash flow using the risk-adjusted approach

$$
E_{t}\left(M_{t, t+1} \mathcal{X}_{t+1}\right)=E_{t}\left(M_{t, t+1}\right) E_{t}\left(\frac{M_{t, t+1}}{E_{t}\left(M_{t, t+1}\right)} \mathcal{X}_{t+1}\right)=e^{-r_{t}} E_{t}^{*}\left(\mathcal{X}_{t+1}\right)
$$

where the expectation is computed under the risk-adjusted conditional probability $p_{t, t+1}^{*}$, and $r_{t}$ is the risk-free rate at time $t$. Thus, the pricing kernel connects the two probabilities via $M_{t, t+1} / E_{t} M_{t, t+1}=e^{-r_{t}} p_{t, t+1}^{*} / p_{t, t+1}$. In this paper, we use both valuation approaches interchangeably.

Implicit in this notation is the dependence of all of the objects on the state of the economy $x_{t}$. We can generically write

$$
x_{t+1}=\mu_{x, t}^{*}+\Sigma_{x, t}^{*} \varepsilon_{x, t+1} .
$$

In the sequel we describe various elements of $x_{t}$ and their dynamics. 


\subsection{CDS valuation}

We start with valuation, as it allows us to introduce the key objects that we model in subsequent sections. A CDS contract with time to maturity $T$ has two legs. The premium leg pays the annual CDS premium $C_{t, T}$ until a default takes place at a random time $\tau$. It pays nothing after the default. The protection leg pays a fraction of the face value of debt that is lost in the default and nothing if there is no default before maturity.

Accordingly, the present value of fixed payments of the USD-denominated contract that a protection buyer pays is

$$
\pi_{t}^{p b}=C_{t, T}^{\$} \sum_{j=1}^{(T-t) / \Delta} E_{t}\left[M_{t, t+j \Delta} I(\tau>t+j \Delta)\right],
$$

where $\Delta$ is the time interval between two successive coupon periods, and $I(\cdot)$ is an indicator function that takes on the value one if the condition inside the brackets is met, and zero otherwise. We have omitted accrual payments for notational simplicity, but take them into account in the actual estimation of the model.

A protection seller is responsible for any losses $L$ upon default and thus the net present value of future payments is given by

$$
\pi_{t}^{p s}=L \cdot E_{t}\left[M_{t, \tau} I(\tau \leq T)\right]
$$

The CDS premium $C_{t, T}^{\$}$ is determined by equalizing the values of the two legs. The premium of a EUR-denominated contract is, similarly,

$$
C_{t, T}^{€}=L \cdot \frac{E_{t}\left[M_{t, \tau} I(\tau \leq T) S_{\tau \wedge T}\right]}{\sum_{j=1}^{(T-t) / \Delta} E_{t}\left[M_{t, t+j \Delta} I(\tau>t+j \Delta) S_{t+j \Delta}\right]} .
$$

It is helpful to introduce the concepts of survival probabilities and hazard rates to handle the computation of expectations involving indicator functions. The information set $\mathcal{F}_{t}$ includes all of the available information up to time $t$, excluding credit events. Let

$$
H_{t} \equiv \operatorname{Prob}\left(\tau=t \mid \tau \geq t ; \mathcal{F}_{t}\right)
$$

be the conditional instantaneous default probability of a given reference entity at day $t$, also known as the hazard rate. Furthermore, let

$$
P_{t} \equiv \operatorname{Prob}\left(\tau>t \mid \mathcal{F}_{t}\right)
$$

be the time- $t$ survival probability, conditional on no earlier default up to and including time t. $P_{t}$ is related to the hazard rate $H_{t}$ via

$$
P_{t}=P_{0} \prod_{j=1}^{t}\left(1-H_{j}\right), \quad t \geq 1
$$


Applying the law of iterated expectations to both the numerator and denominator, we can rewrite the CDS premium as

$$
C_{t, T}^{€}=L \cdot \frac{\sum_{j=1}^{T-t} E_{t}\left[M_{t, t+j}\left(P_{t+j-1}-P_{t+j}\right) S_{t+j}\right]}{\sum_{j=1}^{(T-t) / \Delta} E_{t}\left[M_{t, t+j \Delta} P_{t+j \Delta} S_{t+j \Delta}\right]} .
$$

A similar expression can be obtained for the USD-denominated contract by setting $S_{t}=1$.

\subsection{Credit risk}

The risk-adjusted default hazard rate of each country $k=1, \cdots, M_{c}$ is

$$
H_{t}^{* k}=\operatorname{Prob}^{*}\left(\tau^{k}=t \mid \tau^{k} \geq t ; \mathcal{F}_{t}\right),
$$

where $\tau^{k}$ is the time of the credit event in country $k$, and $M_{c}$ is the number of countries. We posit that the hazard rate is determined by the default intensity $h_{t}^{* k}$ as follows:

$$
H_{t}^{* k}=1-e^{-h_{t}^{* k}}, \quad h_{t}^{* k}=\bar{h}^{* k}+\delta_{w}^{* k \top} w_{t}+\delta_{d}^{* k \top} d_{t-1}
$$

such that the default intensity is affine in the credit variables $w_{t}$ and contagion variables $d_{t}$ that are elements of the state vector $x_{t}$.

We assume that $w_{t}$ consists of $G$ global and $K$ regional factors, so that each intensity $h_{t}^{* k}$ is a function of all global factors and one of the regional factors. We assume that $G=1$ and $K=2$ in our empirical work, implying two factors per country (one global and one regional; by assumption, Germany is exposed to the global factor only, as in Ang and Longstaff, 2013). This choice is motivated by a principal component analysis (PCA) that extracts country-specific components from the quanto spreads. The procedure implies that two factors explain around $99 \%$ of the variation in quanto spreads. Furthermore, the PCA of the combination of the first two components across all countries implies that the first principal component explains $58 \%$ of the variation.

To gain intuition about how our model of contagion works, consider the Poisson arrival of credit events at a conditional rate of $d_{t}$. We would like the realization from this process to affect the conditional rate in the subsequent period. Denote the realization by $\mathcal{P}$ : $\mathcal{P} \mid d_{t} \sim \operatorname{Poisson}\left(d_{t}\right)$.

In our application to Eurozone sovereigns, we expect $d_{t}$ to be small, implying that most of the realizations of $\mathcal{P}$ will be equal to zero (the probability of such an event is $e^{-d_{t}}$ ). The probability of one credit event is equal to $d_{t} e^{-d_{t}}$. Theoretically, it is possible that $\mathcal{P}>1$ with the probability $1-e^{-d_{t}}-d_{t} e^{-d_{t}}$. However, for a small $d_{t}$, such an outcome is unlikely.

In this respect, such a Poisson process can be viewed as an analytically tractable approximation to a Bernoulli distribution that is more appropriate for a credit event in a single 
country. For reasons of parsimony, we use this process to count all contemporaneous events across the countries in our sample. Thus, a Poisson model is a better fit for our framework.

The next step in the contagion model is to determine how the value of $\mathcal{P}$ affects the subsequent arrival rate $d_{t+1}$. First, this value has to be non-negative, so we choose a distribution with a non-negative support. Second, we would like to achieve analytical tractability for valuation purposes, so we choose a Gamma distribution whose shape parameter is controlled by $\mathcal{P}: d_{t+1} \sim \operatorname{Gamma}(\mathcal{P}, 1)$. The idea is that the more credit events we have at time $t$, the larger the impact on $d_{t+1}$. If $\mathcal{P} \mid d_{t}=0$, then $d_{t+1}=0$, by convention.

The resulting distribution of $d_{t+1}$ is

$$
\phi\left(d_{t+1} \mid d_{t}\right)=\sum_{k=1}^{\infty}\left[\frac{d_{t}^{k}}{k !} e^{-d_{t}} \times \frac{d_{t+1}^{k-1} e^{-d_{t+1}}}{\Gamma(k)}\right] \mathbf{1}_{\left[d_{t+1}>0\right]}+e^{-d_{t}} \mathbf{1}_{\left[d_{t+1}=0\right]} .
$$

This expression, representing the description in words above, makes explicit what is missing. We need to replace $d_{t}$ in this expression with $\bar{d}+\phi d_{t}$. The constant is needed to preclude $d_{t}=0$ from becoming an absorbing state. The coefficient $0<\phi<1$ is needed to ensure the stationarity of $d_{t}$.

In our model, the contagion factor $d_{t}$ interacts with other factors that control credit risk, as described below when we specify all of the state variables explicitly. Such a model happens to be autoregressive gamma-zero, $A R G_{0}$, a process introduced by Monfort, Pegoraro, Renne, and Roussellet (2014) for the purpose of modeling interest rates at the zero lower bound. Monfort, Pegoraro, Renne, and Roussellet (2017) use $A R G_{0}$ to model the credit contagion of banks.

\subsection{FX rate}

We model the foreign exchange rate $S_{t}$ as the amount of USD per one EUR. The idea of our model is that the $(\log )$ depreciation rate should be a linear function of the state $x_{t}$ and be exposed to two additional shocks. One is a currency-specific normal shock with varying variance $v_{t}$, and the other one is an extreme move associated with devaluation. Specifically, we posit:

$$
\Delta s_{t+1}=\bar{s}^{*}+\delta_{s}^{* \top} x_{t+1}+\left(\bar{v}+\delta_{v}^{\top} v_{t}\right)^{1 / 2} \cdot \varepsilon_{s, t+1}-z_{s, t+1}
$$

Furthermore, we assume that $\varepsilon_{s, t+1} \sim \operatorname{Normal}(0,1)$ is independent of $\varepsilon_{x, t+1}$. We assume the variance factor $v_{t}$ to be one-dimensional. A jump $z_{t+1}$ is drawn from an independent Poisson-Gamma mixture distribution. Specifically, the jump arrival rate $j_{t+1}$ follows a Poisson distribution with an intensity of $\lambda_{t+1}^{*}, j_{t+1} \sim \mathcal{P}\left(\lambda_{t+1}^{*}\right)$, and jump size $z_{s, t+1} \mid j_{t+1} \sim$ $\operatorname{Gamma}\left(j_{t+1}, \theta^{*}\right)$. The minus sign in front of $z_{s, t+1}$ emphasizes that the EUR is devalued in the case of a Eurozone sovereign credit event. Because jump size has a distribution, some 
of the realized jumps could be severe, reflecting an outright devaluation, and some could be quite modest and similar to the regular innovations in FX.

We link jumps in the FX to the sovereign default risk by assuming that the FX rate jumps only in case of a credit event. Therefore, the FX jump intensity is equal to the sum of all country-specific default intensities:

$$
\lambda_{t}^{*}=\sum_{k} h_{t}^{* k}=\sum_{k} \bar{h}^{* k}+\sum_{k} \delta_{w}^{* k} \cdot w_{t}+\sum_{k} \delta_{d}^{* k} \cdot d_{t-1}=E^{*}\left(d_{t} \mid w_{t}, d_{t-1}\right) .
$$

Our assumptions about the constant mean of the FX jump and the link of its intensity to default intensities are likely to be oversimplifications of reality. Ideally, one would want to separate jumps into default-related and default-unrelated components. Within the first category, one would want to model country-specific links, both in terms of jump intensity and jump mean. While it is certainly possible to specify a model like that, it would be impossible to estimate such a model with any reasonable degree of precision. That is because all these refinements pertain to rare events that are difficult to pin down empirically even if they are identified theoretically.

This connection between jump intensity and country-specific default intensities allows us to identify the LGD, $L$. The USD CDS contracts are informative only about the products $L h_{t}^{* k}$ and, therefore, their sum over $k$ (e.g., Duffie and Singleton, 1999). The quanto feature brings in information about the risk-neutral distribution of exchange rates, which does not depend on the LGD. This allows us to identify $\lambda_{t}^{*}$. Given our identification assumption that links currency jumps to credit events, we can recover $L$ by dividing $\sum L h_{t}^{* k}$ by $\lambda_{t}^{*}$. This description is offered for the development of intuition. In practice, $L$ is estimated jointly with the other parameters using our likelihood-based procedure.

The model of the depreciation rate in Equation (7) could be equivalently written as

$$
\Delta s_{t+1}=\bar{s}^{*}+\delta_{s}^{* \top} \mu_{x, t}^{*}+\delta_{s}^{* \top} \Sigma_{x, t}^{*} \varepsilon_{x, t+1}+\left(\bar{v}+\delta_{v}^{\top} v_{t}\right)^{1 / 2} \cdot \varepsilon_{s, t+1}-z_{s, t+1} .
$$

This expression highlights the (risk-adjusted) expected depreciation rate, $\bar{s}^{*}+\delta_{s}^{* \top} \mu_{x, t}^{*}$, and that the depreciation rate can be conditionally and unconditionally correlated with states $x_{t}$. The model is more parsimonious than the most general one (loadings $\delta_{s}^{*}$ control both expectations and innovations). This expression also shows that we can explore the question of whether regular innovations or jumps in the depreciation rate contribute the most to the magnitude of quanto spreads (see Brigo, Pede, and Petrelli, 2016; Carr and Wu, 2007; Ehlers and Schoenbucher, 2004; Krugman, 1979; Lando and Nielsen, 2017; Monfort, Pegoraro, Renne, and Roussellet, 2017; Na, Schmitt-Grohé, Uribe, and Yue, 2017 for related discussions). 


\subsection{States}

We assume that if investors were risk-neutral, then an $N \times 1$-dimensional multivariate state vector $x_{t+1}$ would evolve according to

$$
x_{t+1}=\mu_{x}^{*}+\Phi_{x}^{*} x_{t}+\Sigma_{x, t}^{*} \cdot \varepsilon_{x, t+1},
$$

where $\Phi_{x}^{*}$ is an $N \times N$ matrix with positive diagonal elements, and $\Sigma_{x, t}^{*}$ is an $N \times N$ matrix that is implied by the specification described below. This implies that $\mu_{x, t}^{*}=\mu_{x}^{*}+\Phi_{x}^{*} x_{t}$. The state $x_{t}$ consists of three sub-vectors

$$
x_{t}=\left(u_{t}^{\top}, g_{t}^{\top}, d_{t}^{\top}\right)^{\top} .
$$

We explain the role of each of the variables as follows.

\subsection{U.S. interest rate curve}

The factor $u_{t}$ is an $M_{u} \times 1$ vector that follows a Gaussian process:

$$
u_{t+1}=\mu_{u}^{*}+\Phi_{u}^{*} u_{t}+\Sigma_{u} \cdot \varepsilon_{u, t+1},
$$

and $\varepsilon_{u, t+1} \sim \mathcal{N}(0, I), \mu_{u}^{*}$ is an $M_{u} \times 1$ vector, and $\Phi_{u}^{*}$ and $\Sigma_{u}$ are all $M_{u} \times M_{u}$ matrices, and the diagonal elements of $\Sigma_{u}$ are denoted by $\sigma_{u_{i}}$, for $i=1,2, \ldots, M_{u}$.

The default-free U.S. dollar interest rate (OIS swap rate) is

$$
r_{t}=\bar{r}+\delta_{u}^{\top} u_{t}
$$

In the applications, we assume for simplicity that there are only $M_{r}=2$ interest rate factors, while $M_{u}=3$ such that $u_{t}=\left(u_{1, t}, u_{2, t}, u_{3, t}\right)^{\top}$. Thus, we set $\delta_{u 3}=0$ for the term structure of interest rates, and use $u_{3, t}$ for modeling the expected depreciation rate with implications for forward FX rates (described below).

The price of a zero-coupon bond paying one unit of the numeraire $n$-periods ahead from now satisfies

$$
Q_{t, T}=E_{t}^{*} B_{t, T-1}
$$

where $B_{t, t+j}=\exp \left(-\sum_{u=0}^{j} r_{t+u}\right)$. Given the dynamics of the interest rate defined in Equation (9), bond prices can be solved using standard techniques. The log zero-coupon bond prices $q_{t}$ are affine in the interest rate state variables $u_{t}$, such that the term structure of interest rates is given by

$$
y_{t, T} \equiv-(T-t)^{-1} \log Q_{t, T}=A_{T-t}+B_{T-t}^{\top} u_{t} .
$$

See Appendix C.1. 


\subsection{Currency forward curve}

Finally, we highlight the role of the Gaussian factor $u_{3, t}$, which was not used for the OIS rate modeling. This factor allows flexibility in the model to match the forward exchange rates, $F_{t, T}=E_{t}^{*} S_{T}$.

Given the dynamics of the exchange rate defined in Equation (7), forward exchange rates can be solved using standard techniques such that the log ratio of the forward to the spot exchange rate $\log \left(F_{t, T} / S_{t}\right)$ is affine in the state vector $x_{t}$ and given by

$$
\log \left(F_{t, T} / S_{t}\right) \equiv \tilde{A}_{j}+\tilde{B}_{j}^{\top} x_{t}
$$

See Appendix C.2.

\subsection{Quanto curve}

\section{Credit factors and variance}

The factor $g_{t}$ is an autonomous multivariate autoregressive gamma process of size $M_{g}$. Each component $i=1, \cdots, M_{g}$ follows an autoregressive gamma process, $g_{i, t+1} \sim$ $A R G\left(\nu_{i}, \phi_{i}^{* \top} g_{t}, c_{i}^{*}\right)$, that can be described as

$$
g_{i, t+1}=\nu_{i} c_{i}^{*}+\phi_{i}^{* \top} g_{t}+\eta_{i, t+1},
$$

where $\phi_{i}^{*}$ is a $M_{g} \times 1$ vector, and $\eta_{i, t+1}$ represents a martingale difference sequence (mean zero shock), with conditional variance given by

$$
\operatorname{var}_{t} \eta_{i, t+1}=\nu_{i} c_{i}^{* 2}+2 c_{i}^{*} \phi_{i}^{* \top} g_{t}
$$

where $c_{i}^{*}>0$ and $\nu_{i}>0$ define the scale parameter and the degrees of freedom, respectively. To ensure that the multivariate autoregressive gamma process is stationary, we impose parameter restrictions on the persistence matrix $\phi^{*}$ such that the eigenvalues have a modulus smaller than one. See Gourieroux and Jasiak (2006), Le, Singleton, and Dai (2010) and Monfort, Pegoraro, Renne, and Roussellet (2014). We further separate the factor $g_{t}$ into factors $w_{t}$ and $v_{t}$, which are used for modeling the credit risk and currency variance, respectively.

\section{Default contagion}

The final factor $d_{t}$ is a multivariate autoregressive gamma-zero process of size $M_{d}$. Each component $k=1, \cdots, M_{d}$ follows an autoregressive gamma-zero process, $d_{t+1}^{k} \mid w_{t+1} \sim$ $A R G_{0}\left(\bar{h}^{* k}+\delta_{w}^{* k \top} w_{t+1}+\delta_{d}^{* k \top} d_{t}^{k}, \rho^{* k}\right)$. We add two more features to the description in 
Section 3.3. First, the contagion factor is affected by conventional credit factors $w_{t}$ in addition to its own value from the previous period. Second, we allow for a scale parameter, $\rho^{* k}$, that could be different from unity in the Gamma distribution.

Besides the explicit distribution, an $A R G_{0}$ process can be described as

$$
d_{t+1}^{k}=\bar{h}^{* k}+\delta_{w}^{* k \top} w_{t+1}+\delta_{d}^{* k \top} d_{t}^{k}+\eta_{t+1}^{k},
$$

where $\eta_{k, t+1}$ is a martingale difference sequence (mean zero shock), with conditional variance given by

$$
\operatorname{var}_{t} \eta_{t+1}^{k}=2 \rho^{* k}\left(\bar{h}^{* k}+\delta_{w}^{* k \top}\left[\nu_{w} \odot c_{w}^{*}+\phi_{w}^{* \top} w_{t}\right]+\delta_{d}^{* k \top} d_{t}\right)
$$

where $\odot$ denotes the Hadamard product. As for the credit factors, we impose parameter restrictions on the matrices $\delta_{w}^{* k}$ and $\delta_{d}^{* k}$ to guarantee stationarity. Specifically, $\delta_{w}^{* k} \geq 0$ and the eigenvalues of $\delta_{d}^{* k}$ have a modulus smaller than one. Comparing expressions (6) and (13) makes it clear that the default hazard rate and the arrival rate of Poisson events in the contagion factors are the same process.

For parsimony, we assume the existence of one common credit event variable that may induce contagion across the different countries and regions. This is conceptually similar to the suggestion of Benzoni, Collin-Dufresne, Goldstein, and Helwege (2015), that a shock to a hidden factor may lead to an updating of the beliefs about the default probabilities of all countries. Thus, given such a restriction, the contagion factor is a scalar, $d_{t+1} \mid w_{t+1} \sim$ $A R G_{0}\left(\bar{h}^{*}+\delta_{w}^{* \top} w_{t+1}+\delta_{d}^{* \top} d_{t}, \rho^{*}\right)$ with appropriate restrictions on the loadings:

$$
\bar{h}^{*}=\sum_{k} \bar{h}^{* k}, \quad \delta_{w}^{*}=\sum_{k} \delta_{w}^{* k}, \quad \delta_{d}^{*}=\sum_{k} \delta_{d}^{* k} .
$$

As a result, we may have more than one credit event per period.

\section{CDS expressions}

Now, we are in a position to express the CDS spread presented in Equation (5) using the risk-adjusted probability as follows:

$$
C_{t, T}^{€}=L \cdot \frac{\sum_{j=1}^{T-t} E_{t}^{*}\left[B_{t, t+j-1}\left(P_{t+j-1}^{*}-P_{t+j}^{*}\right) S_{t+j}\right]}{\sum_{j=1}^{(T-t) / \Delta} E_{t}^{*}\left[B_{t, t+j \Delta-1} P_{t+j \Delta}^{*} S_{t+j \Delta}\right]} .
$$

We can use recursion techniques to derive analytical solutions for CDS premiums by solving for the following two objects:

$$
\tilde{\Psi}_{j, t}=E_{t}^{*}\left[B_{t, t+j-1} \frac{P_{t+j-1}^{*}}{P_{t}^{*}} \frac{S_{t+j}}{S_{t}}\right] \text { and } \Psi_{j, t}=E_{t}^{*}\left[B_{t, t+j-1} \frac{P_{t+j}^{*}}{P_{t}^{*}} \frac{S_{t+j}}{S_{t}}\right] .
$$


These expressions jointly yield the solution for the CDS premium after dividing the numerator and the denominator of Equation (14) by the time- $t$ survival probability $P_{t}^{*}$ and exchange rate $S_{t}$.

$$
C_{t, T}^{€}=L \cdot \frac{\sum_{j=1}^{T-t}\left(\tilde{\Psi}_{j, t}-\Psi_{j, t}\right)}{\sum_{j=1}^{T-t) / \Delta} \Psi_{j \Delta, t}} .
$$

To evaluate the expressions for $\tilde{\Psi}$ and $\Psi$, we conjecture that the expressions in Equation (15) are exponentially affine functions of the state vector $x_{t}$ :

$$
\tilde{\Psi}_{j, t}=e^{\tilde{A}_{j}+\tilde{B}_{j}^{\top} x_{t}} \text { and } \Psi_{j, t}=e^{A_{j}+B_{j}^{\top} x_{t}} .
$$

See Appendix C.3 for the derivation of these loadings.

\subsection{Risk prices}

We have articulated all of the modeling components that are needed for security valuation. To estimate the model, we need the behavior of state variables under the true probability of outcomes. Appendix D demonstrates that there exists a pricing kernel that supports a flexible change in the distribution of variables involved in the valuation of securities. Most parameters could be different under the two probabilities. One may recover the evolution of state variables under the objective probability by dropping the asterisks $*$ in the expressions of Section 3.5.

Given the focus on credit events, we highlight how the prices of default risk work in our model. All of the variables that are related to credit events have true $\left(h_{t}^{k}, \lambda_{t}\right)$ and riskadjusted $\left(h_{t}^{* k}, \lambda_{t}^{*}\right)$ versions because the event risk premium could be time varying. In particular, the true and risk-adjusted counterparts may have a different functional form and a different factor structure. In addition, each of these variables may have different true and risk-adjusted distributions that are related to the respective distributions of the factors that drive them.

The risk-adjusted and true distributions of $h_{t}^{* k}$ and $\lambda_{t}^{*}$ can be identified from the crosssection and time series of quanto spreads, respectively. The true event frequencies $h_{t}^{k}$ and $\lambda_{t}$ can be identified only from the realized credit events themselves - a challenge for financial assets of high credit quality. As mentioned earlier, we circumvent this difficulty by associating credit events with extreme movements in quanto spreads. Even in this case, however, the empirical problem is quite challenging, so we only model common events and assume that they are directed by the same factors as their risk-adjusted counterparts: $d_{t} \mid w_{t} \sim A R G_{0}\left(\bar{h}+\delta_{w}^{\top} w_{t}+\delta_{d} d_{t-1}, \rho\right)$, and $\lambda_{t}=E\left(d_{t} \mid w_{t}, d_{t-1}\right)$. 


\subsection{Implementation}

We jointly use data on the USD/EUR FX rate, forward FX rates, the term structure of OIS interest rates, the term structures of CDS quanto spreads for a cross section of six countries, a cross-section of credit events for six countries, and some data on Greece to estimate the model. The model is estimated using Bayesian MCMC. See Appendix E. The outputs of the procedure are the state variables and parameter estimates. We outline the parameter restrictions that we impose.

We make the following identifying restrictions. For the model of the OIS term structure, we follow Dai and Singleton (2000) and Hamilton and Wu (2012) and restrict $\mu_{u}=0, \Sigma_{u}=I$, $\delta_{u 1} \geq 0, \Phi_{u}^{*}$ lower triangular with real eigenvalues and $\phi_{u 11}^{*} \geq \phi_{u 22}^{*}$. For the credit model, we impose the mean of the state variables $g_{t}$ to be equal to 1 under the true probability to avoid scaling indeterminacy. This implies restrictions on parameters $c_{i}: c_{i} \nu_{i}=1-\phi_{i}^{\top} \iota$, where $\iota$ is a vector of ones. By the same logic, we set $\rho=1$ in the true dynamics of the contagion factor $d_{t}$.

Because of the large number of parameters, we also impose over-identification restrictions. We allow the global credit factor $w_{1 t}$ to affect regional factors, but not vice-versa. This restriction affects elements $\phi_{i}$. We assume the volatility factor $v_{t}$ to be autonomous under both probabilities. Both sets of restrictions translate into identical restrictions under the risk-adjusted probability because of the functional form of the risk prices for these factors. Furthermore, we assume that the contagion factor $d_{t}$ loads only on $w_{1 t}$ under the true probability.

\section{Results}

\subsection{Model selection and fit}

A table in Appendix F displays the estimated parameters of the OIS term structure. The model is standard and the parameter values are in line with the literature. It is difficult to interpret the model because there are multiple equivalent rotations of the factors. The key for this paper, as indicated in Table 3, is that the pricing errors are reasonably small. Therefore, we can use the model to discount cash flows using the risk-adjusted valuation method.

We estimate two versions of the credit model: with and without contagion. We present the estimated parameters in Appendix F. There are common traits to the parameter estimates regardless of the model. The factors $w_{t}$ exhibit near unit-root dynamics under the riskadjusted probability, a common trait of affine models. Under the true probability, only the global credit factor $w_{1 t}$ is highly persistent. 
Furthermore, the peripheral countries in our sample have a much larger weight on the global credit factor than the core countries. France has a smaller loading on the core credit factor than Belgium (Germany's weight is zero by assumption). Spain's weight on the peripheral factor is larger than that of Italy and Greece, and similar to that of Ireland.

The loss-given-default parameter, $L$, is estimated at $41 \%$ in the model without contagion, with a $90 \%$ confidence interval of $35 \%$ to $50 \%$. As a reference point, in CDS valuation, it is commonly assumed that this value is $60 \%$ for corporate and $75 \%$ for EM sovereign bonds. The most comparable estimated numbers are provided in Pan and Singleton (2008) at 23\% for Mexico and Turkey, and $83 \%$ for South Korea. We guess that our estimate would have been lower for core countries, as $L$ is affected by events in the periphery (according to the Greek CDS settlement auction, the true loss was 78.5\%).

We find that the expected depreciation rate does not load on credit factors under either probability, and that the same goes for shocks. The loading of the expected depreciation rate on the variance factor is positive under the true probability and negative under the risk-adjusted one. This implies that, ignoring jumps, the EUR is expected to appreciate/depreciate under the corresponding probabilities.

The FX jump magnitude is just under $1 \%$ under the true probability. This is consistent with the visually mild observed movements in Figure 3B. Under the risk-adjusted probability, it is $14 \%$ implying a huge risk premium associated with currency devaluation upon a sovereign credit event.

We evaluate whether a larger model with contagion is supported by the evidence. The parameters that are contagion-specific, $\delta_{d}^{* k}, \delta_{d}$, and $\rho^{*}$ are statistically significant. The question is whether the extra degrees of freedom associated with a larger model are justified from the statistical and economic perspectives. While we find some credence for the contagion mechanism in our sample, the improvement in the model's fit does not justify the associated increase in statistical uncertainty.

Specifically, a table in Appendix F reports the distributions of the likelihoods of both models, and the associated BICs (the negative of the likelihood plus the penalty for the number of parameters). Both statistics indicate that the difference between the two models is insignificant. Table 3 reports various measures of pricing errors for the model without contagion. The same metrics for the model with contagion are similar and, therefore, are not reported for brevity. Thus, we discuss only the model without contagion in the sequel.

Continuing with Table 3 we see that the overall fit is good, with the RMSE ranging from 2 to 12 basis points. To visualize the fit, we plot the time series of the observed and fitted spreads in Figure 4. The overall high quality of the fit is evident.

As a final and out-of-sample test of the model's quality, we take the estimated factors and re-estimate only the country-specific parameters of the default intensities using data for the remaining 10 countries. The resulting fit is displayed in Figure 5. The overall quality of the 
fit remains high, suggesting that our model is quite reasonable. The selection procedure of the main sample implies that these countries represent less liquid markets. Therefore, fitting these quanto spreads perfectly is not required. The observed spreads for Cyprus are quite erratic, manifesting the illiquidity and riskiness of this sovereign, so the fit here is the worst.

\subsection{Default probabilities}

\section{Credit factors}

Figure 6 displays the filtered credit factors $w_{t}$. Recall that one of the identifying restrictions is that the means of these factors are set to 1 . This explains the similarity in scale. The time-series patterns are quite different. All factors exhibit large movements in 2012, around the height of the sovereign debt crisis. This period was marked by the downgrades of individual sovereigns, the creation of the European Financial Stability Facility, and the political instability in Greece. The crisis reached its peak when Greece officially defaulted in March 2012. The sharp drop in the factors shortly thereafter is associated with the famous speech by Mario Draghi in July 2012, vowing to do "whatever it takes" to save the EUR. All of the factors persistently decrease thereafter.

The peripheral factor $w_{3 t}$, associated with Italy, Ireland, and Spain, also exhibits substantial variation prior to 2012 and, to a lesser degree, for the rest of the sample period. The core factor $w_{2 t}$, which corresponds to Belgium and France, starts to pick up shortly after the marked increase in the periphery factor $w_{3 t}$, but much earlier than the pronounced increase in the common factor $w_{1 t}$. Interestingly, $w_{1 t}$ picks up again at the very end of the sample period.

\section{Time series of risk-adjusted default intensities}

Various combinations of these factors deliver risk-adjusted default intensities for the respective countries via Equation (6). Figure 7A displays these intensities. Given the common variation in credit factors during 2012, it is not surprising to see elevated default probabilities during that period, irrespective of the country. The largest one-period default probability is almost $2.5 \%$ (default probabilities are approximately equal to intensities for such small numbers). Ireland, Italy, and Spain have clearly distinct patterns of intensities in the post-2012 period, a manifestation of their exposure to the factor $w_{3 t}$. The same three countries exhibit some elevation at the end of 2016 - a result of their extensive exposure to the global factor, which also picks up. Overall, Spain is the riskiest county. Germany does not load on the regional components at all. Hence, Germany has the lowest default risk, and its dynamic properties are distinct from those of other countries. These differences in dynamics manifest themselves in the differences between the average quanto curves that we noted in Figure 3. 


\section{Cross-section of risk-adjusted default intensities}

Table 4 summarizes how the default intensities of all countries, including the 10 out-ofsamples ones, load on the factors. The countries are sorted by their loadings on the global credit factor, $\delta_{w 1}^{* k}$. Germany is roughly in the middle. Spain has the largest exposure at four times that of Germany, and Finland the smallest at $14^{-1}$ times.

Overall, the countries exhibit large cross-sectional variation in their exposure to credit factors. Among the core countries, Belgium and France have a sizable exposure to the core factor, while others have nearly zero exposure. Finland appears to be the safest country with tiny exposures to both global and core factors.

On the peripheral side, the relatively recent additions to the Eurozone, such as Estonia and Slovakia, have a tiny exposure to region-specific risk, so they are largely indistinguishable from some core countries, including Germany itself. The Southern European countries have a large regional component. Spain and Greece stand out in this respect.

Eurozone quanto spreads are driven by common variation in the exchange rate and monetary policy. Thus, cross-country differences in model-implied default intensities ought to be related to cross-country differences in fiscal health. To test that conjecture, we collect information on quarterly debt-to-GDP and FX reserves-to-debt ratios and relate them to the model-implied hazard rates. We source these data from the Bank for International Settlements and the International Monetary Fund International Financial Statistics database. The data span is from the start of our sample, that is, the third quarter of 2010, up to the second quarter of 2015. All data are measured in USD for comparability.

We report the relation between these fiscal variables and model-implied hazard rates in Table 5. The relation between debt-to-GDP and hazard rates is positive and statistically significant at the $1 \%$ level, with an $R^{2}$ of $13 \%$ for this univariate regression. The coefficient of 0.20 implies that a one percentage point increase in a country's debt-to-GDP ratio $(+0.01)$ is on average associated with an 0.002 increase in intensity. This is economically meaningful. If hazard rates are constant, CDS premiums may be approximated by $L \cdot h_{t}^{*}$. Given the estimated $L$ of $41 \%$, this implies an increase in CDS premiums of approximately 8 bps.

For the specification in column (2), we add time fixed effects to further absorb any remaining common variation in hazard rates. Given the strong factor structure in CDS premiums in our model, this adjustment should absorb a significant amount of cross-sectional variation. The $R^{2}$ increases to $44 \%$, and the regression coefficient is stable, suggesting a meaningful cross-sectional relation between the model-implied hazard rates and each country's fiscal health.

As an alternative measure of fiscal health, we use a country's foreign exchange rate reserves to debt outstanding in columns (3) and (4). The negative regression coefficient implies that countries that have debt that is better collateralized by foreign exchange rate reserves have 
lower hazard rates. The economic effect is smaller. With $L=0.41$, the coefficient of -0.03 implies a 1 bps lower CDS premium for each additional percentage point in FX reserves relative to debt outstanding. The coefficient is unaltered if we absorb additional common variation through time fixed effects in column (4).

We examine the joint effect of both fiscal variables in columns (5) and (6). Debt-to-GDP appears to be the driving variable. Its coefficient remains stable and significant at the $1 \%$ level.

\section{Credit risk premiums}

While we cannot characterize the default risk premiums for individual countries, we can do so for the overall credit risk. Figure 7B displays the aggregate true and risk-adjusted default intensities $\lambda_{t}$ and $\lambda_{t}^{*}$, respectively. We show them on different scales because the true default intensity is much smaller. Visually, they track each other quite closely, suggesting a constant risk premium. However, this is not the case. To illustrate this, we characterize the corresponding risk premium, in line with the literature, via $\lambda_{t}^{*} / \lambda_{t}$, displayed in Figure $7 \mathrm{C}$.

On average, this number is 1.95 , and is drifting downward toward the end of the sample. Starting from 2014, the premium is insignificantly different from 1. As a benchmark, Driessen (2005) assumes a constant default premium in the context of corporate debt and estimates it to be 2.3. Combining CDS-implied default intensities with Moody's KMV expected default frequencies, Berndt, Douglas, Duffie, and Ferguson (2018) also find an average default premia of around 2 for a sample of 93 firms in three industries. The ratios of risk-adjusted to true default intensities, however, exhibit substantial time variation, between 1 and 6 .

Bai, Collin-Dufresne, Goldstein, and Helwege (2015) and Gouriéroux, Monfort, and Renne (2014) emphasize that if a model of default intensity is missing the contagion effect, then the ratio of intensities might be overstating the true premium for credit risk. In our case, a version of the model with contagion generates an average premium of 2 and by and large similar dynamics.

\subsection{Devaluation contingent on default - the twin Ds}

\section{Probability}

The estimation results allow us to weigh in on the debate about whether default has an immediate or long-term impact on the exchange rate. Krugman (1979) suggests that default leads to a change in the drift of the depreciation rate, with a persistent and continuous 
depreciation of the local currency. Na, Schmitt-Grohé, Uribe, and Yue (2017), in contrast, argue that the FX rate suffers a significant one-time drop upon default. See our discussion around Equation (8).

The aforementioned lack of a significant effect of credit factors on the expected depreciation rate implies that default is unlikely to have a long-term effect on currencies. Thus, the estimation results imply that changes in the FX rate are linked to credit risk only through jumps. The jump component is significant, implying an acute and short-term interaction between the Twin Ds.

How likely is the EUR to devalue if one of the sovereigns in the Eurozone defaults? The answer requires a more formal definition of devaluation. We associate it with an extreme movement in exchange rates, and rely on our model to measure the probability of such an event. Specifically, we define the EUR devaluation as a drop in $S_{t}$ that is larger than three conditional standard deviations.

The model implies that the true 1-week probability of devaluation conditional on default is $4.64 \%$. The risk-adjusted probability of devaluation conditional on default is $76.60 \%$, suggesting a large risk premium for this event. We will quantify this premium directly in the next section. The true 1-year probability is $0.02 \%$, which is smaller than the 1-week probability. Thus, devaluation comes primarily through a sharp, short-term decline in the EUR. This decline in probabilities with the horizon is consistent with a one-off impact of default on the FX rate, as discussed above. This number is also much smaller than those reported by Na, Schmitt-Grohé, Uribe, and Yue (2017) and Reinhart (2002). Part of this difference may be explained by the sample (developed versus emerging economies), and by our primary use of market data, rather than realized defaults. The corresponding 1-year risk-adjusted probability of devaluation conditional on default is $0.85 \%$.

We also measure the sensitivity of the probability of devaluation to changes in the probability of default, which we represent by the default intensity. We can view the previous exercise as a particular case in which the default intensity is equal to infinity. Over the 1-week horizon, the true (risk-adjusted) devaluation probability increases by $0.04 \%(0.73 \%)$ for every $1 \%$ increase in the default intensity. The small sensitivity of the true probability is a manifestation of the small jump size. Thus, a large increase in the intensity is needed for the jump component to affect devaluation. Figure $7 \mathrm{~B}$ shows that the largest movement in the true (risk-adjusted) default intensity was equal to $0.5 \%$ (6.7\%), which occurred between December 2011 and June 2012 during the Eurozone debt crisis. This increase translates into an increase of $0.02 \%$ (4.9\%) in the true (risk-adjusted) probability of devaluation. Over 1 year, the devaluation sensitivities to default are $0 \%$ (under true probability) and $0.04 \%$ (risk-adjusted probability). This decline is consistent with the aforementioned short-term effect of default on devaluation.

Overall, the probability of devaluation related to default is modest under the true probability. Yet, the risk-adjusted counterparts are rather high. This suggests the occurrence of currency devaluation during particularly bad states of the economy that tend to coincide 
with a high marginal utility of the representative agent. This interpretation is similar to the equilibrium models of Augustin and Tédongap (2016) and Chernov, Schmid, and Schneider (2017), who characterize the large risk premia demanded by risk-sensitive investors for selling CDS protection on sovereigns in developed economies. In the next section, we directly measure the risk premiums associated with default-contingent devaluation.

\section{Risk premiums}

We start with the case that ignores the timing of default, and compute both the risk-adjusted expectation of the depreciation rate, $E_{t}^{*}\left[S_{T} / S_{t}\right]$, and its true counterpart, $E_{t}\left[S_{T} / S_{t}\right]$. The first row of Figure 8 shows that the true expectations indicate expected EUR devaluation, and the average term structure of such expectations is downward sloping (EUR is expected to devalue more at longer horizons). The risk-adjusted expectation shows that the USD is expected to devalue, on average, at horizons of up to 3 years.

To understand this result, consider covered interest parity, which implies $E_{t}^{*}\left[S_{T} / S_{t}\right]=$ $F_{t, T} / S_{t}=\exp \left[(T-t)\left(y_{t, T}-\widehat{y}_{t, T}\right)\right]$ with $\widehat{y}_{t, T}$ denoting the EUR benchmark yield. Thus, the expectation is positive whenever $y_{t, T}>\widehat{y}_{t, T}$. The displayed relationship is thus pinned down by the currency forward rates $F_{t, T}$ that we used in estimation.

One implication is that we observe the standard currency premium relationship, $E_{t} S_{T} / E_{t}^{*} S_{T}$, often expressed as the carry trade. Borrowing in the high-interest rate USD, converting to EUR, and then lending in this currency, leads, on average, to negative (log) excess returns at short horizons. At long horizons (log) excess returns are not significantly different from zero, consistent with the evidence in Lustig, Stathopoulos, and Verdelhan (2016).

The second row of Figure 8 includes a condition on the timing $\tau$ of any credit event rather than the one in a specific country. In this case, the arrival rate is controlled by $\lambda_{t}$, and we can compute both the risk-adjusted expectation and its true counterpart. Default risk has almost no impact in the short-term, so the plot for $T=1$ year is similar to that for the nodefault case (it is literally identical if $T=1$ week). The level of risk-adjusted expectations moves upwards with longer maturities in this case, indicating the risk-adjusted expected USD depreciation conditional on default. This happens because early termination leads to a loss in the expected USD appreciation.

In risk premium terms, we observe a drastic difference in relation to the no-default case. Carry returns to EUR are still negative in the short run, and continue to be so as the horizon expands. That is a manifestation of the interaction with default risk. No amount of interest earned on a long-term debt instrument can compensate for currency losses experienced in case of default.

Indeed, we can quantify how much more risk premium is required for such a scenario. Expressing risk premiums in $\operatorname{logs},(T-t)^{-1} \log \left[E_{t} S_{T} / E_{t}^{*} S_{T}\right]$ (no default) and 
$(T-t)^{-1} \log \left[E_{t} S_{t \wedge T} / E_{t}^{*} S_{t \wedge T}\right]$ (default), we can compute the difference between the two. It reflects the extra compensation one earns for the currency loss in case of default, compared with the compensation for the regular currency risk. The third row of Figure 8 displays these differences for $T=1$ and 5 years, and the average term structure.

At short horizons this "excess risk premium" changes sign sporadically and stabilizes at zero after the sovereign debt crisis. The average value is slightly positive and corresponds to a negative extra premium for EUR depreciation. But, as can be seen from the third panel, that extra premium is not significantly different from zero. The same average effects persist for maturities of up to 4 years. ${ }^{2}$ After that, the excess premium for EUR depreciation increases to $0.3 \%$ at the 15 -year horizon and levels off at $0.5 \%$ per week at the 30 -year horizon (not shown). These numbers are large, and liquidity effects could be, in part, responsible for such a magnitude. But even one half of these premiums would still be economically significant.

\section{Expected devaluation and relative quanto spreads}

Several authors, such as Du and Schreger (2016) and Mano (2013), use observed relative quanto spreads, in the context of EM, to measure the anticipated currency devaluation in case of a credit event. As we show in Equation (1), the relative spread consists of two components: the risk-adjusted expected depreciation conditional on default and the interaction of default and FX jump. The second term reflects the propensity of the EUR to depreciate when the default intensity increases.

To facilitate the discussion, we switch to the ratio of the local and the foreign currency CDS spreads, which has a more straightforward connection to the depreciation rate,

$$
\frac{C_{t, T}^{€}}{C_{t, T}^{\Phi}}=E_{t}^{*}\left[\frac{S_{\tau \wedge T}}{S_{t}}\right]+\operatorname{cov}_{t}^{*}\left[\frac{e^{-r(\tau \wedge T-t)} I(\tau \leq T)}{E_{t}^{*} e^{-r(\tau \wedge T-t)} I(\tau \leq T)}, \frac{S_{\tau \wedge T}}{S_{t}}\right] .
$$

This expression makes it explicit that a direct reading of the data, as expected depreciation upon default, is prone to be biased, as it may overstate the importance of the impact of sovereign default on the local currency depreciation. Our model allows us to gauge the relative importance of both terms, both across countries and over time. We illustrate these decompositions in Figure 9.

As a start, focus on the last column that depicts the time-averages of relative quanto spreads across the term structure for the six countries that we use in the main estimation. The black-circled lines display the observed relative CDS spreads, $C_{t, T}^{€} / C_{t, T}^{\$}$. If one were to take the view that the spread reflects the risk-adjusted expectation of the depreciation

\footnotetext{
${ }^{2}$ At first blush, this result appears to be at odds with the large differences in true and risk-adjusted 1-week probabilities of devaluation conditional on default that we reported in the previous section. The risk premiums reflect compensation for any adverse movement in EUR. In contrast, the probabilities reflect an extreme event of at least a three-standard-deviation move.
} 
rate only, then the Figure would tell us that, for 1-year contracts, the Euro is expected to depreciate on average by about 30\% for Germany, 28\% for France, up to about $15 \%$ for Ireland. For longer horizon contracts, the magnitude of the expected impact is increasing. For the 5-year maturity, for example, the expected drop in the local currency given default is as large as $44 \%$ in the case of Germany.

The gray lines depict the model-implied default-contingent risk-adjusted expected depreciation rate $E_{t}^{*}\left[S_{\tau \wedge T} / S_{t}\right]$. The gap between the two lines emphasizes that the view of that expectation as the observed relative quanto spread is biased. Generally, the model-based risk-adjusted expectation is above the relative quanto spread implying a negative $\operatorname{cov}_{t}^{*}$ term in the decomposition, on average. This is intuitive as one would expect the event of default and the value of the EUR to move in the opposite directions. Quantitatively, the difference ranges from a high of $27 \%$ for Germany to a low of $10 \%$ for Ireland at short horizons, and declines at longer horizons. The decline suggests that market participants perceive the sensitivity of the FX rate to default risk to weaken in the long-term.

The cross-country variation in the $\operatorname{cov}_{t}^{*}$ term suggests that the impact of a credit even in one of the core countries is more important than that in the peripheral ones. The time series plots of relative quanto spreads and expected depreciation rates at different horizons, in the first three columns of Figure 9, convey more detail about this observation. We focus on the 5-year horizon in the second column. The gap between the gray and black lines is increasing in the build-up of the European debt crisis in 2011 and 2012. This suggests that the covariance risk became of greater importance during that period. A sharp change of this pattern is visible in July 2012, when the gap between the two plotted lines narrows significantly in particular for the peripheral countries (Ireland, Italy, and Spain), but not for the core countries (Belgium, France, Germany). This episode coincides with Draghi's speech, vowing to do whatever it takes to save the EUR.

One interpretation of the data is that Draghi was to some extent successful in changing the market's perception about the interaction of FX and default risks. This perception has nearly collapsed to zero for peripheral countries, but not so for core countries. That difference highlights the systemic role of the core countries and the fear of the impact of their defaults on the EUR currency, irrespectively of how unlikely that event may be. Consequently, markets may still expect a sell-off of the EUR in the case of default. Crosscountry differences over time consistently suggest that Germany is expected to have the greatest impact on the exchange rate if it were to default.

\section{Conclusion}

Sovereign CDS quanto spreads offer a market perspective on the Twin Ds. We study their interactions and the corresponding risk premiums from an asset pricing perspective. To that end, we propose an affine no-arbitrage model of the joint dynamics of the quanto spreads 
of 17 Eurozone countries and the USD/EUR exchange rate. Controlling for exchange rate risk, credit risk has a parsimonious three-factor structure (global, core, and peripheral), indicating a lot of common movement. Cross-country differences in credit risk are related to a measure of debt, indicating the connection between cross-sectional variation in default risk and variation in fiscal policies.

We find that the probability of devaluation conditional on default is low. But the risk premium for this event is large, much larger than either the credit risk premium or the carry trade return individually. These results pinpoint the economic importance of the Twin Ds, as their occurrence coincides with the worst states of the economy when investors' marginal utility is high. 


\section{References}

Ait-Sahalia, Yacine, Roger J.A. Laeven, and Loriana Pelizzon, 2014, Mutual excitation in eurozone sovereign cds, Journal of Econometrics 183, 151-167.

Ang, Andrew, and Francis A. Longstaff, 2013, Systemic sovereign credit risk: Lessons from the u.s. and europe, Journal of Monetary Economics 60, 493-510.

Augustin, Patrick, 2014, Sovereign credit default swap premia, Journal of Investment Management $12,65-102$.

— , Valeri Sokolovski, Marti G. Subrahmanyam, and Davide Tomio, 2016, Why do investors buy sovereign default insurance?, Working Paper New York University, Stern School of Business.

Augustin, Patrick, and Roméo Tédongap, 2016, Real economic shocks and sovereign credit risk, Journal of Financial and Quantitative Analysis 51, 541-587.

Azizpour, Shahriar, Kay Giesecke, and Gustavo Schwenkler, 2018, Exploring the sources of default clustering, Journal of Financial Economics 129, 154-183.

Bai, Jennie, Pierre Collin-Dufresne, Robert Goldstein, and Jean Helwege, 2015, On bounding credit event risk premia, Review of Financial Studies 28, 2608-2642.

Benzoni, Luca, Pierre Collin-Dufresne, Robert S. Goldstein, and Jean Helwege, 2015, Modeling credit contagion via the updating of fragile beliefs, Review of Financial Studies 28, 1960-2008.

Berndt, Antje, Rohan Douglas, Darrell Duffie, and Mark Ferguson, 2018, Corporate credit risk premia, Review of Finance 22, 419-454.

Borio, Claudio, Robert McCauley, Patrick McGuire, and Vladyslav Sushko, 2016, Covered interest parity lost: understanding the cross-currency basis, BIS Quarterly Review.

Brigo, Damiano, Nicola Pede, and Andrea Petrelli, 2016, Multi currency credit default swaps: Quanto effects and fx devaluation jumps, Working Paper.

Buraschi, Andrea, Emrah Sener, and Murat Menguetuerk, 2014, The geography of funding markets and limits to arbitrage, Review of Financial Studies 28, 1103-1152.

Carr, Peter, and Liuren $\mathrm{Wu}, 2007$, Theory and evidence on the dynamic interactions between sovereign credit default swaps and currency options, Journal of Banking 8 Finance 31, $2383-2403$.

Chernov, Mikhail, Lukas Schmid, and Andres Schneider, 2017, A macrofinance view of us sovereign cds premiums, Working Paper UCLA.

Dai, Qiang, and Kenneth J. Singleton, 2000, Specification analysis of affine term structure models, The Journal of Finance 55, 1943-1978. 
Das, Sanjiv, Darrell Duffie, Nikunj Kapadia, and Leandro Saita, 2007, Common failings: How corporate defaults are correlated, The Journal of Finance 62, 93-117.

Della-Corte, Pasquale, Lucio Sarno, Maik Schmeling, and Christian Wagner, 2016, Exchange rates and sovereign risk, Working Paper.

DeSantis, Roberto A., 2015, A measure of redenomination risk, ECB Working Paper 1785.

Doshi, Hitesh, Redouane Elkamhi, and Chayawat Ornthanalai, 2017, The term structure of expected recovery rates, Journal of Financial and Quantitative Analysis Forthcoming.

Doshi, Hitesh, Kris Jacobs, and Carlos Zurita, 2017, Economic and financial determinants of credit risk premiums in the sovereign cds market, Review of Asset Pricing Studies 1, $43-80$.

Driessen, Joost, 2005, Is default event risk priced in corporate bonds?, The Review of Financial Studies 18, 165-195.

Du, Wenxin, and Jesse Schreger, 2016, Local currency sovereign risk, The Journal of Finance $71,1027-1070$.

Du, Wenxin, Alexander Tepper, and Adrien Verdelhan, 2017, Deviations from covered interest rate parity, NBER Working Paper No.23170.

Duffie, Darrell, Lasse H. Pedersen, and Kenneth J. Singleton, 2003, Modeling sovereign yield spreads: A case study of russian debt, The Journal of Finance 58, 119-159.

Duffie, Darrel, and Kenneth J. Singleton, 1999, Modeling term structures of defaultable bonds, Review of Financial Studies 12, 687-720.

Duffie, Darrell, and Kenneth J. Singleton, 2003, Credit Risk: Pricing, Measurement and Management (Princeton University Press).

Ehlers, Philippe, and Philipp Schoenbucher, 2004, The influence of fx risk on credit spreads, Working Paper.

Elkamhi, Redouane, Kris Jacobs, and Xuhui Pan, 2014, The cross section of recovery rates and default probabilities implied by credit default swap spreads, Journal of Financial and Quantitative Analysis 49, 193-220.

Feldhutter, Peter, and David Lando, 2008, Decomposing swap spreads, Journal of Financial Economics 88, 375-405.

Giglio, Stefano, 2014, Credit default swap spreads and systemic financial risk, Working Paper.

Gourieroux, Christian, and Joann Jasiak, 2006, Autoregressive gamma processes, Journal of Forecasting 25, 129-152. 
Gouriéroux, Christian, Alain Monfort, and Jean-Paul Renne, 2014, Pricing default events: Surprise, exogeneity and contagion, Journal of Econometrics 182, 397-411.

Hamilton, James D., and Jing Cynthia Wu, 2012, Identification and estimation of gaussian affine term structure models, Journal of Econometrics 168, 315-331.

Herbst, Edward P., and Frank Schorfheide, 2016, Bayesian Estimation of DSGE Models (Princeton University Press).

Hoerdahl, Peter, and Oreste Tristani, 2012, The term structure of euro area sovereign bond yields, BIS Working Paper.

Hull, John, and Alan White, 2013, Libor vs. ois: The derivatives discounting dilemma, Journal Of Investment Management 11, 14-27.

Kremens, Lukas, 2018, Leaving a mark on the euro, Working Paper London School of Economics.

Krugman, Paul, 1979, A model of balance-of-payments crisis, Journal of Money, Credit and Banking 11, 311-325.

Kuehn, Lars-Alexander, David Schreindorfer, and Florian Schulz, 2017, Credit and option risk premia, Working Paper.

Lando, David, and Andreas Bang Nielsen, 2017, Quanto cds spreads, Working Paper Copenhagen Business School.

Le, Anh, Kenneth J. Singleton, and Qiang Dai, 2010, Discrete-time affineq term structure models with generalized market prices of risk, Review of Financial Studies 23, 2184-2227.

Li, Zhipeng Leo, 2017, Labor share and credit risk: The expected recovery rate channel, Working Paper UCLA.

Longstaff, Francis A., Jun Pan, Lasse H. Pedersen, and Kenneth J. Singleton, 2011, How sovereign is sovereign credit risk?, American Economic Journal: Macroeconomics 3, 75103.

Lustig, Hanno, Andreas Stathopoulos, and Adrien Verdelhan, 2016, Nominal exchange rate stationarity and long-term bond returns, Working Paper.

Mano, Rui, 2013, Exchange rates upon sovereign default, Working Paper.

Monfort, Alain, Fulvio Pegoraro, Jean-Paul Renne, and Guillaume Roussellet, 2014, Staying at zero with affine processes: a new dynamic term structure model, Journal of Econometrics.

— , 2017, Affine modeling of credit risk, credit event and contagion, Working Paper.

Monfort, Alain, and Jean-Paul Renne, 2013, Decomposing euro-area sovereign spreads: Credit and liquidity risks, Review of Finance 18, 2103-2151. 
Na, S., S. Schmitt-Grohé, M. Uribe, and V. Yue, 2017, The twin ds: Optimal default and devaluation, American Economic Review Forthcoming.

Pan, Jun, and Kenneth J. Singleton, 2008, Default and recovery implicit in the term structure of sovereign cds spreads, The Journal of Finance 63, 2345-2384.

Qiu, Jiaping, and Fan Yu, 2012, Endogenous liquidity in credit derivatives, Journal of Financial Economics 103, 611-631.

Reinhart, Carmen M., 2002, Default, currency crises, and sovereign credit ratings, World Bank Economic Review 16, 151-170.

Siriwardane, E., 2014, Concentrated capital losses and the pricing of corporate credit risk, Working Paper.

Zhang, Frank Xiaoling, 2008, Market expectations and default risk premium in credit default swap prices: A study of argentine default, Journal of Fixed Income 18, 37-55. 
Table 1

\section{Descriptive Statistics of Sovereign CDS Liquidity - Weekly}

\begin{tabular}{|c|c|c|c|c|c|c|c|c|c|c|c|c|c|}
\hline & \multirow[b]{2}{*}{$\mathrm{N}$} & \multicolumn{4}{|c|}{ EUR } & \multicolumn{4}{|c|}{ USD } & \multicolumn{4}{|c|}{ USD Notionals } \\
\hline & & Mean & Min & $\mathrm{p} 50$ & $\operatorname{Max}$ & Mean & Min & $\mathrm{p} 50$ & $\operatorname{Max}$ & Gross & Gross $\%$ & Net & Net $\%$ \\
\hline Austria & 329 & 4.50 & 3 & 4 & 8 & 6.21 & 3 & 6 & 9 & 54.37 & 15.51 & 5.04 & 23.35 \\
\hline Belgium & 329 & 4.73 & 3 & 5 & 8 & 5.55 & 3 & 5 & 10 & 54.96 & 15.55 & 4.50 & 20.72 \\
\hline Cyprus & 329 & 2.75 & 2 & 2 & 6 & 3.69 & 2 & 3 & 9 & 1.88 & 0.48 & 0.25 & 1.24 \\
\hline Estonia & 329 & 3.45 & 2 & 3 & 8 & 4.02 & 3 & 4 & 8 & 2.51 & 0.74 & 0.27 & 1.25 \\
\hline Finland & 329 & 3.15 & 2 & 3 & 9 & 5.79 & 2 & 6 & 9 & 17.48 & 4.98 & 2.17 & 10.28 \\
\hline France & 329 & 4.77 & 2 & 5 & 9 & 5.72 & 2 & 6 & 9 & 136.17 & 37.96 & 15.72 & 73.51 \\
\hline Germany & 329 & 3.89 & 2 & 3 & 8 & 5.19 & 2 & 5 & 9 & 121.24 & 33.97 & 14.99 & 70.54 \\
\hline Greece & 255 & 3.12 & 2 & 3 & 7 & 3.85 & 2 & 4 & 7 & 48.75 & 16.97 & 3.43 & 13.89 \\
\hline Ireland & 329 & 5.14 & 3 & 5 & 9 & 6.60 & 3 & 7 & 10 & 44.36 & 12.72 & 2.80 & 12.82 \\
\hline Italy & 329 & 6.38 & 2 & 7 & 9 & 6.61 & 2 & 7 & 10 & 356.35 & 100.00 & 21.43 & 100.00 \\
\hline Latvia & 329 & 4.02 & 2 & 4 & 10 & 5.32 & 3 & 5 & 10 & 8.96 & 2.58 & 0.50 & 2.34 \\
\hline Lithuania & 329 & 3.68 & 2 & 4 & 7 & 4.47 & 2 & 5 & 9 & 6.53 & 1.86 & 0.48 & 2.24 \\
\hline Netherlands & 326 & 3.60 & 2 & 3 & 8 & 5.27 & 2 & 5 & 9 & 28.38 & 7.94 & 3.00 & 14.28 \\
\hline Portugal & 329 & 5.78 & 3 & 6 & 9 & 7.24 & 2 & 7 & 10 & 69.48 & 19.91 & 4.41 & 20.14 \\
\hline Slovakia & 329 & 3.81 & 2 & 4 & 10 & 5.42 & 3 & 5 & 10 & 10.73 & $\begin{array}{r}3.06 \\
3.06\end{array}$ & 0.75 & $\begin{array}{r}20.11 \\
3.53\end{array}$ \\
\hline Slovenia & 329 & 3.21 & 2 & 3 & 7 & 4.27 & 2 & 4 & 9 & 6.96 & 1.93 & 0.68 & 3.19 \\
\hline Spain & 329 & 5.66 & 2 & 5 & 10 & 6.10 & 2 & 6 & 10 & 171.38 & 48.47 & 12.52 & 57.98 \\
\hline All & 5,516 & 4.23 & 2 & 4 & 10 & 5.39 & 2 & 5 & 10 & 69.05 & 19.56 & 5.64 & 26.24 \\
\hline
\end{tabular}

Notes. This table reports summary statistics (mean, N, min, max, median) for the depth measure, the average number of dealers quoting a contract, of 5-year sovereign CDS spreads denominated in EUR and USD for 17 Eurozone countries that have a minimum of 365 days of non-zero information on USD-EUR quanto CDS spreads. A simple $t$-test for differences in means suggests that differences in means are statistically significant. Depth is defined as the number of dealers used in the computation of the daily mid market CDS quote. The sample period is August 20, 2010 until December 30, 2016. All statistics are based on weekly (Wednesday) data. We also report the gross and net notional amounts of CDS outstanding in billion USD, as well as the ratio of net and gross notional amounts of CDS outstanding to the same quantities of Italy, which represents the most liquid sovereign CDS market. This data is based on weekly information from August 20, 2010 until June 24, 2015. Sources: Markit and Depository Trust and Clearing Corporation (DTCC). 
Table 2

Descriptive Statistics of CDS Quanto Spreads - Weekly

\begin{tabular}{|c|c|c|c|c|c|c|c|c|c|c|c|c|c|c|c|c|c|}
\hline \multicolumn{2}{|c|}{ Maturity } & \multicolumn{2}{|c|}{$1 y$} & \multicolumn{2}{|c|}{$3 y$} & \multicolumn{2}{|c|}{$5 y$} & \multicolumn{2}{|c|}{$7 y$} & \multicolumn{2}{|c|}{$10 \mathrm{y}$} & \multicolumn{2}{|c|}{$15 \mathrm{y}$} & \multicolumn{2}{|c|}{$30 y$} & \multicolumn{2}{|c|}{$10 y-1 y$} \\
\hline Country & Obs & Mean & $\mathrm{SD}$ & Mean & $\mathrm{SD}$ & Mean & SD & Mean & SD & Mean & SD & Mean & SD & Mean & SD & Mean & $\mathrm{SD}$ \\
\hline $\mathrm{AT}$ & 329 & 8 & 11 & 14 & 14 & 21 & 17 & 25 & 17 & 29 & 17 & 33 & 17 & 34 & 16 & 21 & 10 \\
\hline $\mathrm{BE}$ & 329 & 11 & 16 & 20 & 21 & 28 & 22 & 33 & 22 & 37 & 21 & 39 & 21 & 40 & 21 & 26 & 14 \\
\hline $\mathrm{CY}$ & 329 & 28 & 81 & 28 & 52 & 29 & 41 & 30 & 40 & 33 & 40 & 34 & 41 & 40 & 56 & 5 & 73 \\
\hline $\mathrm{EE}$ & 329 & 3 & 6 & 5 & 5 & 6 & 5 & 6 & 5 & 7 & 5 & 7 & 6 & 7 & 7 & 3 & 5 \\
\hline FI & 329 & 3 & 3 & 5 & 3 & 8 & 3 & 11 & 4 & 13 & 4 & 14 & 5 & 14 & 6 & 10 & 5 \\
\hline FR & 329 & 8 & 11 & 17 & 18 & 27 & 23 & 32 & 24 & 37 & 23 & 38 & 23 & 40 & 24 & 29 & 16 \\
\hline $\mathrm{DE}$ & 329 & 3 & 5 & 8 & 8 & 16 & 13 & 20 & 14 & 24 & 14 & 26 & 14 & 26 & 15 & 21 & 12 \\
\hline GR & 255 & 127 & 454 & 91 & 264 & 90 & 227 & 88 & 223 & 80 & 228 & 74 & 168 & 59 & 130 & -29 & 318 \\
\hline IE & 329 & 21 & 24 & 29 & 26 & 34 & 26 & 36 & 25 & 38 & 24 & 40 & 24 & 40 & 24 & 18 & 13 \\
\hline IT & 329 & 21 & 20 & 31 & 23 & 36 & 24 & 39 & 24 & 42 & 24 & 43 & 24 & 45 & 24 & 21 & 9 \\
\hline LV & 329 & 6 & 9 & 9 & 9 & 12 & 9 & 13 & 8 & 15 & 8 & 18 & 8 & 17 & 10 & 10 & 7 \\
\hline LT & 329 & 6 & 9 & 10 & 9 & 13 & 8 & 16 & 7 & 17 & 8 & 19 & 8 & 20 & 10 & 11 & 6 \\
\hline NL & 329 & 5 & 6 & 10 & 8 & 17 & 11 & 21 & 12 & 25 & 13 & 27 & 15 & 28 & 15 & 20 & 10 \\
\hline $\mathrm{PT}$ & 329 & 34 & 36 & 37 & 27 & 40 & 24 & 42 & 22 & 44 & 21 & 42 & 21 & 42 & 25 & 10 & 24 \\
\hline SK & 329 & 6 & 9 & 7 & 7 & 8 & 7 & 9 & 8 & 10 & 8 & 13 & 9 & 13 & 10 & 4 & 9 \\
\hline SI & 329 & 10 & 13 & 14 & 13 & 17 & 13 & 19 & 14 & 21 & 15 & 24 & 16 & 25 & 17 & 10 & 12 \\
\hline ES & 329 & 27 & 28 & 38 & 33 & 44 & 33 & 47 & 33 & 50 & 32 & 53 & 31 & 53 & 31 & 22 & 11 \\
\hline Total & 5,519 & 13 & 72 & 18 & 104 & 21 & 63 & 25 & 56 & 28 & 55 & 30 & 55 & 33 & 40 & 32 & 33 \\
\hline
\end{tabular}

Notes. This table reports summary statistics (mean, sd) for the sovereign CDS quanto spreads (difference between the USD and EUR denominated CDS spreads) for 17 Eurozone that have a minimum of 365 days of non-zero information on USD-EUR CDS quanto spreads. We report values for maturities of $1 \mathrm{y}, 3 \mathrm{y}, 5 \mathrm{y}, 7 \mathrm{y}, 10 \mathrm{y}, 15 \mathrm{y}$, and $30 \mathrm{y}$, as well as the slope, defined as the difference between the 10y and 1y quanto spreads. The sample period is August 20, 2010 until December 30, 2016. The data frequency is weekly, based on Wednesday quotes. Source: Markit. 
Table 3

Model fit

\begin{tabular}{ccccccccc}
\multicolumn{1}{c}{ Bond yield } & \multicolumn{7}{c}{ Quanto spread } \\
\hline & & Germany & Belgium & France & Ireland & Italy & Spain & Avg across countries \\
\hline $1 \mathrm{y}$ & - & 2.3 & 5.8 & 4.6 & 11.6 & 9.8 & 9.0 & 7.2 \\
3y & 1.7 & 3.3 & 6.8 & 7.2 & 7.8 & 7.2 & 7.6 & 6.7 \\
$5 \mathrm{y}$ & 1.1 & 4.1 & 6.1 & 6.2 & 7.6 & 5.9 & 6.7 & 6.1 \\
$7 \mathrm{y}$ & - & 5.3 & 3.8 & 5.1 & 7.8 & 5.6 & 6.4 & 5.7 \\
$10 \mathrm{y}$ & 2.2 & 6.7 & 6.1 & 7.3 & 7.1 & 4.9 & 6.9 & 6.5 \\
$15 \mathrm{y}$ & 2.8 & 7.4 & 7.4 & 8.5 & 7.3 & 5.3 & 8.1 & 7.3 \\
\hline Avg across maturity & 2.0 & 4.9 & 6.0 & 6.5 & 8.2 & 6.4 & 7.4 & - \\
\hline
\end{tabular}

Notes. In this table, we report results for the model fit in terms of root mean squared errors (RMSE). For the term structure model, we do not allow for measurement errors for 1-year- and 7-year maturity bonds in the estimation. We report the RMSE in basis points. The sample period is August 20, 2010 to December 30, 2016. The data frequency is weekly, based on Wednesday rates. 
Table 4

Credit factor loadings

\begin{tabular}{llll}
\hline Country & Global, $\delta_{w 1}^{* k}$ & Core,$\delta_{w 2}^{* k}$ & Periphery, $\delta_{w 3}^{* k}$ \\
\hline Spain & $0.0059^{* *}$ & - & $0.0037^{* *}$ \\
Italy & $0.0047^{* *}$ & - & $0.0013^{* *}$ \\
Cyprus & $0.0035^{*}$ & - & $0.0018^{*}$ \\
Greece & $0.0030^{*}$ & - & $0.0057^{*}$ \\
Slovenia & $0.0028^{* *}$ & - & $0.0040^{* *}$ \\
Ireland & $0.0027^{* *}$ & - & $0.0044^{* *}$ \\
Austria & $0.0026^{* *}$ & 0.0000 & - \\
Slovakia & $0.0019^{* *}$ & - & 0.0000 \\
Germany & $0.0014^{* *}$ & - & - \\
Netherlands & $0.0012^{* *}$ & 0.0001 & - \\
Lithuania & $0.0007^{* *}$ & - & $0.0007^{* *}$ \\
Latvia & $0.0006^{* *}$ & - & $0.0007^{*}$ \\
Portugal & $0.0006^{* *}$ & - & $0.0001^{* *}$ \\
Belgium & $0.0003^{* *}$ & $0.0032^{* *}$ & - \\
Estonia & $0.0003^{* *}$ & - & $0.0001^{* *}$ \\
France & $0.0002^{* *}$ & $0.0031^{* *}$ & - \\
Finland & $0.0001^{*}$ & $0.0001^{*}$ & - \\
\hline
\end{tabular}

Notes. In this table, we report the hazard rate loadings of each country, sorted in the descending order for global loadings. Notation: ${ }^{* *} p<0.05,{ }^{*} p<0.1$. A dash, - , indicates a loading restricted to zero. 
Table 5

Default intensities and fiscal health

\begin{tabular}{lcccccc}
\hline & $(1)$ & $(2)$ & $(3)$ & $(4)$ & $(5)$ & $(6)$ \\
& & & & & & \\
\hline & & & & & \\
& & & & & \\
Debt/GDP & $0.20^{* * *}$ & $0.23^{* * *}$ & & & & $0.25^{* * *}$ \\
& $(0.03)$ & $(0.02)$ & & & $0.03)$ & $(0.03)$ \\
FX Res/Debt & & & $-0.03^{* *}$ & $-0.03^{* * *}$ & 0.01 & 0.01 \\
& & & $(0.01)$ & $(0.01)$ & $(0.01)$ & $(0.01)$ \\
Constant & $0.13^{* * *}$ & $0.11^{* * *}$ & $0.30^{* * *}$ & $0.31^{* * *}$ & $0.12^{* * *}$ & $0.10^{* * *}$ \\
& $(0.03)$ & $(0.02)$ & $(0.01)$ & $(0.01)$ & $(0.03)$ & $(0.02)$ \\
Time FE & & & & & & $\checkmark$ \\
$N$ & & & & & & \\
$R^{2}$ & 324 & 324 & 307 & 307 & 307 & 307 \\
& 0.13 & 0.44 & 0.02 & 0.29 & 0.15 & 0.45 \\
\hline
\end{tabular}

Notes. In this table, we report the regression output from the panel regression of model-implied riskadjusted default intensities of 17 Eurozone countries against their corresponding debt-to-GDP and foreign exchange reserves-to-debt ratios. The data frequency is quarterly. Debt/GDP and FX-Debt ratios are sourced from the Bank for International Settlements and the International Monetary Fund International Financial Statistics database. We have the data from the start of our sample, i.e., 3rd quarter of 2010, up to the 2nd quarter in 2015. All data is measured in USD for comparability. Standard errors are reported in parentheses; ${ }^{* *},{ }^{* *}$, and ${ }^{*}$ defines statistical significance at the $10 \%, 5 \%$, or $1 \%$ level. 
Figure 1

\section{Cash flows to various sovereign instruments}

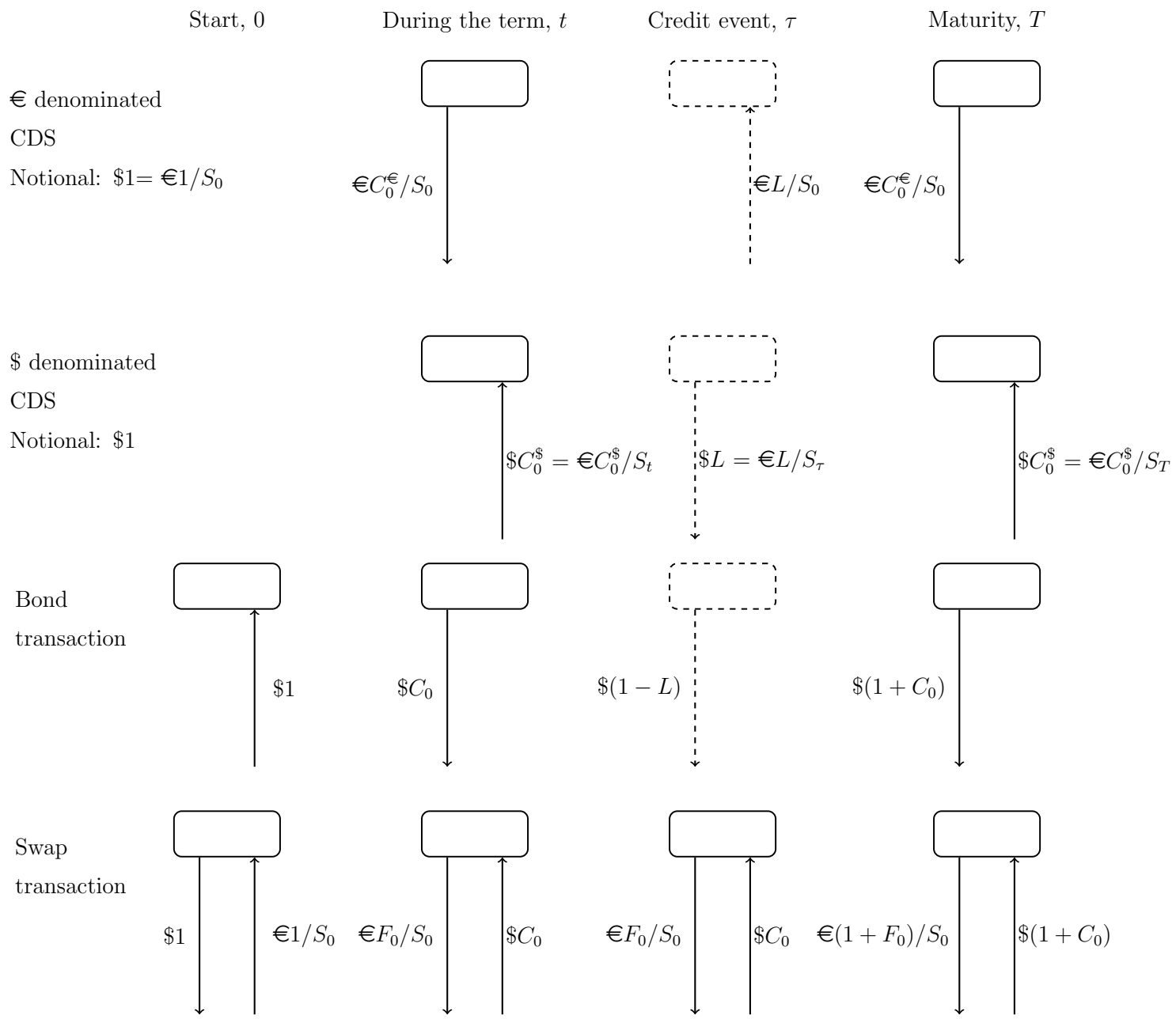

Notes. Dashed boxes emphasize uncertainty of credit events. $S_{t}$ is $\$ / €$ rate. The notional is $\$ 1=€ 1 / S_{0}$ for all instruments. Loss given default, $L$, is expressed as a percentage of notional. The first row depicts a $€$-denominated CDS contract (long protection) with a premium of $€ C_{0}^{€}$ established at time 0 , implying an annual payment of $€ C_{0}^{€} / S_{0}$. In case of a credit event, the long position receives $€ L / S_{0}$. The second row shows a $\$$-denominated CDS contract (short protection) with a premium of $\$ C_{0}^{\$}$. A quarterly payment is $\$ C_{0}^{\$}$, which is equivalent to $€ C_{0}^{\$} / S_{t}$ at the spot exchange rates. In case of a credit event, the short position pays out $\$ L=€ L / S_{\tau}$. The third row shows a short position in the $\$$-denominated par bond. It pays out coupons $\$ C_{0}$, and in case of a credit event it pays out recovery $1-L$. The fourth row shows a currency swap with a rate $F_{0}$. After exchanging the same notional expressed in different currencies at inception, one party pays interest on the $€$-denominated notional, $€ F_{0} / S_{0}$, and the other party pays interest on the $\$$-denominated notional $\$ C_{0}$. At maturity, the parties swap back the notionals and pay the last interest. 


\section{Figure 2}

Data: A first look

(A) German 5-year CDS premiums denominated in USD

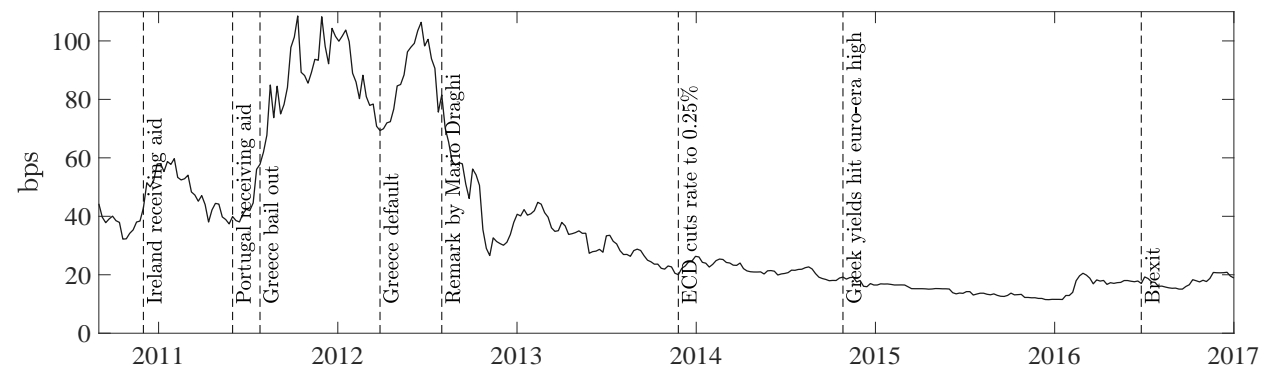

(B) FX rate

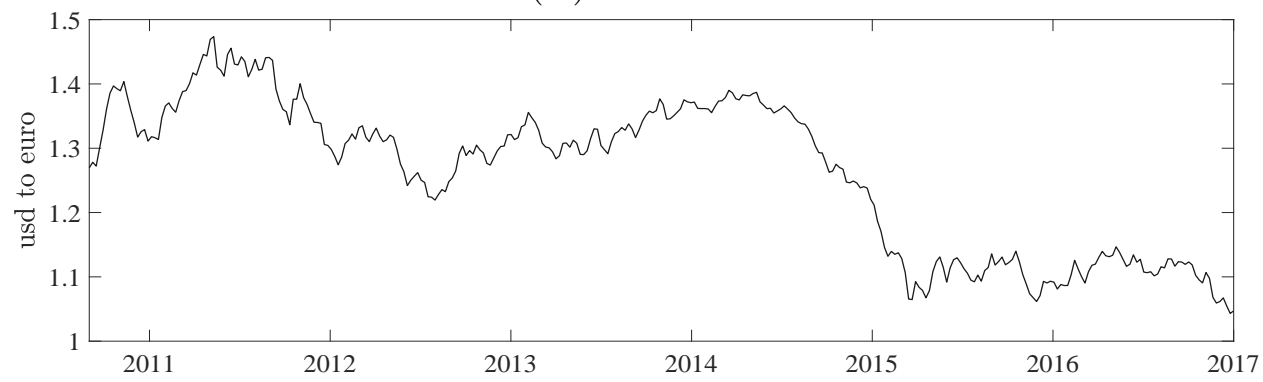

(C) Cross-correlation

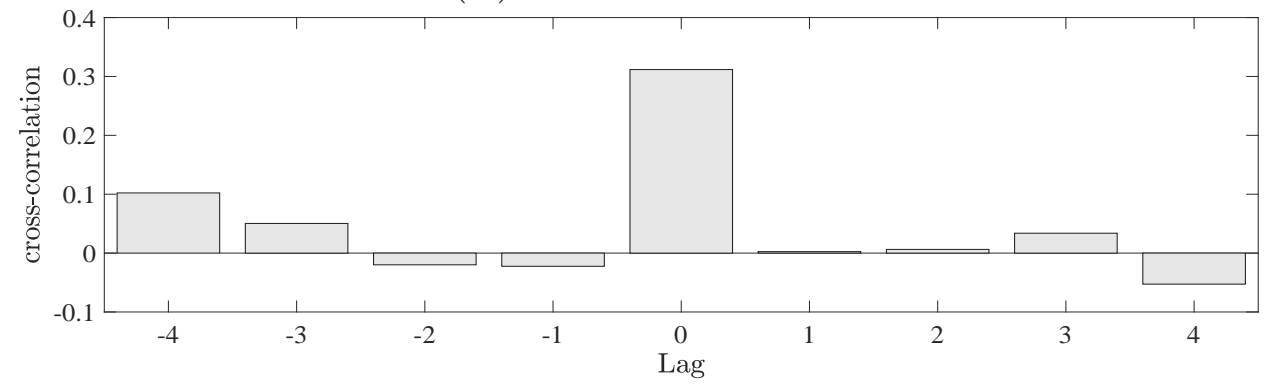

(D) German 5-year Quanto spreads

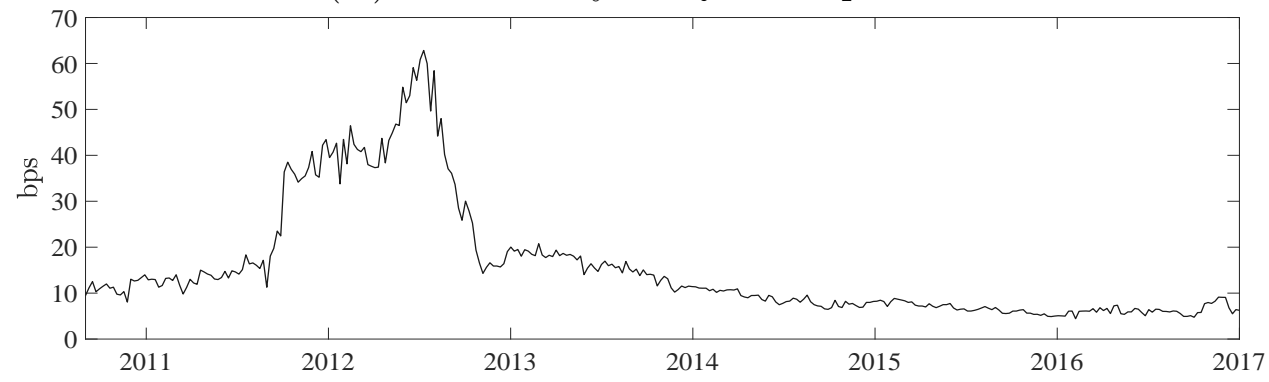

Notes. We offer a first look at some elements of data: CDS premiums and quanto spreads, exchange rate, and cross-correlogram between the first principal component of changes in 5-year CDS premiums across all countries and the depreciation rate. 
Figure 3

Quanto term spreads and exchange rate

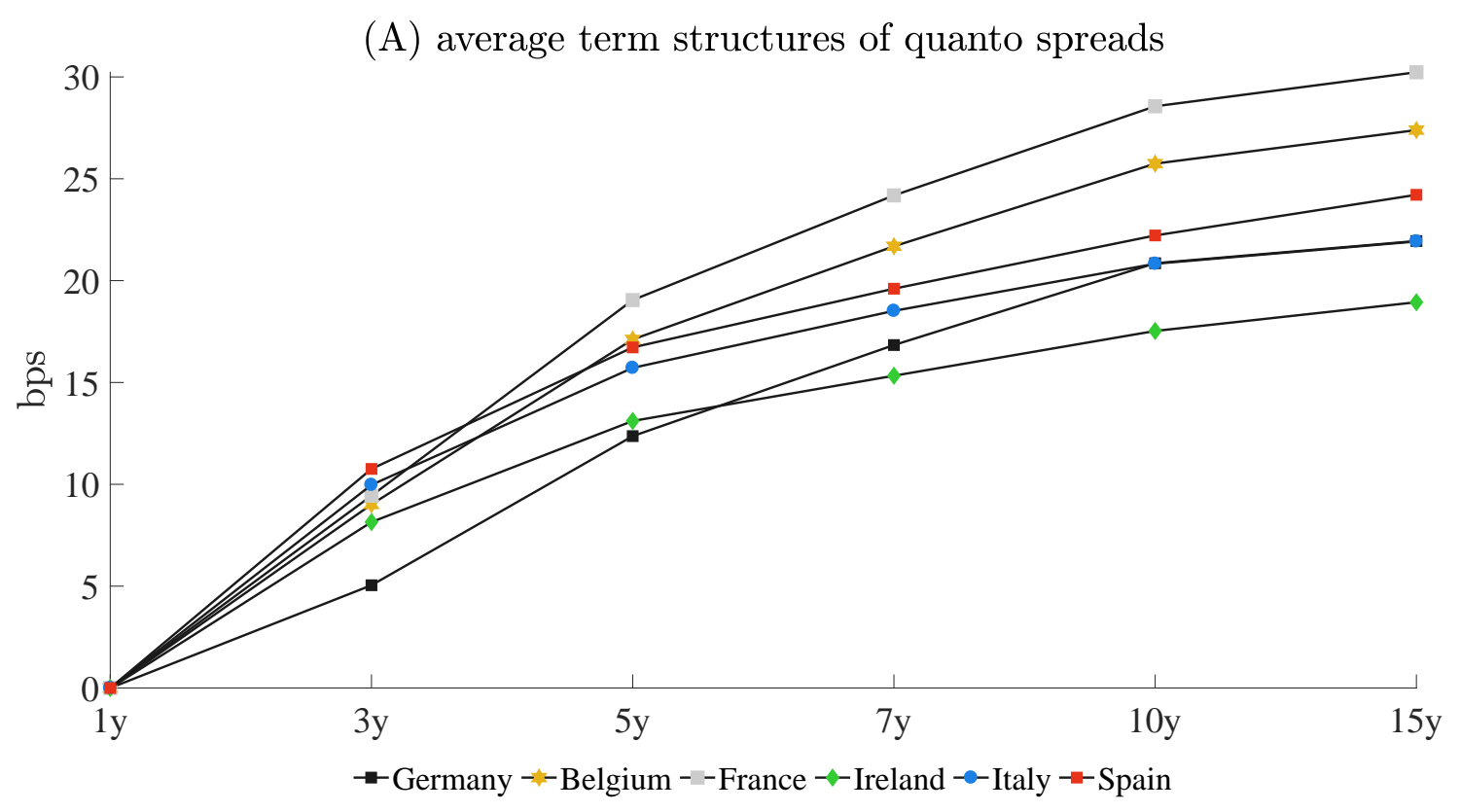

(B) depreciation rate (log change in FX rates)

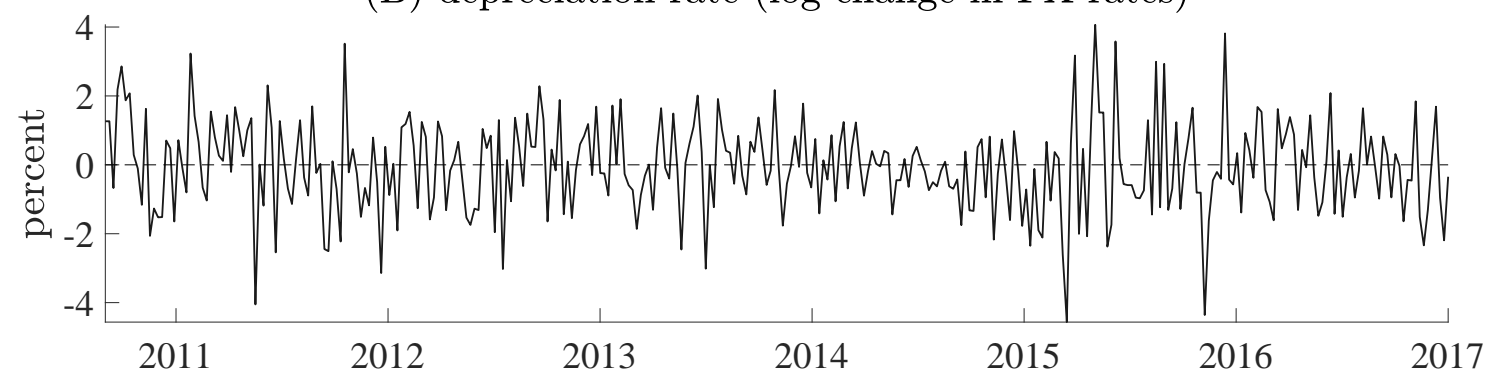

Notes. Panel A displays the term structure of CDS quanto spreads, defined as the difference between the USD and EUR denominated CDS spreads, for 6 Eurozone countries: Germany, Belgium, France, Ireland, Italy, and Spain. We compute average term spreads of maturities 3 years, 5 years, 7 years, 10 years, 15 years, and 30 years relative to the 1 year quanto spread. All spreads are expressed in basis points. Panel B shows weekly Wednesday-to-Wednesday changes in the USD/EUR exchange rate, expressed in percentage point changes. The sample period is August 20, 2010 to December 30, 2016. 
Figure 4

Quanto spreads: main sample
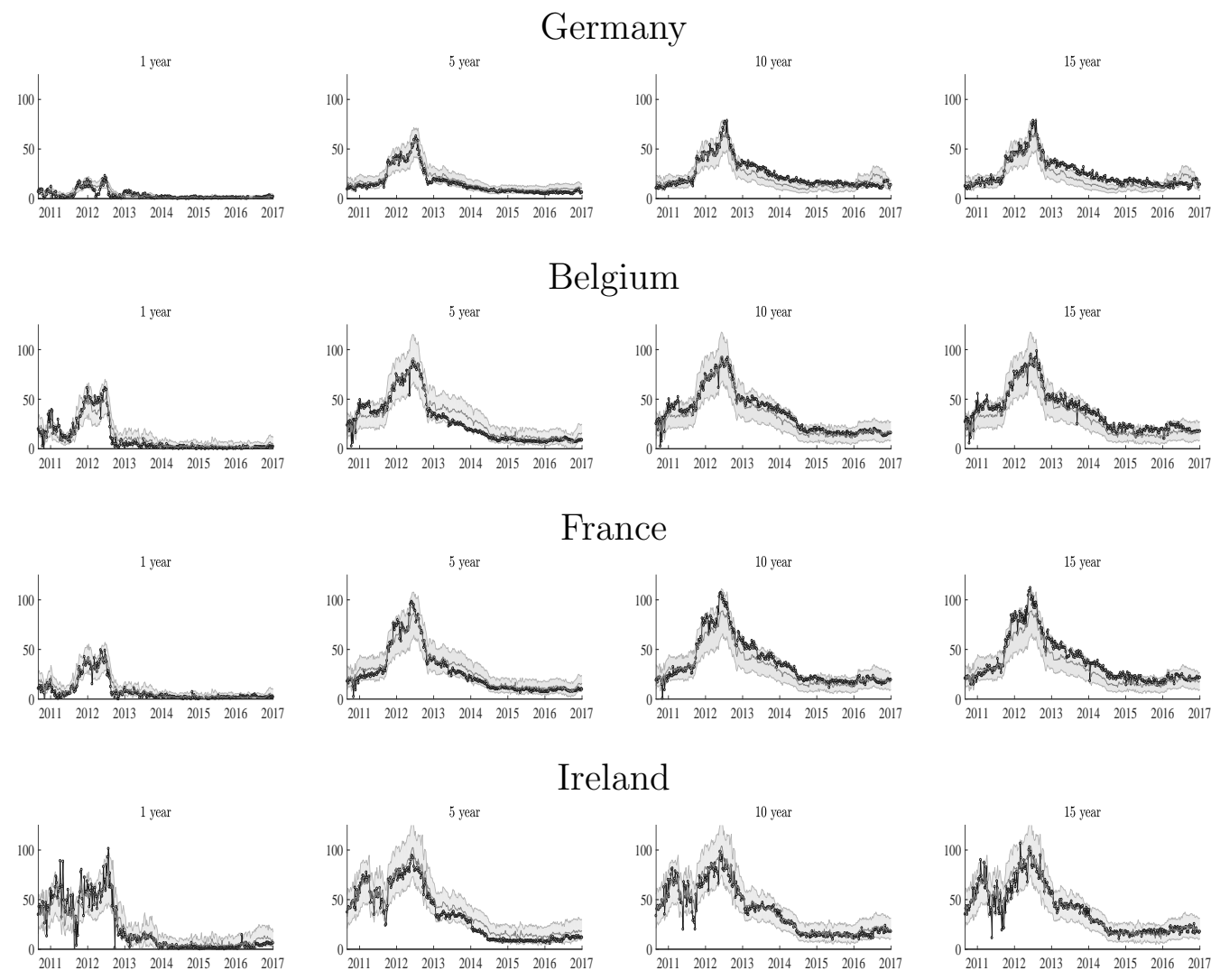

Ireland
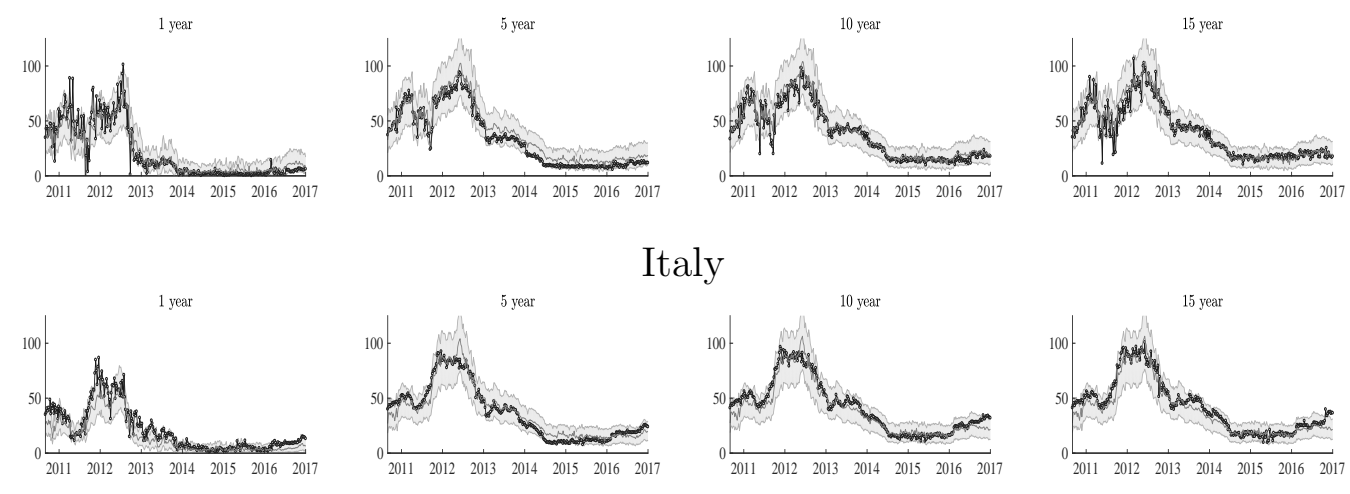

Italy
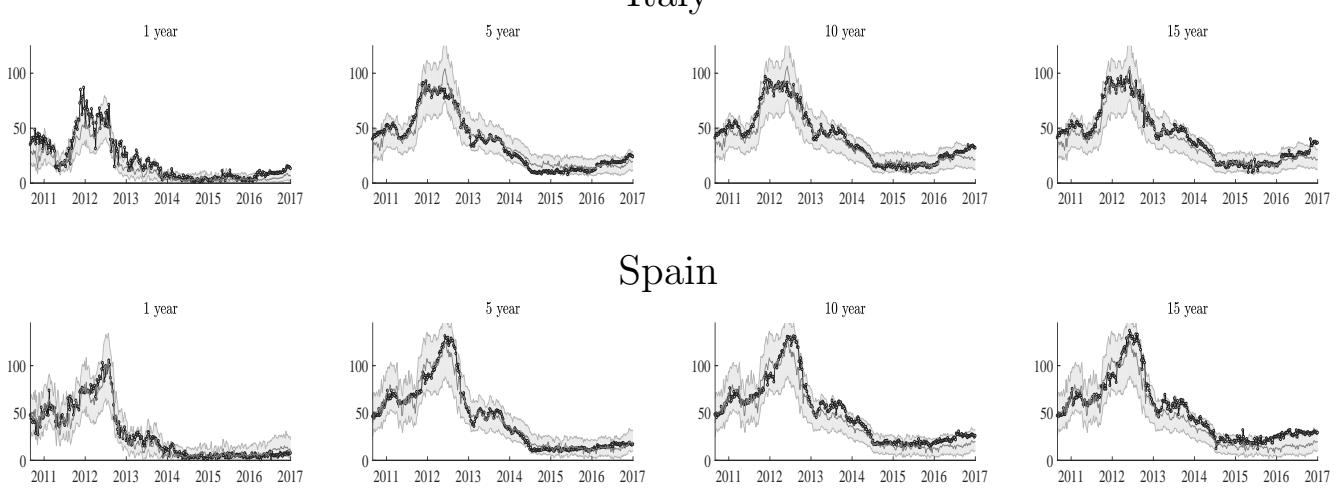

Spain

Notes. In these figures, we plot the observed and model-implied USD/EUR quanto spreads for Germany, Belgium, France, Ireland, Italy, and Spain. We report values for maturities of 1y, 5y, 10y, and 15y. Gray lines represent posterior medians of quanto spreads and gray-shaded areas correspond to $90 \%$ credible intervals. The true quanto spreads are plotted with black-circled lines. The sample period is August 20, 2010 to December 30, 2016. 
Figure 5

Quanto spreads: auxiliary sample

Austria
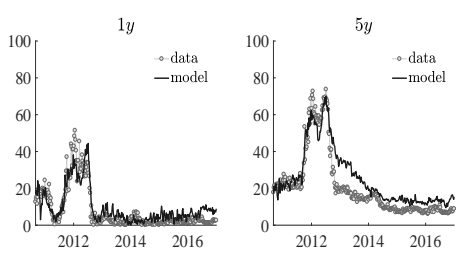

Estonia
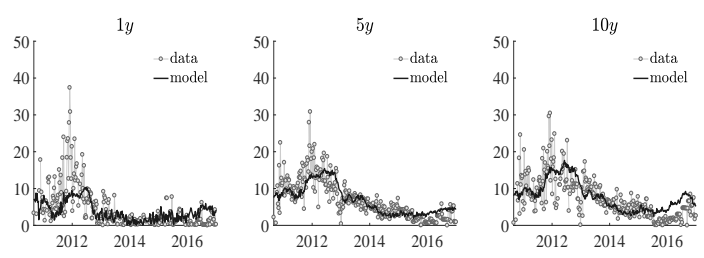

Latvia
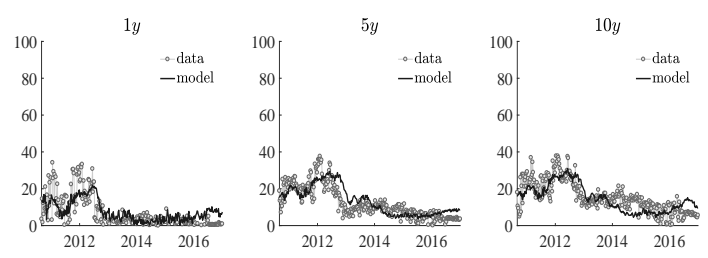

Netherlands
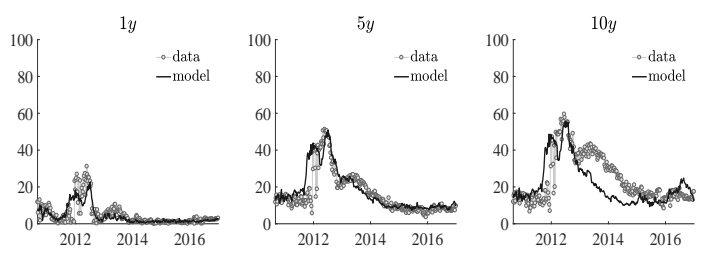

Slovakia
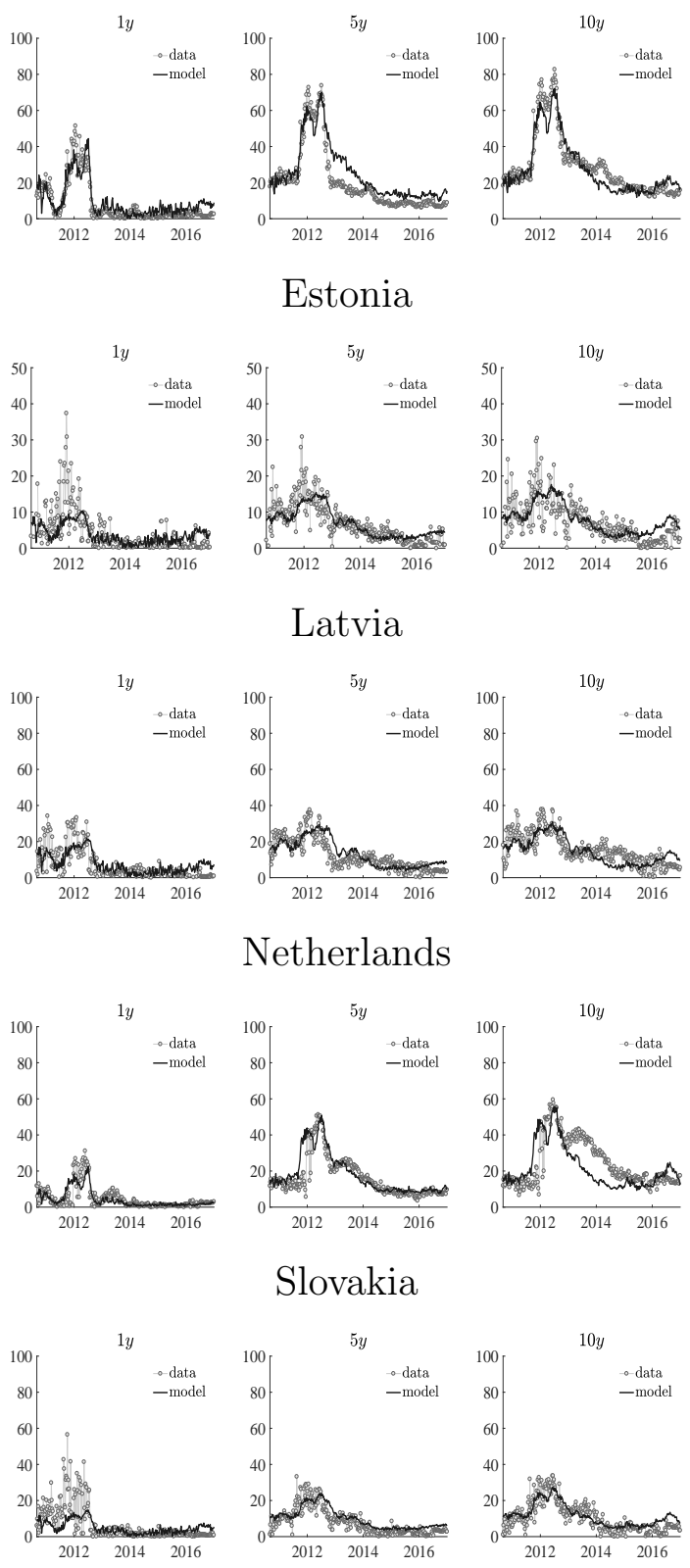
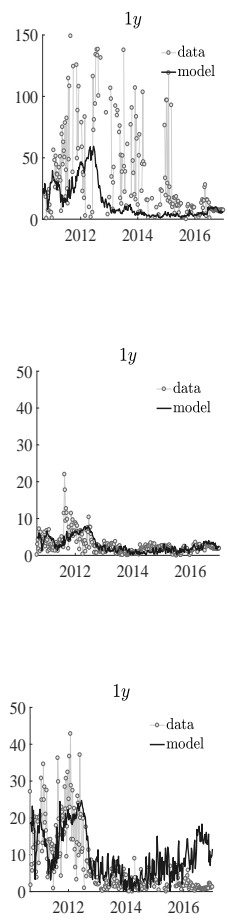

Lithuania
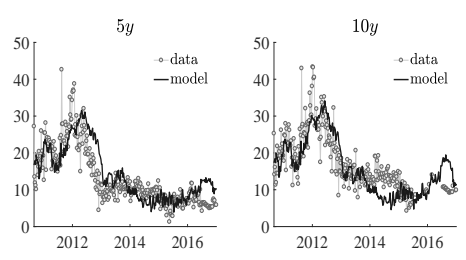

Portugal
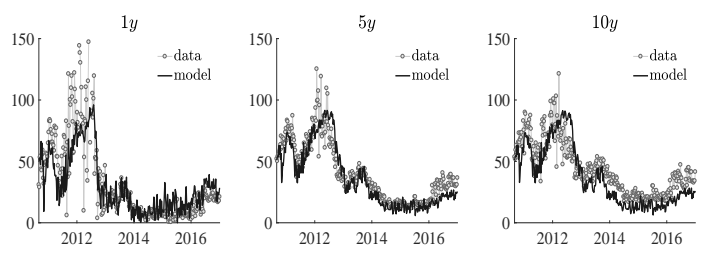

Slovenia
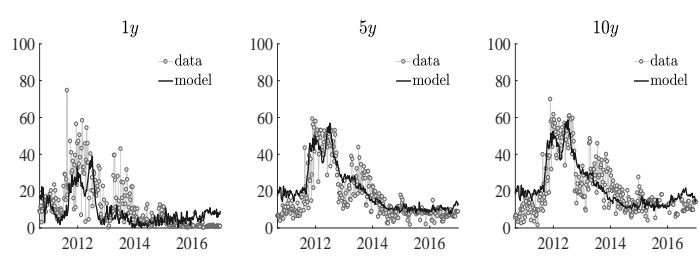

Notes. In these figures, we plot the observed and model-implied USD/EUR quanto spreads for Austria, Cyprus, Estonia, Finland, Latvia, Lithuania, Netherlands, Portugal, Slovakia, and Slovenia. We report values for maturities of $1 \mathrm{y}, 5 \mathrm{y}$, and 10y. Black lines represent posterior medians of quanto spreads and the true quanto spreads are plotted with white-circled lines. The sample period is August 20, 2010 to December 30, 2016. 
Figure 6

State
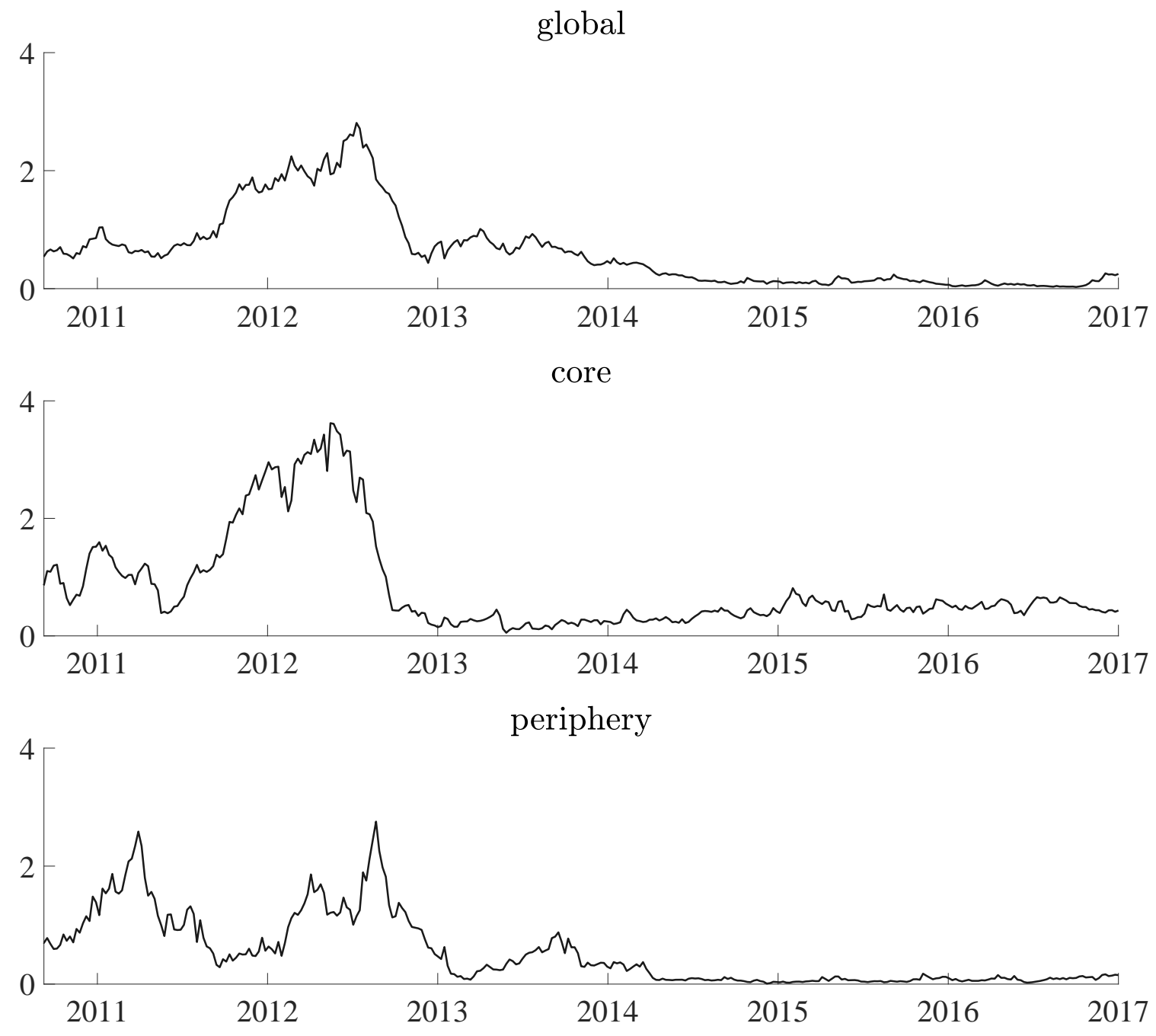

Notes. These figures depict the filtered latent credit and volatility factors implied by the model. $w_{1 t}$ is the global credit factor, $w_{2 t}$ is a regional credit factor corresponding to the core countries in the Eurozone (Belgium and France), and $w_{3 t}$ is a regional credit factor corresponding to the peripheral countries (Ireland, Italy, Spain). The sample period is August 20, 2010 until December 30, 2016. The data frequency is weekly. 


\section{Figure 7 \\ Default intensities}

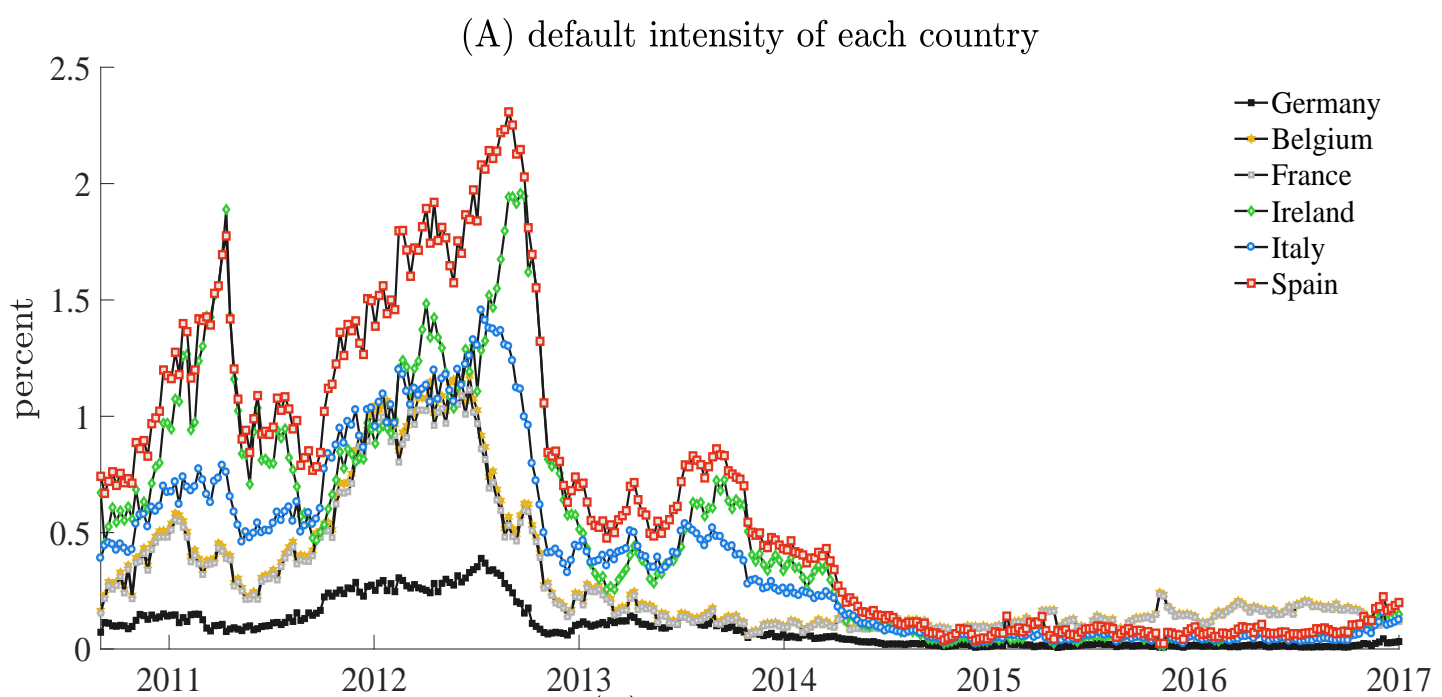

(B) default intensity

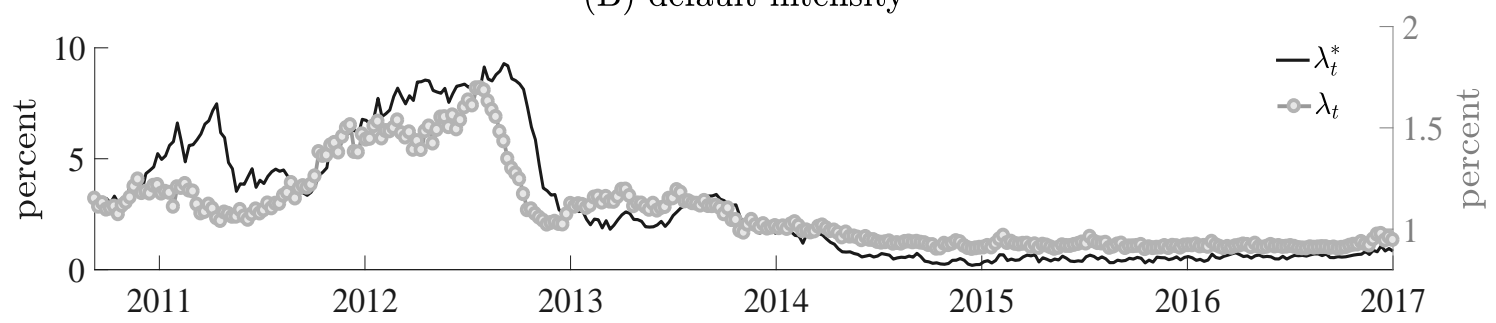

(C) credit risk premium

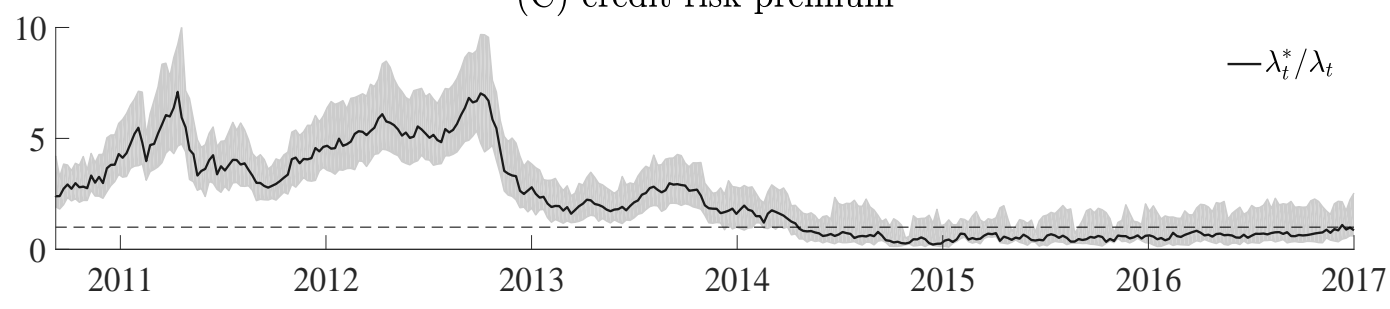

Notes. Panel A depicts the estimated risk-adjusted default intensities for Germany, Belgium, France, Ireland, Italy, and Spain. In Panel B, we plot the aggregate true and risk-adjusted default intensities. In Panel $\mathrm{C}$, we plot the default risk premium. The dashed horizontal line indicates a zero premium (ratio of intensities is equal to 1). The gray-shaded area represents $90 \%$ credible intervals. The sample period is August 20, 2010 until December 30, 2016. The data frequency is weekly, based on Wednesday quotes. 


\title{
Figure 8
}

\section{True and risk-adjusted expectations of the depreciation rate}

\author{
Expected depreciation without default
}
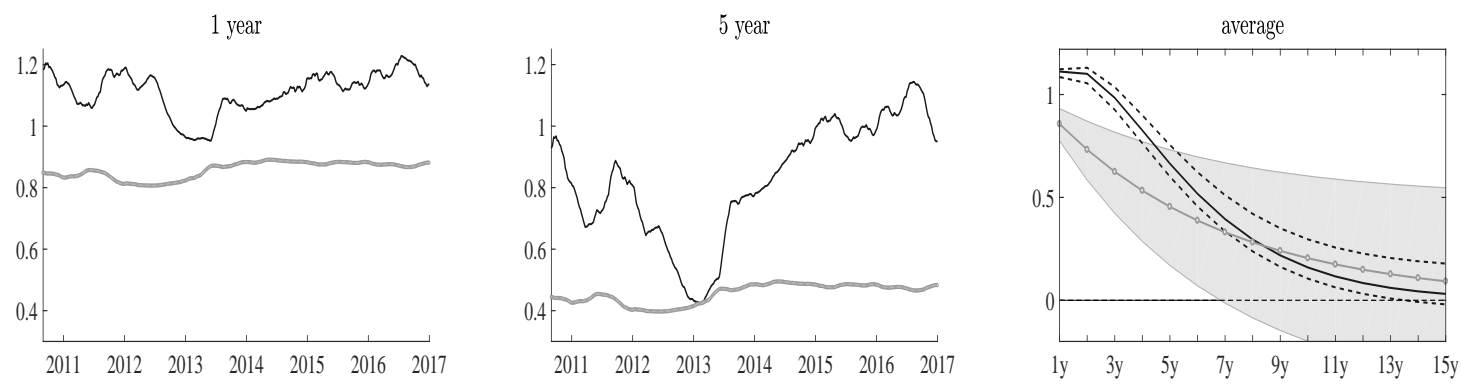

Expected depreciation with default
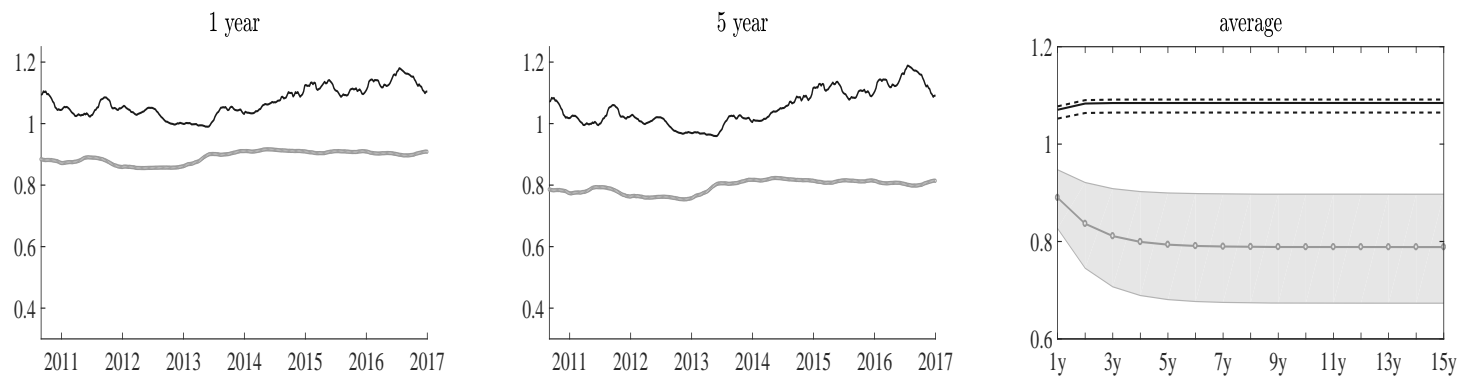

Expected excess return difference
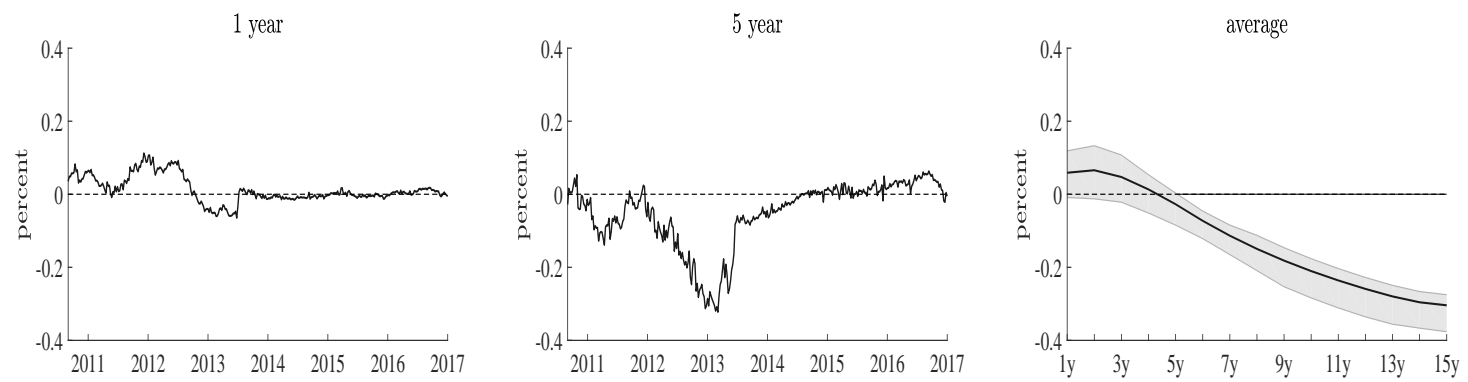

Notes. The figures depict the true (light gray) and risk-adjusted (black) expectations of the depreciation rate. The first row shows the expectations ignoring default, $E_{t}\left[S_{T} / S_{t}\right]$ and $E_{t}^{*}\left[S_{T} / S_{t}\right]$. The second row accounts for default, $E_{t}\left[S_{\tau \wedge T} / S_{t}\right]$ and $E_{t}^{*}\left[S_{\tau \wedge T} / S_{t}\right]$. The credit event time $\tau$ is triggered by a credit event in any of the countries. The left and middle panels show the time-series for $T=1$ year and 5 years, respectively. The right panels display time-series averages of these quantities for a variety of $T$ 's. The last row computes the difference between excess log expected returns corresponding to the two scenarios: $(T-t)^{-1} \log \left[E_{t} S_{\tau \wedge T} / E_{t}^{*} S_{\tau \wedge T} \cdot E_{t}^{*} S_{T} / E_{t} S_{T}\right]$. 


\section{Figure 9}

\section{Relative quanto spread and expected depreciation rate}
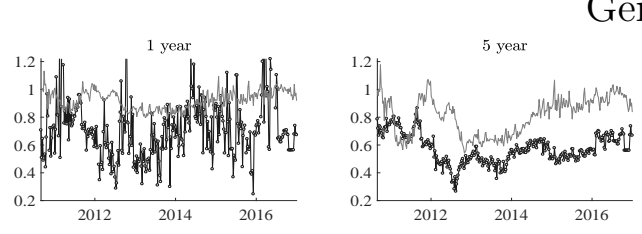

\section{Germany}
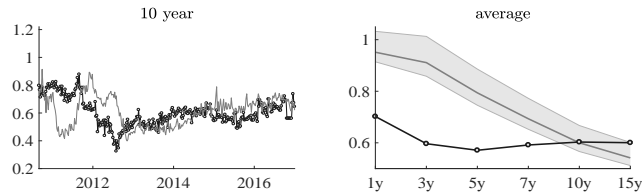

Belgium
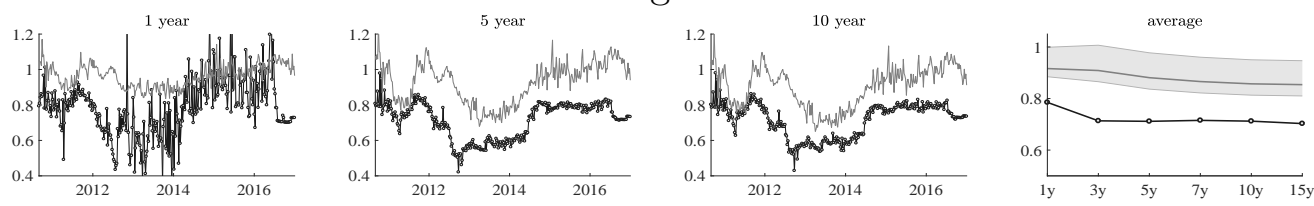

France
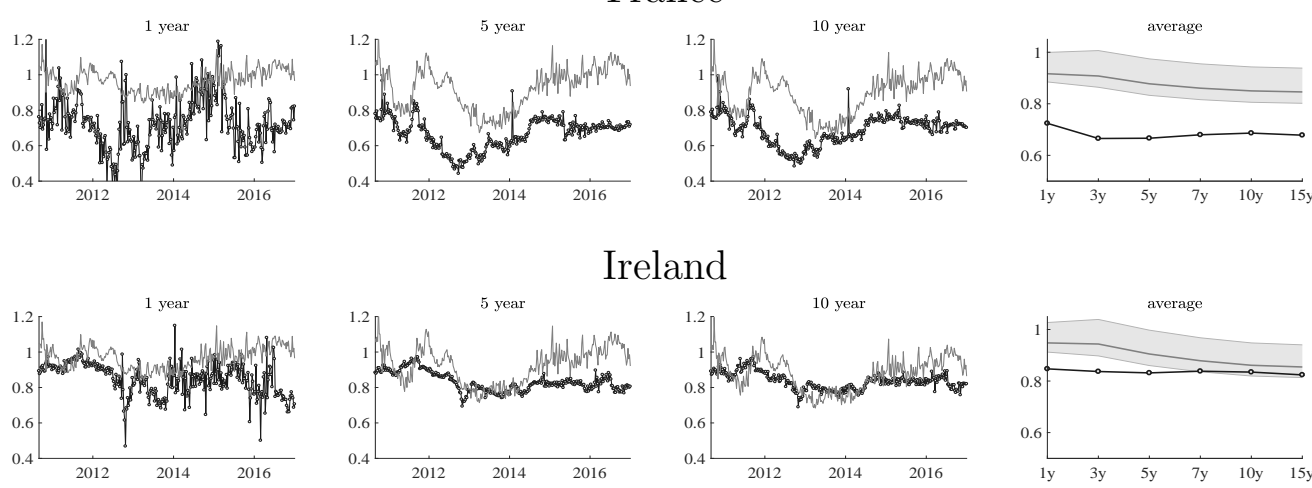

Ireland
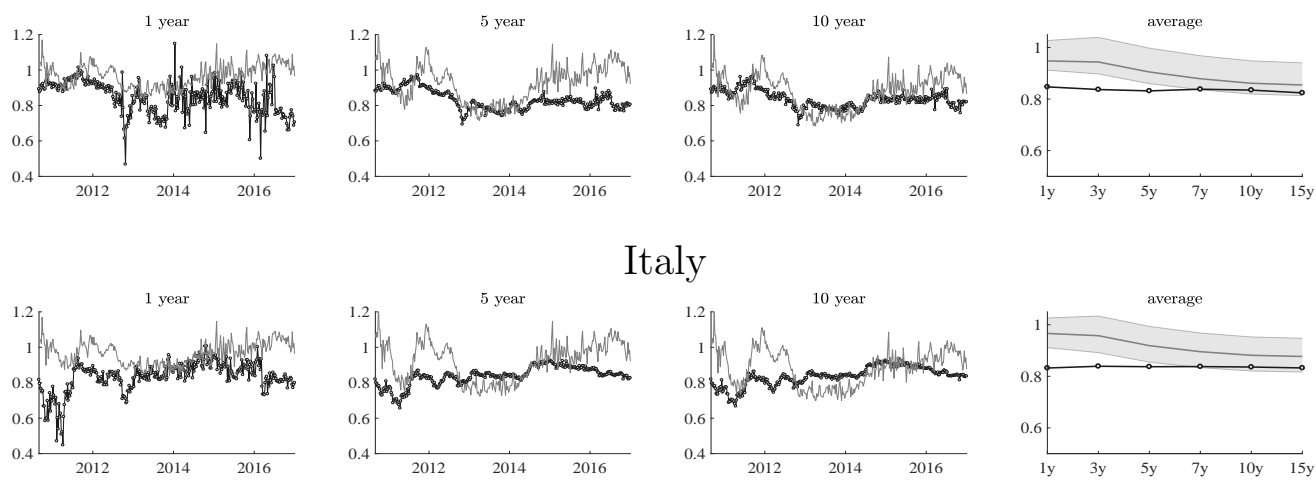

Italy
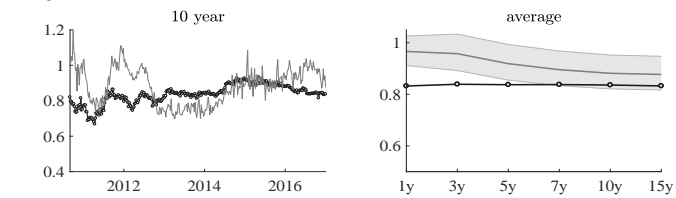

Spain
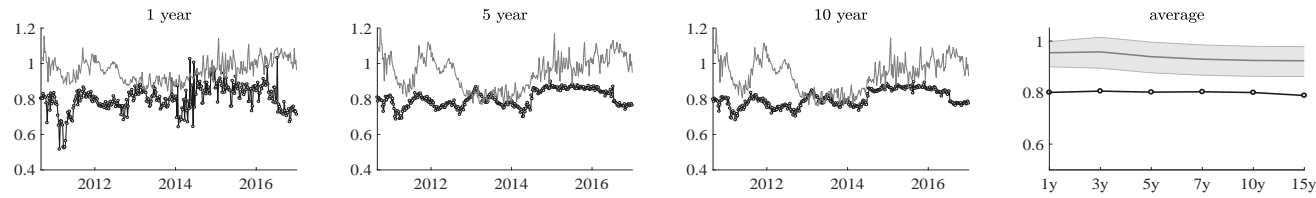

Notes. In this figure, we plot the observed relative quanto spreads (black-circled lines) and the model-implied expected depreciation rate $E_{t}^{*}\left[S_{\tau \wedge T} / S_{t}\right]$ for $T=1,5$, and 10 years, together with their sample averages in the last column (gray-shaded areas correspond to $90 \%$ credible intervals). The results are for Germany, Belgium, France, Ireland, Italy, and Spain. 


\section{A Institutional background}

CDS contracts are controlled by three documents: the Credit Derivatives Definitions ("the Definitions"), the ISDA Credit Derivatives Physical Settlement Matrix ("the Physical Settlement Matrix"), and the Confirmation Letter ("the Confirmation").

The Physical Settlement Matrix is the most important document because the push for standardization has created specific transaction types that are by convention applicable to certain types of a sovereign reference entity, e.g., Standard Western European Sovereign (SWES) or Standard Emerging European Sovereign (SEES) single-name contracts. In total, there are nine transaction types listed in the sovereign section of the Physical Settlement Matrix that contain details about the main contractual provisions for transactions in CDS referencing sovereign entities.

Given the over-the-counter (OTC) nature of CDS contracts, parties are free to combine features from different transaction types, which would be recognized in the Confirmation, i.e., the letter that designates the appropriate terms for a CDS contract. The Confirmation, which is mutually negotiated and drafted between two counterparties, can thereby amend legal clauses attributed to conventional contract characteristics. Hence, there may be slight variations from standard transaction types if counterparties agree to alter the terms of conventional CDS contracts. Such changes introduce legal risk, and potentially make the contracts less liquid, given the customization required for efficient central clearing.

The terms used in the documentation of most credit derivatives transactions are defined in the Definitions. On 22 September 2014, ISDA introduced the 2014 Credit Derivatives Definitions, which update the 2003 Credit Derivatives Definitions. We use contracts governed by the 2003 Definitions to guarantee internal consistency throughout our sample period.

It is important to distinguish between the circumstances under which a CDS payout/credit event could be triggered, and the restrictions on obligations eligible for delivery in the settlement process upon the occurrence of a qualifying credit event. The Physical Settlement matrix lays out the credit events that trigger CDS payment, which follows the ruling by a determinations committee of the occurrence of a credit event and a credit event auction. SWES transaction types recognize three sovereign credit events, namely Failure to Pay, Repudiation/Moratorium, and Restructuring. SEES contracts further list Obligation Acceleration as a valid event that could trigger the CDS payout.

The most disputed among all credit events is the Restructuring credit event clause related to a change to the reference obligation that is binding on all holders of the obligation. The most controversial among such changes is the redenomination of the 
principal or interest payment into a new currency. For the credit event to be triggered under the 2014 Definitions, this new currency must be any currency other than the lawful currency of Canada, Japan, Switzerland, the United Kingdom, the United States of America, and the Euro (or any successor currency to any of the currencies listed; in the case of the Euro, the new currency must replace the Euro in whole). In the 2003 Definitions, permitted currencies were defined as those of G7 countries and AAA-rated OECD economies.

Another important dimension to consider is the obligation category and the associated obligation characteristics which may trigger a credit event. For SWES contracts, the Obligation category is defined broadly as "borrowed money," which includes deposits and reimbursement obligations arising from a letter of credit or qualifying guarantees. Such contracts also feature no restrictions on the characteristics of obligations relevant for the triggers of default payment. For SEESs, however, markets have agreed on more specificity for the reference obligations, which encompass only "bonds," which are not allowed to be subordinated, denominated in domestic currency, issued domestically or under domestic law, as indicated by the restrictions of the obligation characteristics.

The final non-trivial aspect relates to the deliverable obligation categories and the associated characteristics. While in the presence of Credit Events for SWESs, bonds or loans are deliverable during the auction settlement process, SEES contracts allow only for bonds to be delivered. Several restrictions apply to the deliverable obligations, such that for SWESs they have to be denominated in a specified currency (i.e., the Euro or the currencies of Canada, Japan, Switzerland, the UK, or the USA), they must be non-contingent, non-bearer and transferable, limited to a maximum maturity of 30 years, and loans must be assignable and consent is required. SEES contracts exclude these restrictions on loans and the maximum deliverable maturity, but impose the additional constraints that the obligation cannot be subordinated, and issued domestically or under domestic law.

\section{B Term structure of quanto spreads in the iid case}

We show that the term structure of quanto spreads is flat when hazard and depreciation rates are iid, and the risk-free interest rate is constant. To achieve analytical tractability, we consider that CDS contracts are fully settled upfront.

Assuming that both the default intensity, $h_{t}^{*}$, and depreciation rate are iid and using 
the law of iterated expectations, the upfront premium for the EUR CDS is given by

$$
\begin{aligned}
C_{0}^{€} & =L \cdot E_{0}^{*}\left[e^{-r(\tau \wedge T)} \cdot S_{\tau \wedge T} / S_{0} \cdot I(\tau \leq T)\right] \\
& =L \cdot E_{0}^{*}\left[e^{-r(\tau \wedge T)} \cdot S_{\tau \wedge T} / S_{0} \cdot(1-I(\tau>T))\right] \\
& =L \cdot E_{0}^{*}\left[e^{-r T+s_{T}-s_{0}}\right]-L \cdot E_{0}^{*}\left[e^{-r T+s_{T}-s_{0}-\sum_{j=1}^{T} h_{j}^{*}}\right] \\
& =L \cdot E_{0}^{*}\left[e^{-r T}\right] \cdot E_{0}^{*}\left[e^{s_{T}-s_{0}}\right] \cdot\left[1-E_{0}^{*} e^{-\sum_{j=1}^{T} h_{j}^{*}}\right],
\end{aligned}
$$

where $s_{t}=\log S_{t}$.

Similarly, the upfront premium for the USD CDS is given by

$$
C_{0}^{\$}=L \cdot E_{0}^{*}\left[e^{-r T}\right] \cdot\left[1-E_{0}^{*} e^{-\sum_{j=1}^{T} h_{j}^{*}}\right] .
$$

Therefore, the quanto spread for any maturity $T$, is given by

$q_{0}^{\$, €}=-T^{-1}\left(\log C_{0}^{\$}-\log C_{0}^{€}\right)=T^{-1} \log E_{0}^{*} e^{s_{T}-s_{0}}=T^{-1} \log E_{0}^{*} e^{T\left(s_{1}-s_{0}\right)}=\log E_{0}^{*} e^{s_{1}-s_{0}}$.

It follows that the difference in quanto spreads of any two maturities is zero, implying a flat term structure of quanto spreads.

\section{Details of asset valuation}

\section{C.1 Bonds}

To derive closed-form solutions for the term structure of interest rates, we conjecture that zero-coupon bond prices $Q_{t, T}$ are exponentially affine in the state vector $u_{t}$

$$
q_{t, T}=\log Q_{t, T}=-\tilde{A}_{T-t}-\tilde{B}_{T-t}^{\top} u_{t} .
$$

Because the interest rate is an affine function of the state, $r_{t}=\bar{r}+\delta_{r}^{\top} u_{t}$, log-bond prices are fully characterized by the cumulant-generating function of $u_{t}$. The law of iterated expectations implies that $Q_{t, T}$ satisfies the recursion

$$
Q_{t, T}=e^{-r_{t}} E_{t}^{*} Q_{t+1, T-1}
$$

It can be shown that for all $n=0,1 \ldots, T-t$, the scalar $\tilde{A}_{n}$ and components of the column vector $\tilde{B}_{n}$ are given by

$$
\begin{aligned}
& \tilde{A}_{n}=\tilde{A}_{n-1}+\bar{r}+\tilde{B}_{n-1}^{\top} \mu_{u}-\frac{1}{2} \tilde{B}_{n-1}^{\top} \Sigma_{u} \Sigma_{u}^{\top} \tilde{B}_{n-1} \\
& \tilde{B}_{n}^{\top}=\delta_{r}^{\top}+\tilde{B}_{n-1}^{\top} \Phi_{u},
\end{aligned}
$$


with initial conditions $\tilde{A}_{0}=0$ and $\tilde{B}_{0}=0$.

Then the yields are

$$
y_{t, T}=-(T-t)^{-1} \log Q_{t, T}=A_{T-t}+B_{T-t}^{\top} u_{t}
$$

with $A_{T-t}=-(T-t)^{-1} \tilde{A}_{T-t}$ and $B_{T-t}=-(T-t)^{-1} \tilde{B}_{T-t}$.

\section{C.2 Forward exchange rates}

According to covered interest rate parity, a forward exchange rate with settlement date $T$ is equal to the expected future value of the exchange rate, i.e., $F_{t, T}=E_{t}^{*}\left[S_{T}\right]$. Dividing each side of this equation by $S_{t}$, we can solve for the log ratio of the forward to the spot exchange rate, $\log \left(F_{t, T} / S_{t}\right)=\log E_{t}^{*}\left[e^{\Delta s_{t+T}}\right]$. Thus, deriving closed-form solutions for the log ratio of the forward to the spot exchange rates is akin to solving for the cumulant-generating function of the depreciation rate.

We can use recursion techniques to derive analytical solutions for these expressions by solving for $\log \tilde{\Lambda}_{j, t}=\log E_{t}^{*}\left[S_{t+j} / S_{t}\right]$. To evaluate the expressions for $\tilde{\Lambda}$, we conjecture that the expression is (in the model without contagion) an affine function of the state vector $x_{t}$, i.e., $\log \tilde{\Lambda}_{j, t}=\tilde{A}_{j}+\tilde{B}_{j}^{\top} x_{t}$. The law of iterated expectations implies that $\tilde{\Lambda}_{j, t}$ satisfies the recursions $\tilde{\Lambda}_{j, t}=E_{t}^{*}\left[\left(S_{t+1} / S_{t}\right) \tilde{\Lambda}_{j-1, t+1}\right]$, where the recursions start at $j=0$ for $\tilde{\Lambda}_{j, t}$. It can be shown that for all $j=1,2, \ldots, T-t$, the scalar $\tilde{A}_{j}$ and components of the column vectors $\tilde{B}_{j}=\left[\tilde{B}_{u, j}^{\top}, \tilde{B}_{g, j}^{\top}\right]^{\top}$ are given by

$$
\begin{aligned}
\tilde{A}_{j} & =\tilde{A}_{j-1}+\bar{s}^{*}+\frac{1}{2} \bar{v}^{*}-\bar{h}^{*}\left[\frac{\theta^{*}}{1+\theta^{*}}\right]+\left(\tilde{B}_{u, j-1}+\delta_{s u}^{*}\right)^{\top} \mu_{u} \\
& +\frac{1}{2}\left(\tilde{B}_{u, j-1}+\delta_{s u}^{*}\right)^{\top} \Sigma_{u}\left(\tilde{B}_{u, j-1}+\delta_{s u}^{*}\right) \\
& -\sum_{l=1}^{M_{g}} \nu_{l} \log \left(1-\left(\tilde{B}_{g_{l}, j-1}+\delta_{s g_{l}}^{*}-\delta_{w_{l}}^{*}\left[\frac{\theta^{*}}{1+\theta^{*}}\right]\right) c_{l}^{*}\right) \\
\tilde{B}_{u, j}= & \Phi_{u}^{\top}\left[\tilde{B}_{u, j-1}+\delta_{s u}^{*}\right] \\
\tilde{B}_{g_{i}, j}= & \sum_{l=1}^{M_{g}} \frac{\left(\tilde{B}_{g_{l}, j-1}+\delta_{s g_{l}}^{*}-\delta_{w_{i}}^{*}\left[\frac{\theta^{*}}{1+\theta^{*}}\right]\right) \phi_{i_{l}}^{*}}{1-\left(\tilde{B}_{g_{l}, j-1}+\delta_{s g_{l}}^{*}-\delta_{w_{i}}^{*}\left[\frac{\theta^{*}}{1+\theta^{*}}\right]\right) c_{l}^{*}}+\frac{1}{2} \delta_{v_{i}}^{*} .
\end{aligned}
$$

where we have indexed the sub-components of $\tilde{B}_{g, j}$ using an $i$ subscript. The initial condition for $\tilde{\Lambda}$ is given by $\log \tilde{\Lambda}_{0, t}=A_{0}+B_{0}^{\top} x_{t}$, where the scalar $A_{0}=0$ and the column vector $B_{0}=0$. 


\section{C.3 CDS}

The true implementation of CDS valuation extends Equation (14) by accounting for accrual payments:

$$
C_{t, T}^{€}=L \cdot \frac{\sum_{j=1}^{T-t}\left(\tilde{\Psi}_{j, t}-\Psi_{j, t}\right)}{\sum_{j=1}^{T-t) / \Delta} \Psi_{j \Delta, t}+\sum_{j=1}^{T-t}\left(\frac{j}{\Delta}-\left\lfloor\frac{j}{\Delta}\right\rfloor\right)\left(\tilde{\Psi}_{j, t}-\Psi_{j, t}\right)},
$$

where the floor function $\lfloor\cdot\rfloor$ rounds to the nearest lower integer. The law of iterated expectations implies that $\Psi_{j, t}$ and $\Psi_{j, t}$ satisfy the recursions

$$
\tilde{\Psi}_{j, t}=E_{t}^{*}\left[B_{t, t}\left(1-H_{t+1}\right) \frac{S_{t+1}}{S_{t}} \tilde{\Psi}_{j-1, t+1}\right], \Psi_{j, t}=E_{t}^{*}\left[B_{t, t}\left(1-H_{t+1}\right) \frac{S_{t+1}}{S_{t}} \Psi_{j-1, t+1}\right],
$$

starting at $j=1$ for $\tilde{\Psi}_{j, t}$ and at $j=0$ for $\Psi_{j, t}$. To evaluate the expressions for $\tilde{\Psi}$ and $\Psi$, we conjecture that these expressions are exponentially affine functions of the state vector $x_{t}$. See Equation (17).

We define the column vectors $\tilde{B}_{j}=\left[\tilde{B}_{u, j}^{\top}, \tilde{B}_{g, j}^{\top}, \tilde{B}_{d, j}^{\top}\right]^{\top}$, with $u=1,2, \ldots, M_{u}$, $g=1,2, \ldots, M_{g}$, and $d=1,2, \ldots, M_{d}$. Next, the column vectors of ones with length $M_{u}, M_{g}$, and $M_{d}$ are denoted by $\mathbb{1}_{M_{u}}, \mathbb{1}_{M_{g}}$, and $\mathbb{1}_{M_{d}}$, respectively. Define the matrices $\Delta_{w}^{*}=\left[\delta_{w}^{* 1}, \delta_{w}^{* 2}, \ldots, \delta_{w}^{* M_{c}}\right]$ and $\Delta_{d}^{*}=\left[\delta_{d}^{* 1}, \delta_{d}^{* 2}, \ldots, \delta_{d}^{* M_{c}}\right]$. Finally, we subdivide the vector $\delta_{s}^{*}$ into sub-matrices $\delta_{s}^{* \top}=\left[\delta_{s u}^{* \top}, \delta_{s g}^{* \top}, \delta_{s d}^{* \top}\right]$, for $u=1,2, \ldots, M_{u}, g=1,2, \ldots, M_{g}$, and $d=1,2, \ldots, M_{d}$. It can be shown that for each country $k=1,2, \ldots, M_{c}$ and for all $j=1,2, \ldots, T-t$, the scalar $\tilde{A}_{j}$ and components of the column vectors $\tilde{B}_{j}$ are 
given by

$$
\begin{aligned}
\tilde{A}_{j} & =\tilde{A}_{j-1}-\bar{r}-\bar{h}^{* k}+\bar{s}^{*}+\frac{1}{2} \bar{v}^{*}-\bar{h}^{*}\left[\frac{\theta^{*}}{1+\theta^{*}}\right]+\left(\tilde{B}_{u, j-1}+\delta_{s u}^{*}\right)^{\top} \mu_{u} \\
& +\frac{1}{2}\left(\tilde{B}_{u, j-1}+\delta_{s u}^{*}\right)^{\top} \Sigma_{u} \Sigma_{u}^{\top}\left(\tilde{B}_{u, j-1}+\delta_{s u}^{*}\right)+\left[\frac{\tilde{B}_{d, j-1} \odot \bar{H}^{*}}{\mathbb{1}_{M_{d}}-\tilde{B}_{d, j-1} \odot \rho^{*}}\right]^{\top} \cdot \mathbb{1}_{M_{d}} \\
& -\left(\nu \odot \operatorname { l o g } \left[\mathbb{1}_{M_{g}}-\left(\tilde{B}_{g, j-1}+\delta_{s g}^{*}-\delta_{w}^{* k}-\delta_{w}^{*} \odot\left[\frac{\theta^{*}}{1+\theta^{*}}\right]\right.\right.\right. \\
& \left.\left.\left.+\left[\Delta_{w}^{*}\left(\frac{\tilde{B}_{d, j-1}}{\mathbb{1}_{M_{d}}-\tilde{B}_{d, j-1} \odot \rho^{*}}\right)\right]\right) \odot c^{*}\right]\right)^{\top} \cdot \mathbb{1}_{M_{g}} \\
\tilde{B}_{u, j} & =\Phi_{u}^{\top}\left[\tilde{B}_{u, j-1}+\delta_{s u}^{*}\right]-\delta_{r} \\
\tilde{B}_{g, j} & =\Phi_{g}^{* \top}\left(\frac{\tilde{B}_{g, j-1}+\delta_{s g}^{*}-\delta_{w}^{* k}-\delta_{w}^{*} \odot\left[\frac{\theta^{*}}{1+\theta^{*}}\right]+\left[\Delta_{w}^{*}\left(\frac{\tilde{B}_{d, j-1}}{\mathbb{1}_{M_{d}-\tilde{B}_{d, j-1} \odot \rho^{*}}}\right)\right]}{\left.\mathbb{B}_{g, j-1}+\delta_{s g}^{*}-\delta_{w}^{* k}-\delta_{w}^{*} \odot\left[\frac{\theta^{*}}{1+\theta^{*}}\right]+\left[\Delta_{w}^{*}\left(\frac{\tilde{B}_{d, j-1}}{\mathbb{1}_{M_{d}-\tilde{B}_{d, j-1} \odot \rho^{*}}}\right)\right]\right] c^{*}}\right) \\
& +\frac{1}{2} \delta_{v}^{*} \\
\tilde{B}_{d, j} & =\Delta_{d}^{* \top}\left(\frac{\tilde{B}_{d, j-1}}{\mathbb{1}_{M_{d}}-\tilde{B}_{d, j-1} \odot \rho^{*}}\right)-\delta_{d}^{* k}-\delta_{d}^{*} \odot\left[\frac{\theta}{1+\theta}\right],
\end{aligned}
$$

where $\odot$ defines the Hadamard product for element-wise multiplication, and where we slightly abuse notation as the division and log operators work element-by-element when applied to vectors or matrices. The recursions for $\Psi$ are identical. It is sufficient to replace $\tilde{A}$. and $\tilde{B}$. by $A$. and $B$., respectively.

The initial condition for $\tilde{\Psi}$ is given by

$$
\tilde{\Psi}_{1, t}=e^{\tilde{A}_{1}+\tilde{B}_{1}^{\top} x},
$$

where the scalar $\tilde{A}_{1}$ and components of the column vectors $\tilde{B}_{1}=\left[\tilde{B}_{u, 1}^{\top}, \tilde{B}_{g, 1}^{\top}, \tilde{B}_{d, 1}^{\top}\right]^{\top}$ 
are given by

$$
\begin{aligned}
\tilde{A}_{1} & =\bar{s}^{*}-\bar{r}+\delta_{s u}^{* \top} u_{u}+\frac{1}{2} \delta_{s u}^{* \top} \Sigma_{u} \Sigma_{u}^{\top} \delta_{s u}^{*}+\frac{1}{2} \bar{v}^{*} \\
& -\left[\nu \odot \log \left(\mathbb{1}_{M_{g}}-\left(\delta_{s g}^{*}-\delta_{w}^{*} \odot\left[\frac{\theta^{*}}{1+\theta^{*}}\right]\right) \odot c^{*}\right)\right]^{\top} \cdot \mathbb{1}_{M_{g}}-\bar{h}^{*}\left[\frac{\theta^{*}}{1+\theta^{*}}\right] \\
\tilde{B}_{u, 1} & =\Phi_{u}^{\top} \delta_{s u}^{*}-\delta_{r} \\
\tilde{B}_{g, 1} & =\Phi_{g}^{* \top}\left(\frac{\delta_{s g}^{*}-\delta_{w}^{*} \odot\left[\frac{\theta^{*}}{1+\theta^{*}}\right]}{\mathbb{1}_{M_{g}}-\left(\delta_{s g}^{*}-\delta_{w}^{*} \odot\left[\frac{\theta^{*}}{1+\theta^{*}}\right]\right) \odot c^{*}}\right)+\frac{1}{2} \delta_{v}^{*} \\
\tilde{B}_{d, 1} & =-\delta_{d}^{*} \odot\left[\frac{\theta^{*}}{1+\theta^{*}}\right] .
\end{aligned}
$$

The initial condition for $\Psi$ is given by

$$
\Psi_{0, t}=e^{A_{0}+B_{0}^{\top} x_{t}}
$$

where the scalar $A_{0}=0$ and the column vector $B_{0}=0$.

The pricing equation for the USD-CDS spread is obtained in closed form by setting $S_{t+j}=1$ in all recursions.

\section{The affine pricing kernel}

A multiperiod pricing kernel is a product of one-period ones: $M_{t, t+n}=M_{t, t+1} \cdot M_{t+1, t+2}$. $\ldots \cdot M_{t+n-1, t+n}$. In this section, we specify the pricing kernel and show how the associated prices of risk modify the distribution of state $x_{t}$.

The (log) pricing kernel is:

$$
m_{t, t+1}=-r_{t}-k_{t}\left(-\gamma_{x, t} ; \varepsilon_{x, t+1}\right)-k_{t}\left(-1 ; z_{m, t+1}\right)-\gamma_{x, t}^{\top} \varepsilon_{x, t+1}-z_{m, t+1},
$$

where $k_{t}\left(s ; e_{t+1}\right)=\log E_{t} e^{s \cdot e_{t+1}}$ is the cumulant-generating function (cgf), and $z_{m, t+1}$ is a jump process with intensity $\lambda_{t+1}$. The behavior of risk premiums is determined by $\gamma_{x, t}$ and the jump magnitude $z_{m, t+1} \mid j_{t+1}$.

In the case of factor $u_{t}$, the risk premium is $\gamma_{u, t}=\Sigma_{u}^{-1}\left(\bar{\gamma}_{u}+\delta_{u} u_{t}\right)$ implying

$$
\Phi_{u}^{*}=\Phi_{u}-\delta_{u}, \quad \mu_{u}^{*}=\mu_{u}-\bar{\gamma}_{u}
$$

with $k_{t}\left(-\gamma_{u, t} ; \varepsilon_{u, t+1}\right)=\gamma_{u, t}^{\top} \gamma_{u, t} / 2$. In the case of factor $g_{t}$, the risk premium is $\gamma_{g, t}=\bar{\gamma}_{g}$ implying

$$
\phi_{i j}^{*}=\phi_{i j}\left(1-\bar{\gamma}_{g i} c_{i}\right)^{-2}, \quad c_{i}^{*}=c_{i}\left(1-\bar{\gamma}_{g i} c_{i}\right)^{-1}
$$


with

$$
k_{t}\left(-\gamma_{g, t} ; \eta_{g, t+1}\right)=-\sum_{i=1}^{M_{g}}\left(\nu_{i}\left[\log \left(1+\gamma_{g i, t}\right)-\gamma_{g i, t} c_{i}\right]+\gamma_{g i, t}\left[\left(1+\gamma_{g i, t} c_{i}\right)^{-1}-1\right] \phi_{i}^{\top} g_{t}\right) \text {. }
$$

See Le, Singleton, and Dai (2010).

In the case of jumps, the risk premium is

$$
z_{m, t+1}\left|j_{t+1}=\sum_{k}-\left(h_{t+1}^{k}-h_{t+1}^{* k}\right)-j_{t+1}^{k} \log h_{t+1}^{* k} / h_{t+1}^{k}+j_{t+1}^{k} \log \theta^{*} / \theta+\left(\theta^{*-1}-\theta^{-1}\right) \cdot z_{s, t+1}\right| j_{t+1}^{k}
$$

implying a risk-adjusted jump $z_{s, t+1}$ with Poisson arrival rate of $\lambda_{t+1}^{*}=\sum_{k} h_{t+1}^{* k}$ and magnitude $z_{s, t+1} \mid j_{t+1} \sim \operatorname{Gamma}\left(j_{t+1}, \theta^{*}\right)$. The corresponding cgf is $k_{t}\left(-1 ; z_{m, t+1}\right)=$ 0 .

Indeed, a Poisson mixture of gammas distribution implies arbitrary forms of risk premiums without violating no-arbitrage conditions. To see this, first observe that

$$
p_{t+1}\left(z_{s} \mid j\right)=\frac{e^{-\lambda_{t+1}} \lambda_{t+1}^{j}}{j !} \frac{1}{\Gamma(j) \theta^{j}} z_{s}^{j-1} e^{-z_{s} / \theta}
$$

Second, assume that the risk-adjusted distribution features an arbitrary arrival rate $\lambda_{t+1}^{*}$ and jump size mean $\theta^{*}$ (this does not have to be a constant). Then

$$
p_{t+1}^{*}\left(z_{s} \mid j\right)=\frac{e^{-\lambda_{t+1}^{*}} \lambda_{t+1}^{* j}}{j !} \frac{1}{\Gamma(j) \theta^{* j}} z_{s}^{j-1} e^{-z_{s} / \theta^{*}} .
$$

We characterize the ratio $p_{t+1}^{*}(z) / p_{t+1}(z)$ via the moment-generating function (mgf) of its log. First, we compute the expectation with respect to the jump-size distribution

$$
\begin{aligned}
& \tilde{h}_{t+1}\left(s ; \log p_{t+1}^{*}\left(z_{s}\right) / p_{t+1}\left(z_{s}\right)\right)=E_{t+1} e^{s \log p_{t+1}^{*}\left(z_{s}\right) / p_{t+1}\left(z_{s}\right)} \\
= & \sum_{j=0}^{\infty} \frac{e^{-\lambda_{t+1}} \lambda_{t+1}^{j}}{j !} e^{\left(\lambda_{t+1}-\lambda_{t+1}^{*}\right)+j \log \lambda_{t+1}^{*} / \lambda_{t+1}-j \log \theta^{*} / \theta}\left(1-s \theta\left(\theta^{-1}-\theta^{*-1}\right)\right)^{-j} .
\end{aligned}
$$

This functional form of the mgf reflects a Poisson mixture with intensity $\lambda_{t+1}$ and magnitude $z_{m}\left|j=\left(\lambda_{t+1}-\lambda_{t+1}^{*}\right)+j_{t+1} \log \lambda_{t+1}^{*} / \lambda_{t+1}-j_{t+1} \log \theta^{*} / \theta-\left(\theta^{*-1}-\theta^{-1}\right) \cdot z_{s}\right| j$. The expression could be simplified further:

$$
\begin{aligned}
\tilde{h}_{t+1}\left(s ; \log p_{t+1}^{*}\left(z_{s}\right) / p_{t+1}\left(z_{s}\right)\right) & =\sum_{j=0}^{\infty} \frac{e^{-\lambda_{t+1}^{*}}}{j !}\left[\lambda_{t+1}^{*} \theta / \theta^{*}\left(1-s \theta\left(\theta^{-1}-\theta^{*-1}\right)\right)^{-1}\right]^{j} \\
& =e^{\lambda_{t+1}^{*}\left(\theta / \theta^{*}\left(1-s \theta\left(\theta^{-1}-\theta^{*-1}\right)\right)^{-1}-1\right)} .
\end{aligned}
$$


Second, we obtain the mgf by computing the expectation with respect to the distribution of the jump intensity:

$$
h_{t}\left(s ; \log p_{t+1}^{*}\left(z_{s}\right) / p_{t+1}\left(z_{s}\right)\right)=E_{t} \tilde{h}_{t+1}\left(s ; \log p_{t+1}^{*}\left(z_{s}\right) / p_{t+1}\left(z_{s}\right)\right) \equiv E_{t} e^{\lambda_{t+1}^{*} f\left(s, \theta, \theta^{*}\right)} .
$$

The cgf is

$$
k_{t}\left(s ; \log p_{t+1}^{*}\left(z_{s}\right) / p_{t+1}\left(z_{s}\right)\right)=\log E_{t} e^{\lambda_{t+1}^{*} f\left(s, \theta, \theta^{*}\right)}=k_{t}\left(f\left(s, \theta, \theta^{*}\right), \lambda_{t+1}^{*}\right) .
$$

Note that $k_{t}\left(-1 ; z_{m, t+1}\right)$ corresponds to $k_{t}\left(1 ; \log p_{t+1}^{*}\left(z_{s}\right) / p_{t+1}\left(z_{s}\right)\right)$, and $f\left(1, \theta, \theta^{*}\right)=0$, so $k_{t}\left(-1 ; z_{m, t+1}\right)=0$.

\section{E Details of the estimation}

\section{E.1 State-space representation}

\section{State transition equation}

We consider three interest rate factors $u_{1, t}, u_{2, t}, u_{3, t}$, three credit factors $g_{1, t}, g_{2, t}, g_{3, t}$, one volatility factor $g_{4, t}=v_{t}$, and one contagion factor $d_{t}$

$$
\begin{aligned}
& \underbrace{\left[\begin{array}{l}
u_{1, t+1} \\
u_{2, t+1} \\
u_{3, t+1}
\end{array}\right]}_{u_{t+1}}=\underbrace{\left[\begin{array}{l}
\mu_{u 1} \\
\mu_{u 2} \\
\mu_{u 3}
\end{array}\right]}_{\mu_{u}}+\underbrace{\left[\begin{array}{lll}
\phi_{u 11} & \phi_{u 12} & \phi_{u 13} \\
\phi_{u 21} & \phi_{u 22} & \phi_{u 23} \\
\phi_{u 31} & \phi_{u 32} & \phi_{u 33}
\end{array}\right]}_{\Phi_{u}} \underbrace{\left[\begin{array}{l}
u_{1, t} \\
u_{2, t} \\
u_{3, t}
\end{array}\right]}_{u_{t}}+\underbrace{\left[\begin{array}{l}
\eta_{u 1, t+1} \\
\eta_{u 2, t+1} \\
\eta_{u 3, t+1}
\end{array}\right]}_{\eta_{u, t+1}} \\
& \underbrace{\left[\begin{array}{l}
g_{1, t+1} \\
g_{2, t+1} \\
g_{3, t+1} \\
g_{4, t+1}
\end{array}\right]}_{g_{t+1}}=\underbrace{\left[\begin{array}{l}
\nu_{g 1} c_{g 1} \\
\nu_{g 2} c_{g 2} \\
\nu_{g 3} c_{g 3} \\
\nu_{g 4} c_{g 4}
\end{array}\right]}_{\mu_{g}}+\underbrace{\left[\begin{array}{llll}
\phi_{g 11} & \phi_{g 12} & \phi_{g 13} & \phi_{g 14} \\
\phi_{g 21} & \phi_{g 22} & \phi_{g 23} & \phi_{g 24} \\
\phi_{g 31} & \phi_{g 32} & \phi_{g 33} & \phi_{g 34} \\
\phi_{g 41} & \phi_{g 42} & \phi_{g 43} & \phi_{g 44}
\end{array}\right]}_{\Phi_{g}} \underbrace{\left[\begin{array}{c}
g_{1, t} \\
g_{2, t} \\
g_{3, t} \\
g_{4, t}
\end{array}\right]}_{g_{t}}+\underbrace{\left[\begin{array}{l}
\eta_{g 1, t+1} \\
\eta_{g 2, t+1} \\
\eta_{g 3, t+1} \\
\eta_{g 4, t+1}
\end{array}\right]}_{\eta_{g, t+1}} \\
& d_{t+1}=\mu_{d}+\delta_{d, g} \underbrace{\left(\mu_{g}+\Phi_{g} g_{t}+\eta_{g, t+1}\right)}_{g_{t+1}}+\Phi_{d} d_{t}+\eta_{d, t+1}
\end{aligned}
$$


where $\eta_{u, t} \sim N\left(0, \Sigma_{u} \Sigma_{u}^{\prime}\right), \eta_{g, t}, \eta_{d, t}, \eta_{\lambda, t}$ represent a martingale difference sequence (mean zero shock). In vector notation, the joint dynamics are

$$
\begin{aligned}
\underbrace{\left[\begin{array}{c}
u_{t+1} \\
g_{t+1} \\
d_{t+1}
\end{array}\right]}_{x_{t+1}}=\underbrace{\left[\begin{array}{c}
\mu_{u} \\
\mu_{g} \\
\mu_{d}+\delta_{d, g} \mu_{g}
\end{array}\right]}_{\mu_{x}}+\underbrace{\left[\begin{array}{ccc}
\Phi_{u} & 0 & 0 \\
0 & \Phi_{g} & 0 \\
0 & \delta_{d, g} \Phi_{g} & \Phi_{d}
\end{array}\right]}_{\Phi_{x}} \underbrace{\left[\begin{array}{c}
u_{t} \\
g_{t} \\
d_{t}
\end{array}\right]}_{x_{t}} \\
+\underbrace{\left[\begin{array}{ccc}
1 & 0 & 0 \\
0 & 1 & 0 \\
0 & \delta_{d, g} & 1
\end{array}\right]}_{\Omega_{x}} \underbrace{\left[\begin{array}{c}
\eta_{u, t+1} \\
\eta_{g, t+1} \\
\eta_{d, t+1}
\end{array}\right]}_{\eta_{x, t+1}} .
\end{aligned}
$$

Here, we are assuming that we observe the sequence $u_{1,1: T}$ and $u_{2,1: T}$. Note that while $\mu_{d}, \delta_{d, g}, \Phi_{d}$, which govern the true dynamics, are estimated freely, we impose the following restrictions in the risk neutral dynamics.

$$
\mu_{d}^{*}=\sum_{k=1}^{M_{c}} \bar{h}^{*, k}, \quad \delta_{d, g}^{*}=\left[\begin{array}{llll}
\sum_{k=1}^{M_{c}} \delta_{h, g 1}^{*, k} & \sum_{k=1}^{M_{c}} \delta_{h, g 2}^{*, k} & \sum_{k=1}^{M_{c}} \delta_{h, g 3}^{*, k} & 0
\end{array}\right], \quad \Phi_{d}^{*}=\sum_{k=1}^{M_{c}} \delta_{h, d}^{*, k}
$$

\section{Measurement equations}

There are two forms of measurement equations. Denote observables in the first measurement equation and the second measurement equation by $y_{1, t}$ and $y_{2, t}$, respectively. Define $y_{t}=\left\{y_{1, t}, y_{2, t}\right\}$ and $Y_{1: t-1}=\left\{y_{1}, \ldots, y_{t-1}\right\}$.

The first measurement equation consists of quanto spreads of six different maturities for each country $k$

$$
q s_{t}^{k}=\left\{q s_{t, 1 y}^{k}, q s_{t, 3 y}^{k}, q s_{t, 5 y}^{k}, q s_{t, 7 y}^{k}, q s_{t, 10 y}^{k}, q s_{t, 15 y}^{k}\right\}^{\top}
$$

and the log ratio of the forward to the spot exchange rate

$$
f s_{t}=\left\{f s_{t, 1 w}, f s_{t, 1 m}\right\}
$$

and the log depreciation USD/EUR rate. To ease exposition, define

$$
A_{1: T}^{k}=\left\{A_{1}^{k}, \ldots, A_{T}^{k}\right\}, \quad B_{1: T}^{k}=\left\{B_{1}^{k}, \ldots, B_{T}^{k}\right\}
$$


and $\tilde{A}_{1: T}^{k}, \tilde{B}_{1: T}^{k}$ are defined similarly. The model-implied quanto spread is a nonlinear function of the solution coefficients and the current and lagged states, which we express as

$$
q s_{t, T}^{k}=\Xi\left(A_{1: T}^{k}, B_{1: T}^{k}, \tilde{A}_{1: T}^{k}, \tilde{B}_{1: T}^{k}, x_{t}\right) .
$$

Similarly, the model-implied log ratio of the forward to the spot exchange rate can be expressed as

$$
f s_{t, T}=\Xi\left(A_{1: T}, B_{1: T}, \tilde{A}_{1: T}, \tilde{B}_{1: T}, x_{t}\right)
$$

where the solution coefficients associated with the forward exchange rate valuation are expressed without any superscript.

Put together, the first measurement equation becomes

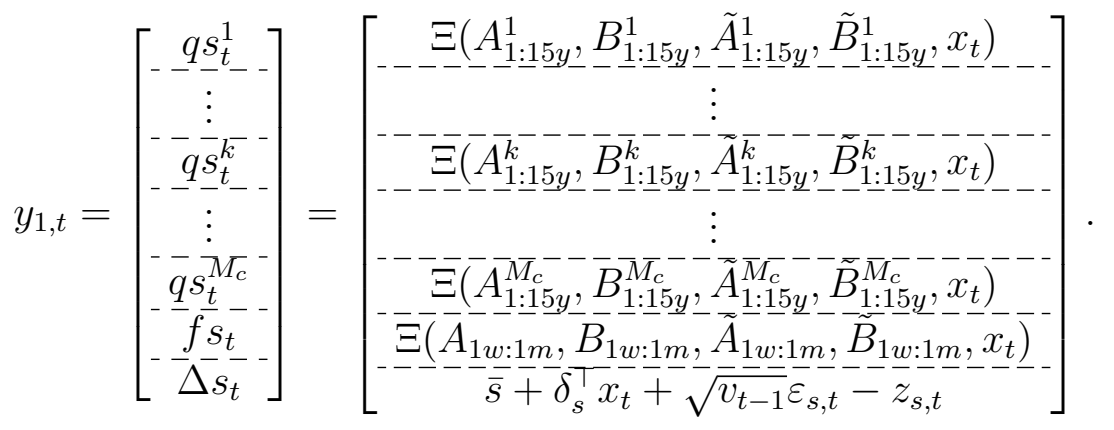

The second measurement equation consists of credit events for each country $e_{k, t}$

$$
y_{2, t}=\left\{e_{1, t}, \ldots, e_{M_{c}, t}\right\} .
$$

Instead of providing its measurement equation form, we directly express the likelihood function below.

\section{E.2 Implementation}

\section{Likelihood function}

We exploit the conditional independence between $y_{1, t}$ and $y_{2, t}$. We express $P\left(y_{1, t}, y_{2, t} \mid Y_{1: t-1}, \Theta\right)$

$$
\begin{aligned}
& =\int P\left(y_{1, t}, y_{2, t} \mid x_{t}, Y_{1: t-1}, \Theta\right) P\left(x_{t} \mid x_{t-1}, Y_{1: t-1}, \Theta\right) P\left(x_{t-1} \mid Y_{1: t-1}, \Theta\right) d x_{t-1} \\
& =\int \underbrace{P\left(y_{2, t} \mid x_{t}, Y_{1: t-1}, \Theta\right)}_{(A)} \underbrace{P\left(y_{1, t} \mid x_{t}, Y_{1: t-1}, \Theta\right)}_{(B)} \underbrace{P\left(x_{t} \mid x_{t-1}, Y_{1: t-1}, \Theta\right)}_{(C)} P\left(x_{t} \mid Y_{1: t-1}, \Theta\right) d x_{t-1},
\end{aligned}
$$


where (C) can be deduced from (G.1).

The likelihood function corresponding to (A) in (G.3) can be written as

$$
P\left(y_{1, t} \mid x_{t}, Y_{1: t-1}, \Theta\right)=(2 \pi)^{-n_{1} / 2}\left|V_{1}\right|^{-1 / 2} \exp \left\{-\frac{1}{2}\left(y_{1, t}-\hat{y}_{1, t}\right)^{\top} V_{1}^{-1}\left(y_{1, t}-\hat{y}_{1, t}\right)\right\}
$$

where $n_{1}$ is the dimensionality of the vector space, $V_{1}$ is a measurement error variance matrix, and $\hat{y}_{1, t}$ is from (G.2).

The likelihood function corresponding to (B) can be expressed as

$$
P\left(y_{2, t} \mid x_{t}, Y_{1: t-1}, \Theta\right)=\exp \left(-M_{c} \lambda_{t}\right) \prod_{i=k}^{M_{c}}\left\{e_{k, t} \lambda_{t}+\left(1-e_{k, t}\right)\right\},
$$

following (Das, Duffie, Kapadia, and Saita, 2007).

\section{Bayesian inference}

For convenience, the parameters associated with the factors, hazard rates, exchange rate, and defaults are collected in $\Theta_{g}, \Theta_{h}, \Theta_{s}, \Theta_{d}, \Theta_{l}, \Theta_{u}$, respectively.

$$
\begin{aligned}
\Theta_{g}= & \left\{\left\{\phi_{g 11}^{*}, \phi_{g 21}^{*}, \phi_{g 22}^{*}, \phi_{g 31}^{*}, \phi_{g 33}^{*}, \phi_{g 44}^{*}\right\},\left\{\phi_{g 11}, \phi_{g 21}, \phi_{g 22}, \phi_{g 31}, \phi_{g 33}, \phi_{g 44}\right\}, \ldots\right. \\
& \left.\left\{\nu_{g 1}^{*}, \nu_{g 2}^{*}, \nu_{g 3}^{*}, \nu_{g 4}^{*}\right\},\left\{c_{g 1}^{*}, c_{g 2}^{*}, c_{g 3}^{*}, c_{g 4}^{*}\right\}\right\}, \\
\Theta_{h}= & \left\{\left\{\bar{h}^{*, 1}, \delta_{h, g 1}^{*, 1}, \delta_{h, d}^{*, 1}\right\},\left\{\bar{h}^{*, 2}, \delta_{h, g 1}^{*, 2}, \delta_{h, g 2}^{*, 2}, \delta_{h, d}^{*, 2}\right\},\left\{\bar{h}^{*, 3}, \delta_{h, g 1}^{*, 3}, \delta_{h, g 2}^{*, 3}, \delta_{h, d}^{*, 3}\right\}, \ldots\right. \\
& \left\{\bar{h}^{*, 4}, \delta_{h, g 1}^{*, 4}, \delta_{h, g 3}^{*, 4}, \delta_{h, d}^{*, 4}\right\},\left\{\bar{h}^{*, 5}, \delta_{h, g 1}^{*, 5}, \delta_{h, g 3}^{*, 5}, \delta_{h, d}^{*, 5}\right\},\left\{\bar{h}^{*, 6}, \delta_{h, g 1}^{*, 6}, \delta_{h, g 3}^{*, 6}, \delta_{h, d}^{*, 6}\right\}, \ldots \\
& \left.\left\{\bar{h}^{*, 7}, \delta_{h, g 1}^{*, 7}, \delta_{h, g 3}^{*, 7}, \delta_{h, d}^{*, 7}\right\}\right\}, \\
\Theta_{s}= & \left\{\left\{\bar{s}^{*}, \delta_{s, 3}^{*}, \delta_{s, 7}^{*}, \theta^{*}\right\},\left\{\bar{s}, \delta_{s, 3}, \delta_{s, 7}, \bar{v}, \delta_{v}, \theta\right\}\right\}, \\
\Theta_{d}= & \left\{\left\{\mu_{d}, \delta_{d, g 1}\right\},\left\{\Phi_{d}, \rho_{d}^{*}\right\}\right\}, \\
\Theta_{l}= & \{L\}, \\
\Theta_{u}= & \left\{\left\{\mu_{u 3}^{*}, \phi_{u 33}^{*}\right\},\left\{\phi_{u 33}\right\}\right\} .
\end{aligned}
$$

The number of parameters are as follows: 
- The model with contagion has a total of 65 parameters $\# \Theta_{g}=20, \# \Theta_{h}=$ $27, \# \Theta_{s}=10, \# \Theta_{d}=4, \# \Theta_{l}=1, \# \Theta_{u}=3$.

- The model without contagion has a total of 56 parameters $\# \Theta_{g}=20, \# \Theta_{h}=$ $20, \# \Theta_{s}=10, \# \Theta_{d}=2, \# \Theta_{l}=1, \# \Theta_{u}=3$. Here, we are removing $\delta_{h, d}^{*, k}$ for $k \in\{1, \ldots, 7\}$ and $\left\{\Phi_{d}, \rho_{d}^{*}\right\}$.

It is important to mention that the following parameters associated with the interest rate factors

$$
\Theta_{u}=\left\{\mu_{u 1}^{*}, \mu_{u 2}^{*}, \phi_{u 11}^{*}, \phi_{u 21}^{*}, \phi_{u 22}^{*}, \bar{r}, \delta_{u 1}, \delta_{u 2}\right\}
$$

are not estimated and provided from the first stage interest rate estimation. We use a Bayesian approach to make joint inference about parameters $\Theta=$ $\left\{\Theta_{g}, \Theta_{h}, \Theta_{s}, \Theta_{d}, \Theta_{l}, \Theta_{u}\right\}$ and the latent state vector $x_{t}$ in Equation (G.1). Bayesian inference requires the specification of a prior distribution $p(\Theta)$ and the evaluation of the likelihood function $p(Y \mid \Theta)$. Most of our priors are noninformative. We use MCMC methods to generate a sequence of draws $\left\{\Theta^{(j)}\right\}_{j=1}^{n_{s i m}}$ from the posterior distribution $p(\Theta \mid Y)=\frac{p(Y \mid \Theta) p(\Theta)}{p(Y)}$. The numerical evaluation of the prior density and the likelihood function $p(Y \mid \Theta)$ is done with the particle filter.

Given (A), (B), (C), we use a particle-filter approximation of the likelihood function (G.3) and embed this approximation into a fairly standard random walk Metropolis algorithm. See Herbst and Schorfheide (2016) for a review of the particle filter.

In the subsequent exposition we omit the dependence of all densities on the parameter vector $\Theta$. The particle filter approximates the sequence of distributions $\left\{p\left(x_{t} \mid Y_{1: t}\right)\right\}_{t=1}^{T}$ by a set of pairs $\left\{x_{t}^{(i)}, \pi_{t}^{(i)}\right\}_{i=1}^{N}$, where $x_{t}^{(i)}$ is the $i$ th particle vector, $\pi_{t}^{(i)}$ is its weight, and $N$ is the number of particles. As a by-product, the filter produces a sequence of likelihood approximations $\hat{p}\left(y_{t} \mid Y_{1: t-1}\right), t=1, \ldots, T$.

- Initialization: We generate the particle values $x_{0}^{(i)}$ from the unconditional distribution. We set $\pi_{0}^{(i)}=1 / N$ for each $i$.

- Propagation of particles: We simulate (G.1) forward to generate $x_{t}^{(i)}$ conditional on $x_{t-1}^{(i)}$. We use $q\left(x_{t} \mid x_{t-1}^{(i)}, y_{t}\right)$ to represent the distribution from which we draw $x_{t}^{(i)}$.

- Correction of particle weights: Define the unnormalized particle weights for period $t$ as

$$
\tilde{\pi}_{t}^{(i)}=\pi_{t-1}^{(i)} \times \frac{p\left(y_{t} \mid x_{t}^{(i)}\right) p\left(x_{t}^{(i)} \mid x_{t-1}^{(i)}\right)}{q\left(x_{t}^{(i)} \mid x_{t-1}^{(i)}, y_{t}\right)} .
$$


The term $\pi_{t-1}^{(i)}$ is the initial particle weight and the ratio $\frac{p\left(y_{t} \mid x_{t}^{(i)}\right) p\left(x_{t}^{(i)} \mid x_{t-1}^{(i)}\right)}{q\left(x_{t}^{(i)} \mid x_{t-1}^{(i)}, y_{t}\right)}$ is the importance weight of the particle. The last equality follows from the fact that we chose $q\left(x_{t}^{(i)} \mid x_{t-1}^{(i)}, y_{t}\right)=p\left(x_{t}^{(i)} \mid x_{t-1}^{(i)}\right)$.

The log likelihood function approximation is given by

$$
\log \hat{p}\left(y_{t} \mid Y_{1: t-1}\right)=\log \hat{p}\left(y_{t-1} \mid Y_{1: t-2}\right)+\log \left(\sum_{i=1}^{N} \tilde{\pi}_{t}^{(i)}\right) .
$$

- Resampling: Define the normalized weights

$$
\pi_{t}^{(i)}=\frac{\tilde{\pi}_{t}^{(i)}}{\sum_{j=1}^{N} \tilde{\pi}_{t}^{(j)}}
$$

and generate $N$ draws from the distribution $\left\{x_{t}^{(i)}, \pi_{t}^{(i)}\right\}_{i=1}^{N}$ using multinomial resampling. In slight abuse of notation, we denote the resampled particles and their weights also by $x_{t}^{(i)}$ and $\pi_{t}^{(i)}$, where $\pi_{t}^{(i)}=1 / N$.

\section{F Tables}


Table F1

\section{Affine Term Structure Models of Sovereign Credit Spreads}

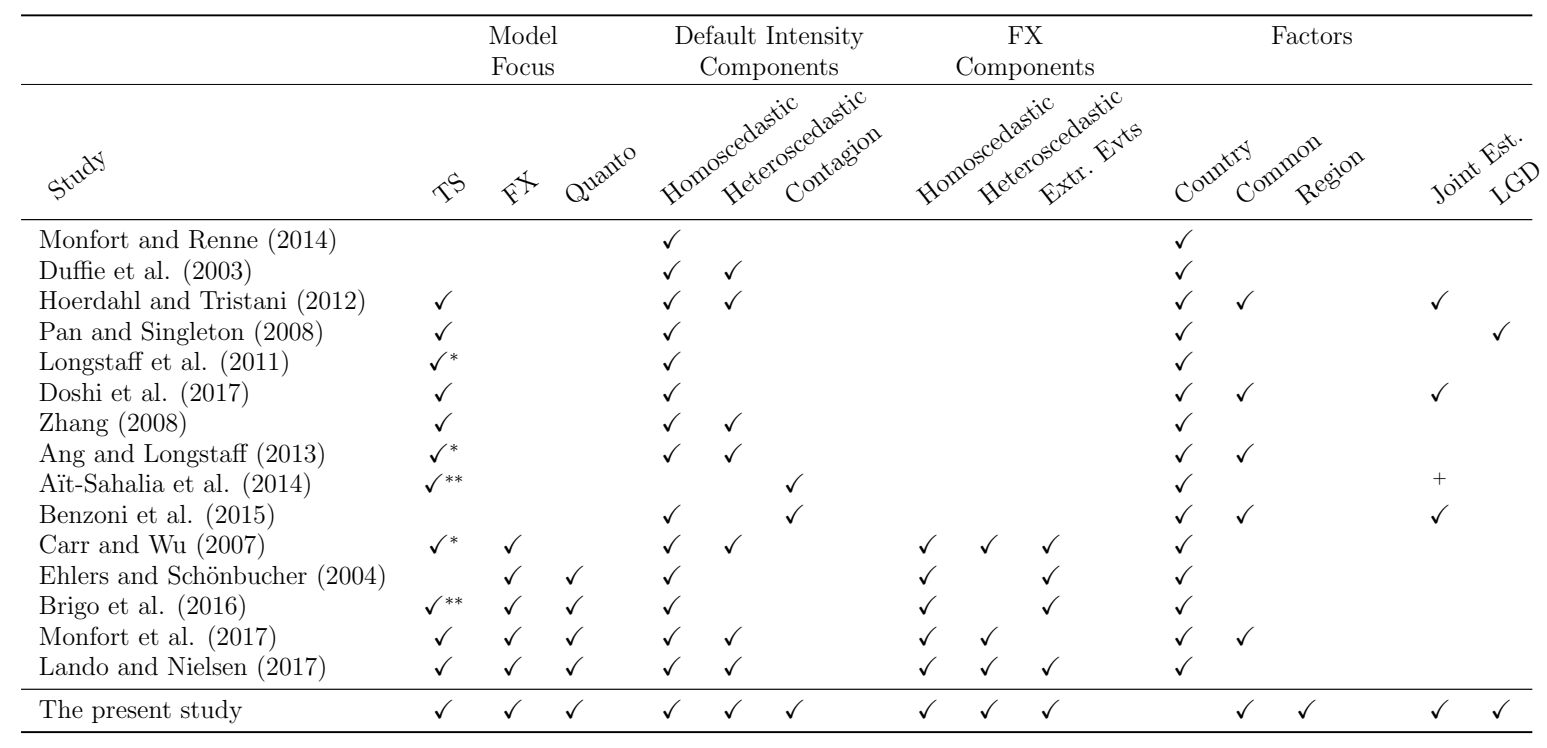

Notes. This table summarizes the main affine term structure models proposed for the pricing of sovereign credit spreads using intensity-based frameworks. We describe the focus of the paper, which can encompass the term structure (TS), foreign exchange rates (FX), and CDS quantos (Quanto). We also indicate the main model components of the default intensity, and, if applicable, of the depreciation rate dynamics. We refer to the presence of homoscedastic or heteroscedastic shocks, extreme events, and contagion. We further describe the type of risk factors, which can be country-specific, regional, or common. We indicate whether the estimation is done jointly for all countries, or on a country-by-country basis. + indicates that the estimation is done pairwise for two countries. The $*$ refers to the fact that the estimation is performed on the short end of the term structure, up to the 5-year maturity. ** denotes that the estimation considers only two maturity segments, 5 and 10 years. LGD indicates whether a paper estimates the Loss Given Default. 
Table F2

Parameter estimates: Model of the OIS term structure

\begin{tabular}{lrrrlrrr}
\hline & $5 \%$ & $50 \%$ & $95 \%$ & & $5 \%$ & $50 \%$ & $95 \%$ \\
\hline$\mu_{u 1}^{*}$ & 0.1859 & 0.5208 & 0.8651 & $\bar{r}$ & 0.0000 & 0.0001 & 0.0005 \\
$\mu_{u 2}^{*}$ & -0.6540 & -0.3636 & 0.0464 & $\delta_{u 1}$ & 0.0009 & 0.0015 & 0.0022 \\
$\mu_{u 3}^{*}$ & -0.2693 & -0.1827 & -0.1523 & $\delta_{u 2}$ & 0.0014 & 0.0018 & 0.0027 \\
\hline$\phi_{u 11}^{*}$ & 0.9985 & 0.9997 & 0.9999 & $\phi_{u 11}$ & 0.7761 & 0.8928 & 0.9276 \\
$\phi_{u 12}^{*}$ & - & - & - & $\phi_{u 12}$ & -0.1215 & -0.0947 & -0.0800 \\
$\phi_{u 21}^{*}$ & -0.0035 & -0.0026 & -0.0020 & $\phi_{u 21}$ & 0.0062 & 0.0098 & 0.0126 \\
$\phi_{u 22}^{*}$ & 0.9904 & 0.9918 & 0.9927 & $\phi_{u 22}$ & 0.9780 & 0.9900 & 0.9919 \\
$\phi_{u 33}^{*}$ & 0.8735 & 0.9010 & 0.9324 & $\phi_{u 33}$ & 0.8060 & 0.8768 & 0.9105 \\
\hline
\end{tabular}

Notes. In this table, we report the parameter estimates for the OIS term structure. The model is estimated using Bayesian MCMC. We report the posterior medians, as well as the 5th and 95th percentiles of the posterior distribution. The sample period is August 20, 2010 to December 30, 2016. The data frequency is weekly, based on Wednesday rates. 
Table F3

Parameter estimates: Model without contagion

\begin{tabular}{|c|c|c|c|c|c|c|c|}
\hline & $5 \%$ & $50 \%$ & $95 \%$ & & $5 \%$ & $50 \%$ & $95 \%$ \\
\hline \multicolumn{8}{|c|}{ (A) factor dynamics } \\
\hline$\phi_{11}^{*}$ & 0.9989 & 0.9995 & 0.9999 & $\phi_{11}$ & 0.9558 & 0.9881 & 0.9960 \\
\hline$\phi_{21}^{*}$ & 0.0045 & 0.0061 & 0.0066 & $\phi_{21}$ & -0.0506 & -0.0307 & 0.0015 \\
\hline$\phi_{22}^{*}$ & 0.9971 & 0.9976 & 0.9990 & $\phi_{22}$ & 0.9167 & 0.9894 & 0.9994 \\
\hline$\phi_{31}^{*}$ & -0.0036 & -0.0029 & -0.0020 & $\phi_{31}$ & -0.0206 & 0.0540 & 0.1152 \\
\hline$\phi_{33}^{*}$ & 0.9970 & 0.9974 & 0.9986 & $\phi_{33}$ & 0.8501 & 0.9321 & 0.9649 \\
\hline$\phi_{44}^{*}$ & 0.9937 & 0.9942 & 0.9949 & $\phi_{44}$ & 0.9382 & 0.9744 & 0.9933 \\
\hline$c_{1}^{*}$ & 0.0033 & 0.0045 & 0.0066 & $\nu_{1}$ & 1.5963 & 1.7537 & 1.9147 \\
\hline$c_{2}^{*}$ & 0.0119 & 0.0136 & 0.0157 & $\nu_{2}$ & 1.8945 & 1.9870 & 2.1420 \\
\hline$c_{3}^{*}$ & 0.0079 & 0.0096 & 0.0112 & $\nu_{3}$ & 0.7970 & 0.8413 & 0.8918 \\
\hline$c_{4}^{*}$ & 0.0061 & 0.0067 & 0.0073 & $\nu_{4}$ & 2.5721 & 2.6969 & 2.8131 \\
\hline \multicolumn{8}{|c|}{ (B) hazard rates } \\
\hline $10000 \times \bar{h}^{* 1}$ & 0.3511 & 0.3841 & 0.4278 & $10000 \times \bar{h}^{* 2}$ & 0.2451 & 0.3220 & 0.3637 \\
\hline$\delta_{w 1}^{* 1}$ & 0.0011 & 0.0014 & 0.0018 & $\delta_{w 1}^{* 2}$ & 0.0001 & 0.0003 & 0.0005 \\
\hline- & - & - & - & $\delta_{w 2}^{* 2}$ & 0.0028 & 0.0032 & 0.0036 \\
\hline $10000 \times \bar{h}^{* 3}$ & 0.2741 & 0.3432 & 0.4029 & $10000 \times \bar{h}^{* 4}$ & 0.0323 & 0.0950 & 0.1101 \\
\hline$\delta_{w 1}^{* 3}$ & 0.0001 & 0.0002 & 0.0005 & $\delta_{w 1}^{* 4}$ & 0.0021 & 0.0027 & 0.0032 \\
\hline$\delta_{w 2}^{* 3}$ & 0.0019 & 0.0031 & 0.0037 & $\delta_{w 3}^{* 4}$ & 0.0032 & 0.0044 & 0.0053 \\
\hline $10000 \times \bar{h}^{* 5}$ & 0.2134 & 0.2790 & 0.3234 & $10000 \times \bar{h}^{* 6}$ & 0.1782 & 0.2341 & 0.2914 \\
\hline$\delta_{w 1}^{* 5}$ & 0.0041 & 0.0047 & 0.0056 & $\delta_{w 1}^{* 6}$ & 0.0039 & 0.0059 & 0.0073 \\
\hline$\delta_{w 3}^{* 5}$ & 0.0007 & 0.0013 & 0.0020 & $\delta_{w 3}^{* 6}$ & 0.0031 & 0.0037 & 0.0049 \\
\hline $10000 \times \bar{h}^{* 7}$ & 0.1847 & 0.4051 & 0.6735 & - & - & - & - \\
\hline$\delta_{w 1}^{* 7}$ & 0.0008 & 0.0030 & 0.0058 & - & - & - & - \\
\hline$\delta_{w 3}^{* 7}$ & 0.0024 & 0.0057 & 0.0083 & - & - & - & - \\
\hline \multicolumn{8}{|c|}{ (C) loss given default } \\
\hline$L$ & 0.3504 & 0.4125 & 0.4981 & & & & \\
\hline \multicolumn{8}{|c|}{ (D) exchange rates } \\
\hline $\bar{s}^{*}$ & 0.0086 & 0.0090 & 0.0096 & $\bar{s}$ & -0.0048 & -0.0002 & 0.0009 \\
\hline$\delta_{s 3}^{*}$ & -0.0038 & -0.0035 & -0.0028 & $\delta_{s 3}$ & -0.0036 & -0.0027 & 0.0003 \\
\hline$\delta_{s 7}^{*}$ & -0.0078 & -0.0067 & -0.0055 & $\delta_{s 7}$ & 0.0005 & 0.0013 & 0.0015 \\
\hline- & - & - & - & $\bar{v}$ & 0.0001 & 0.0001 & 0.0002 \\
\hline- & - & - & - & $\delta_{v}$ & 0.0000 & 0.0001 & 0.0002 \\
\hline$\theta^{*}$ & 0.1113 & 0.1353 & 0.1535 & $\theta$ & 0.0079 & 0.0093 & 0.0134 \\
\hline \multicolumn{8}{|c|}{ (E) default intensity } \\
\hline $10000 \times \bar{h}$ & 0.6120 & 0.7204 & 1.1729 & & & & \\
\hline$\delta_{w 1}$ & 0.0021 & 0.0031 & 0.0039 & & & & \\
\hline
\end{tabular}

Notes. We report the parameter estimates for the CDS quanto model without contagion. We report the posterior medians, as well as the 5th and 95th percentiles of the posterior distribution. The superscripts in default intensity parameters $1-7$ in Panel B refer to countries in the following order: Germany, Belgium, France, Ireland, Italy, Spain, and Greece. 


\section{Table F4}

\section{Parameter estimates: Model with contagion}

\begin{tabular}{|c|c|c|c|c|c|c|c|}
\hline & $5 \%$ & $50 \%$ & $95 \%$ & & $5 \%$ & $50 \%$ & $95 \%$ \\
\hline \multicolumn{8}{|c|}{ (A) factor dynamics } \\
\hline$\phi_{11}^{*}$ & 0.9990 & 0.9995 & 0.9997 & $\phi_{11}$ & 0.9672 & 0.9860 & 0.9949 \\
\hline$\phi_{21}^{*}$ & 0.0048 & 0.0050 & 0.0058 & $\phi_{21}$ & -0.0174 & 0.0387 & 0.0680 \\
\hline$\phi_{22}^{*}$ & 0.9975 & 0.9978 & 0.9983 & $\phi_{22}$ & 0.8885 & 0.9670 & 0.9834 \\
\hline$\phi_{31}^{*}$ & -0.0036 & -0.0031 & -0.0027 & $\phi_{31}$ & -0.0179 & 0.0367 & 0.0668 \\
\hline$\phi_{33}^{*}$ & 0.9972 & 0.9977 & 0.9984 & $\phi_{33}$ & 0.8645 & 0.9298 & 0.9721 \\
\hline$\phi_{44}^{*}$ & 0.9965 & 0.9973 & 0.9991 & $\phi_{44}$ & 0.9032 & 0.9642 & 0.9818 \\
\hline$c_{1}^{*}$ & 0.0024 & 0.0046 & 0.0071 & $\nu_{1}$ & 1.5750 & 1.7353 & 1.8813 \\
\hline$c_{2}^{*}$ & 0.0091 & 0.0115 & 0.0137 & $\nu_{2}$ & 1.8624 & 2.0072 & 2.1751 \\
\hline$c_{3}^{*}$ & 0.0081 & 0.0091 & 0.0097 & $\nu_{3}$ & 0.7774 & 0.8537 & 0.9423 \\
\hline$c_{4}^{*}$ & 0.0064 & 0.0070 & 0.0076 & $\nu_{4}$ & 2.4123 & 2.6558 & 2.9251 \\
\hline \multicolumn{8}{|c|}{ (B) hazard rates } \\
\hline $10000 \times \bar{h}^{* 1}$ & 0.2575 & 0.3161 & 0.4170 & $10000 \times \bar{h}^{* 2}$ & 0.2230 & 0.3003 & 0.3809 \\
\hline$\delta_{w 1}^{* 1}$ & 0.0011 & 0.0014 & 0.0017 & $\delta_{w 1}^{* 2}$ & 0.0000 & 0.0001 & 0.0002 \\
\hline- & - & - & - & $\delta_{w 2}^{* 2}$ & 0.0030 & 0.0036 & 0.0041 \\
\hline$\delta_{d}^{* 1}$ & 0.0001 & 0.0018 & 0.0043 & $\delta_{d}^{* 2}$ & 0.0075 & 0.0102 & 0.0132 \\
\hline $10000 \times \bar{h}^{* 3}$ & 0.3029 & 0.4049 & 0.4739 & $10000 \times \bar{h}^{* 4}$ & 0.0319 & 0.0859 & 0.1085 \\
\hline$\delta_{w 1}^{* 3}$ & 0.0001 & 0.0002 & 0.0005 & $\delta_{w 1}^{* 4}$ & 0.0020 & 0.0026 & 0.0032 \\
\hline$\delta_{w 2}^{* 3}$ & 0.0020 & 0.0029 & 0.0037 & $\delta_{w 3}^{* 4}$ & 0.0032 & 0.0043 & 0.0053 \\
\hline$\delta_{d}^{* 33}$ & 0.0001 & 0.0027 & 0.0108 & $\delta_{d}^{* 4}$ & 0.0094 & 0.0122 & 0.0151 \\
\hline $10000 \times \bar{h}^{* 5}$ & 0.2074 & 0.2872 & 0.3143 & $10000 \times \bar{h}^{* 6}$ & 0.1656 & 0.2262 & 0.3146 \\
\hline$\delta_{w 1}^{* 5}$ & 0.0037 & 0.0044 & 0.0055 & $\delta_{w 1}^{* 6}$ & 0.0037 & 0.0048 & 0.0079 \\
\hline & 0.0010 & 0.0012 & 0.0019 & $\delta_{w 3}^{* 6}$ & 0.0024 & 0.0035 & 0.0039 \\
\hline & 0.0100 & 0.0144 & 0.0184 & $\delta_{d}^{* 6}$ & 0.0187 & 0.0249 & 0.0308 \\
\hline $10000 \times \bar{h}^{* 7}$ & 0.1574 & 0.3872 & 0.5543 & & & & \\
\hline$\delta_{w 1}^{* 7}$ & 0.0017 & 0.0027 & 0.0055 & & & & \\
\hline$\delta_{w 3}^{* 7}$ & 0.0020 & 0.0060 & 0.0074 & & & & \\
\hline$\delta_{d}^{* 7}$ & 0.0164 & 0.0201 & 0.0233 & & & & \\
\hline \multicolumn{8}{|c|}{ (C) loss given default } \\
\hline$L$ & 0.3678 & 0.4352 & 0.5284 & & & & \\
\hline \multicolumn{8}{|c|}{ (D) exchange rates } \\
\hline $\bar{s}^{*}$ & 0.0067 & 0.0085 & 0.0089 & $\bar{s}$ & -0.0041 & -0.0002 & 0.0006 \\
\hline$\delta_{s 3}^{*}$ & -0.0045 & -0.0033 & -0.0020 & $\delta_{s 3}$ & -0.0035 & -0.0026 & 0.0004 \\
\hline$\delta_{s 7}^{*}$ & -0.0105 & -0.0069 & -0.0050 & $\delta_{s 7}$ & -0.0002 & 0.0010 & 0.0014 \\
\hline- & - & - & - & $\bar{v}$ & 0.0000 & 0.0001 & 0.0002 \\
\hline - & - & - & - & $\delta_{v}$ & 0.0001 & 0.0002 & 0.0003 \\
\hline$\theta^{*}$ & 0.0926 & 0.1512 & 0.1839 & $\theta$ & 0.0090 & 0.0102 & 0.0155 \\
\hline \multicolumn{8}{|c|}{ (E) default intensity } \\
\hline $10000 \times \bar{h}$ & 0.1002 & 0.8120 & 1.1222 & $\rho^{*}$ & 1.0619 & 1.4039 & 2.0572 \\
\hline$\delta_{w 1}$ & 0.0082 & 0.0094 & 0.0122 & $\delta_{d}$ & 0.0000 & 0.0002 & 0.0004 \\
\hline
\end{tabular}

Notes. In this table, we report the parameter estimates for the CDS quanto model with contagion. The model is estimated using Bayesian MCMC. We report the posterior medians, as well as the 5th and 95th percentiles of the posterior distribution. In Panel A, we report estimates for the credit and volatility factors. In Panel B we report estimates for the hazard rates. The superscripts in default intensity parameters refer to countries in the following order: Germany, Belgium, France, Ireland, Italy, Spain. In Panel C, we report estimates for the exchange rate dynamics. In Panel D, we report estimates for the aggregate physical default intensity. 
Table F5

Model comparison

\begin{tabular}{lcccccc}
\hline & \multicolumn{3}{c}{ With contagion } & \multicolumn{3}{c}{ Without contagion } \\
& $5 \%$ & $50 \%$ & $95 \%$ & $5 \%$ & $50 \%$ & $95 \%$ \\
\hline $\ln p(Y \mid \Theta)$ & 86014 & 86220 & 86450 & 85948 & 86198 & 86435 \\
$\mathrm{BIC}$ & -86224 & -85994 & -85788 & -86241 & -86004 & -85754 \\
\hline
\end{tabular}

Notes. In this table, we report the distributions of the likelihoods of both models, and the associated Bayesian Information Criteria (negative of the likelihood plus penalty for the number of parameters). The model is estimated using Bayesian MCMC. We report the posterior medians, as well as the 5th and 95th percentiles of the posterior distribution. The model with the lowest Bayesian Information Criterion (BIC) is preferred. 


\section{G Figures}

\section{Figure G1}

Time series of the OIS interest rates

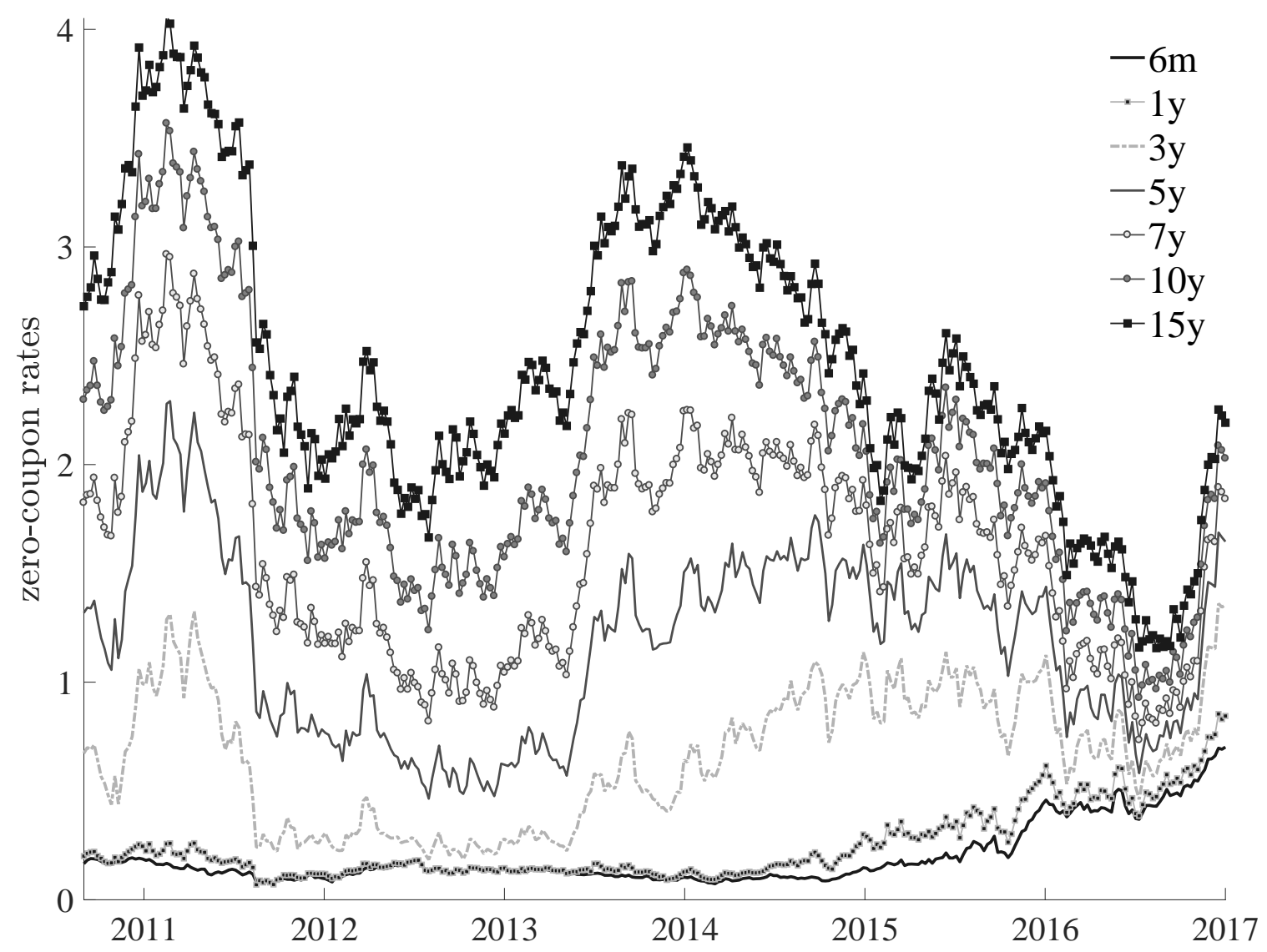

Notes. The Figure displays weekly zero-coupon rates bootstrapped from the term structure of overnight indexed and interest rate swaps. The sample period is August 20, 2010 through December 30, 2016. 
Figure G2

Time series of credit events
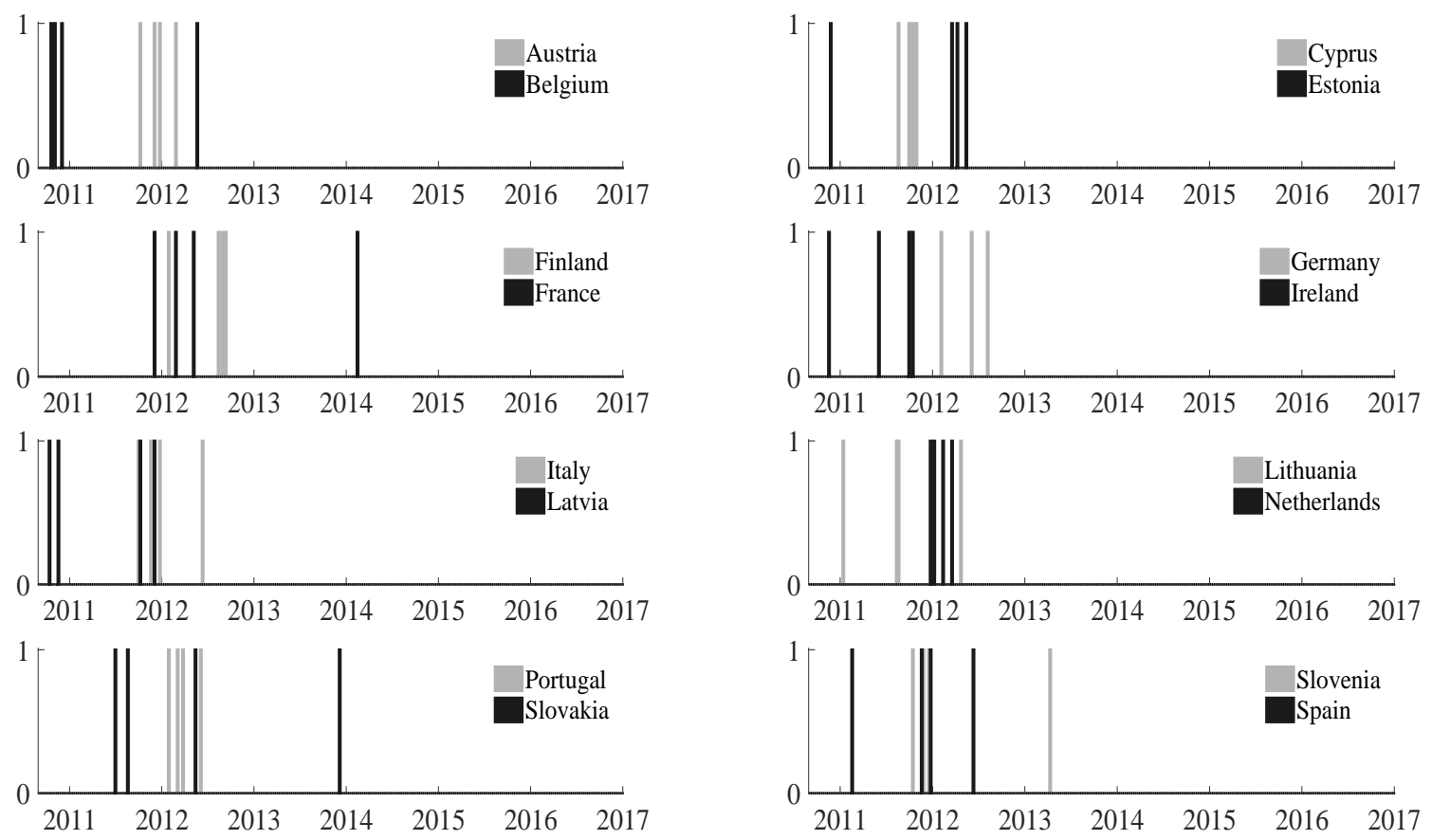

Notes. These figures depict the time series of credit events for 16 Eurozone countries that have a minimum of 365 days of non-zero information on USD-EUR quanto CDS spreads. Greece is omitted from this figure. In the absence of true credit events, we define them as occurrences when a 5-year quanto spread is above the 99th percentile of the country-specific distribution of quanto spread changes. The sample period is August 20, 2010 to December 30, 2016. 


\section{Figure G3}

Greece

(A) CDS premium

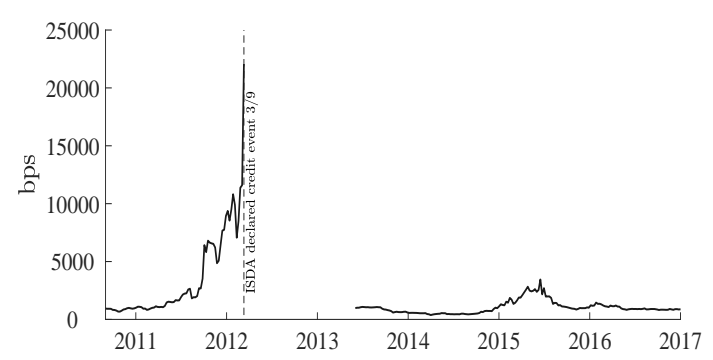

(C) Model-implied quanto spread

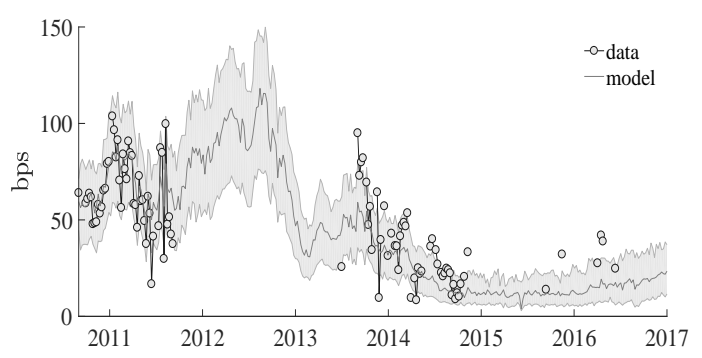

(B) Quanto spread

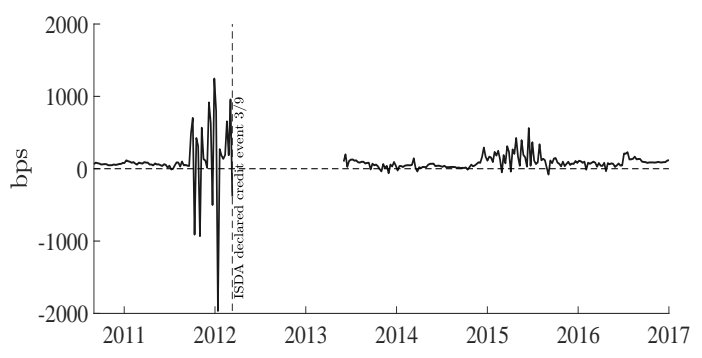

(D) Model-implied default intensity

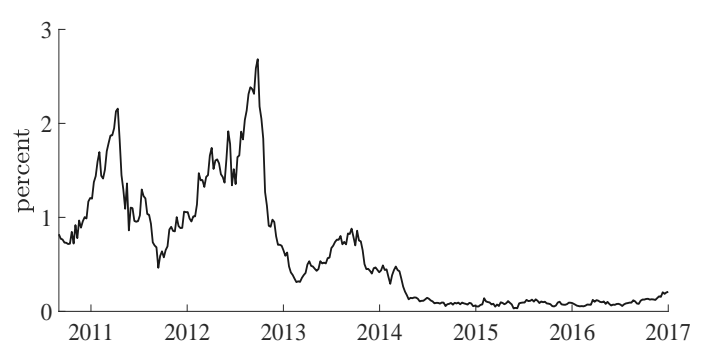

Notes. In these figures, we plot the observed USD denominated CDS premium for Greece (A), the observed and model-implied USD/EUR quanto spreads for Greece (B and C). We report values for maturities of 5y. Gray lines represent posterior medians of quanto spreads and gray-shaded areas correspond to $90 \%$ credible intervals. The true quanto spreads are plotted with black-circled lines. In Panel D, we provide an illustration of the model-implied default intensity for Greece. The sample period is August 20, 2010 to December 30, 2016. 